\title{
LOWER LEAF HARVESTING OPTIONS AND LEAF POSITION EFFECTS ON SOME AGRONOMIC, CHEMICAL, AND MINERAL CHARACTERISTICS \\ OF FLUE-CURED TOBACCO
}

By

GLENN RALPH STOCKS

A DISSERTATION PRESENTED TO THE GRADUATE SCHOOL

OF THE UNIVERSITY OF FLORIDA IN PARTIAL FULFILLMENT

OF THE REQUIREMENTS FOR THE DEGREE OF

DOCTOR OF PHILOSOPHY

UNIVERSITY OF FLORIDA 


\section{PRELUDE}

"At the awful day of judgment, the discrimination of the good from the wicked, is not made by the criterion of the sects or of dogmas, but by one which constitutes the daily employment and the greatest end of agriculture. The judge upon this occasion has by anticipation pronounced, that to feed the hungry, clothe the naked, and give drink to the thirsty are the passports to future happiness; and the divine intelligence which selected an Agricultural state as a paradise for its first favorite, has here again prescribed the Agricultural virtues as the means for the admission of their posterity into heaven."

John Taylor, 1813 


\section{ACKNOWLEDGMENTS}

In this study, 30,024 tobacco leaves were used to generate 40,224 data points. Of the 30,024 leaves used, 10,592 had the midribs removed manually. There were 3636 samples that were ground for either mineral and chemical, or total nonstructural carbohydrate analysis. To accomplish all of this work required the assistance of many people and the author intends to duly recognize all involved who made this Ph.D research program possible.

Gerald Durden, David Durden, and Shannon Brown's technical assistance in harvesting and measurement of the agronomic parameters is greatly appreciated. Ernest Terry's assistance in grinding, and processing of samples for TNC and mineral analysis was invaluable. Chief Tobacco Technician Rick Hill's assistance in the total management of this program is gratefully appreciated.

Much appreciation is given to Dr. D.G. Shilling and Dr. J.M. Bennett for their advice and counsel all through the conducting of this study. Also, gratitude is given to Dr. R.N. Gallaher for the use of his dryer for desiccating the samples used in the TNC study and the use of his laboratory for sample preparation for mineral analysis. The use of Dr. Bennett's lab space for the TNC analysis is much appreciated. Unfortunately, Dr. F.M. Rhoads was stationed outside of Gainesville and interaction with him was limited by the miles; however, his willingness to serve on the supervisory committee is appreciated.

To all committee members, the author is grateful for the challenges presented to him in the qualifying examinations. The diversity of this committee challenged the author on the written and oral exams. Each and every member posed probing questions that caused the student to question his reasoning for being in graduate school. The 
successful completion of such a diverse qualifying examination process no doubt was the turning point of this student's program.

The author's parents lifelong devotion to him is greatly appreciated. Had his father, a farmer, not involved the author with the farming operation, a career in agriculture might not have become a reality. The author's mom basically did all the paper work for the author to be enrolled at N.C. State. Had she not done this, the author might well have ended up in the armed forces.

By the time the author has completed this dissertation, he will will have taken a bride. The loving devotion of Kathleen Best has carried the author through the inevitable low points of this graduate program. Kathleen has shared the good times and bad times with equal vigor and picked the author up when he was feeling down. Many years of happy marriage are looked forward to by the author.

Dr. E.B. Whitty has been a godsend to the author. As a major professor, Dr. Whitty has provided leadership to the author. As a person, Dr. Whitty is one of the author's best friends. As a scientist, Dr. Whitty is clearly a leader in his field, as his recognition as 1991 Florida Extension Specialist of the Year clearly demonstrates. In the author's humble opinion (although some might say there is nothing humble about the author), there is not a better major professor than Dr. Whitty. Academics aside, Dr. Whitty has allowed the author to develop professionally by including him on extension programs and sending him to numerous professional meetings. From a research standpoint, whenever the author needed something for his studies, Dr. Whitty willingly supplied the needed equipment. The author is forever indebted to Dr. Whitty for having served as his major professor for both the M.S. and Ph.D programs. Without question, whatever success the author experiences over his career will be directly due to his interaction with Dr. Whitty.

The funding of the research assistantship by R.J. Reynolds Tobacco Company made it possible for the author to obtain his Ph.D degree. R.J. Reynolds has been an intricate 
part of the author's academic career since he was an RJR research apprentice in 1984. This program got the author interested in agriculture research and led directly to him attending graduate school at the University of Florida. The interaction with Mr. A.R. Mitchum, Mr. R.C. Reich, Dr. D.L. Davis, and Dr. C.R. Miller, all of RJR, has allowed the author to develop friendships with industry that hopefully will continue throughout the author's career.

Without the cooperation of R.J. Reynolds and Philip Morris Tobacco Companies in running the leaf chemical analyses, these studies would not have been complete. The author is indebted to both companies for their willingness to run these analyses. The cooperation of Mr. A.R. Mitchum of RJR and Mr. D.L. Connor of PM is gratefully appreciated in arranging to have these samples processed and analyzed.

In summary, anyone who has read this dissertation recognizes the immense amount of data that was generated. This was clearly a team project and all involved deserve and are accorded a gargantuan thank you from the author, Glenn R. Stocks. 


\section{TABLE OF CONTENTS}

CHAPTERS

Introduction

Materials and Methods

Results and Discussion

Conclusions

LOWER LEAF HARVESTING EFFECTS ON AGRONOMIC CHARACTERISTICS OF FLUE-CURED TOBACCO

Introduction

Materials and Methods

Results and Discussion

Conclusions

LOWER LEAF HARVESTING: THE INFLUENCE OF TIME ON THE CHEMICAL AND MINERAL CHARACTERISTICS OF FLUE-CURED TOBACCO LEAF POSITIONS

Introduction

Materials and Methods

Results and Discussion

Conclusions 


\section{Abstract of Dissertation Presented to the Graduate School of the University of Florida in Partial Fulfillment of the Requirements for the Degree of Doctor of Philosophy \\ LOWER LEAF HARVESTING OPTIONS AND LEAF POSITION EFFECTS ON SOMEAGRONOMIC, CHEMICAL, AND MINERAL CHARACTERISTICS OF FLUE-CURED TOBACCO}

\section{By}

\section{Glenn Ralph Stocks}

December, 1991

Chairman: Dr. E.B. Whitty

Major Department: Agronomy

Lower leaf harvesting options are management tools of flue-cured tobacco (Nicotiana tabacum L.) farmers that are determined by economic considerations. The lowest leaves of the flue-cured tobacco plant are the lowest in yield and value and some farmers choose not to harvest them because of their relatively low economic return. There are inherent differences in the agronomic, chemical, and mineral characteristics of tobacco leaves depending on where the leaves are positioned on the stalk. Pruning and discarding the lowest three or four leaves has been shown in some studies to not adversely affect total yield. However, pruning lower leaves reduced yield in another study. The objective of this study was to evaluate the effects of five lower leaf harvesting options on leaf position characteristics of flue-cured tobacco plants having exactly 21 leaves prior to pruning. The responses of leaf position parameters were evaluated under normal harvesting methods and a time after pruning study involving acquisition of all leaves that remained on plants at a given period of time. Not harvesting the lower leaves reduced yield as total leaf number harvested declined, but average value per kilogram was increased because the lowest leaves were the lowest valued. No differences in leaf position yield or total non-structural carbohydrate concentration were found, leading to the conclusion that lower leaf harvesting treatments had no effect 
on net photosynthesis of the leaves above them. Not pruning and not harvesting the lower leaves resulted in lower lamina nicotine and $\mathrm{P}$ concentrations and higher concentration ratios of $\mathrm{N}$ to nicotine and reducing sugars to nicotine. The reduced concentrations of nicotine and $\mathrm{P}$ were associated with a dilution effect due to not pruning and not harvesting the lowest leaves on the tobacco plants. Results from these studies describe the influence that the position of tobacco leaves on the stalk had on leaf agronomic, chemical, and mineral parameters and the influence of leaf maturity on the development of those same leaf parameters. 
Lower leaf harvesting options of flue-cured tobacco (Nicotiana tabacum L.) provide practical means of managing the yield and value per unit of the crop. Lower leaf harvesting options have become management tools for two reasons: 1) the federal program for flue-cured tobacco controls the weight of tobacco that can be sold from a farm, and 2) there are inherent differences in value per kilogram of tobacco based on the position of the leaves on the stalk. The value per kilogram of flue-cured tobacco generally is lowest for the lowest leaves and increases progressively to the middle- and upper-leaf positions on the stalk.

Because the lowest leaves on the tobacco plant are the lowest in yield and value and improved cultivars produce high yields, some growers choose not to harvest the lowest leaves. Data from previous studies dealing with lower leaf harvesting options of flue-cured tobacco suggested that pruning and discarding the lowest three or four leaves did not adversely affect total yield and improved the average value per kilogram when compared to harvesting all leaves (Suggs, 1972; Currin and Pitner, 1980; Stocks, 1988). However, Court and Hendel (1989) found that if the number of leaves harvested was reduced from 18 to 15 to 12, either by lower leaf pruning or topping to a lower leaf number, total yield was progressively reduced.

In that lower leaf harvesting options reduce the total number of leaves harvested, other methods may be used to achieve the same goal. Woltz and Mason (1966) found that increasing the leaf number per hectare through higher plant populations increased yield with the response fitting a quadratic model. When leaf quality was evaluated, 296,400 leaves per hectare were found to be the optimum. Collins et al. (1969) found a leaf 
population of 444,600 per hectare increased yield and value when compared to 296,400 leaves per hectare, but value per kilogram decreased with the increase in leaf population. They concluded that the production of the additional leaves was not economically feasible. Kittrell et al. (1972) found a leaf population of 370,500 per hectare increased yield and value when compared to 296,400 leaves per hectare, but gross and net prices were reduced by the higher leaf population.

Topping height and within-row plant spacing are the most common methods used to achieve a desired leaf population. Kittrell et al. (1972) found that with equal withinrow plant spacings a topping height of 20 leaves per plant yielded higher than that observed when topping at 16 leaves per plant with equal gross prices for the respective topping heights. Net price was higher for the 20 leaves per plant topping height. Elliot (1976) evaluated the effects of several within-row plant spacings and topping heights on flue-cured tobacco. He found that increasing topping heights from 12 to 15 to 18 leaves per plant generally increased total yield and value per hectare for each increase in leaf number per plant, except for a lower value per kilogram for the 18 leaf topping height treatment. Lower topping did not increase the specific leaf weight of the lowest leaves or highest leaves, but increased the specific leaf weight of the middle leaves. Increasing within-row plant spacings decreased yield and value per hectare, but increased specific leaf weight of all leaves. Lower topping heights and wider within-row plant spacings increased nicotine and total $\mathrm{N}$ concentration, with no response of topping height or plant spacing on reducing sugar concentration.

The objective of lower leaf harvesting options is to maximize the use of quota by selling the highest quality leaves. By not harvesting lower leaf tobacco, the lowest quality and value leaves are not marketed. Information in the literature suggests that the weight, and perhaps the quality, of the lower leaves can be improved by wider spacing of plants within the row. Lower topping did not increase the weight of the lowest leaves, but lamina weight increases were found in the middle leaves on the stalk. 
However, lower yields resulted from both options. Increasing the within-row plant spacing or topping to a lower leaf number limits the farmer's lower leaf harvesting options in that he probably will need to harvest all the leaves produced on the plant to make full use of his allotted quota. Within-row spacings and topping heights that produce good quality tobacco and that may allow a farmer to exceed his allotted quota under favorable growing conditions would enable the farmer to decide whether or not to harvest the lower leaves. Those decisions would be based on the expected quality and price per kilogram for the lower leaves, as well as the expected total yield of the crop.

All the studies dealing with lower leaf harvesting options have reported total yield and explanations for the yield responses were not fully elucidated. Yield of each leaf position would be a useful parameter when evaluating the effects of lower leaf harvesting options. If the studies reported by Suggs (1972), Currin and Pitner (1980), and Stocks (1988) had included yield by leaf position, the distribution of the total yield on the plant could have been evaluated to determine where the yield redistribution occurred due to lower leaf pruning.

Physiologically, lower leaf harvesting options of tobacco can be viewed as a manipulation of the source-sink relationship of the plant. In flue-cured tobacco production, the reproductive sink is removed (topping) to increase the yield and quality of the leaves that remain on the stalk. The topping process has been found to eliminate the traditional source-sink relationship of the tobacco plant causing the leaves to function as alternate sinks (Hurng et al., 1989). Some effects of topping are increased specific leaf weight and leaf carbohydrate concentration (Hurng et al., 1989), and increased leaf nicotine concentration (Woltz, 1955). Given equivalent environmental and nutritional conditions, the timing of topping has significant effects on the agronomic and chemical properties of the tobacco crop. Early topping increased leaf yield and nicotine concentration more than late topping (Woltz, 1955; Steinberg and Jeffery, 1957; Marshall and Seltmann, 1964; Elliot, 1966; Stocks and Whitty, 1992). Woltz 
(1955), Marshall and Seltmann (1964), and Elliot (1966) found $\mathrm{N}$ and reducing sugar concentrations were not affected by topping delays. As topping has such a dramatic influence on some of the agronomic and chemical qualities of the crop, further manipulation of the plant's source-sink relationship, i.e., lower leaf harvesting options, might be expected to influence similar parameters. Suggs (1972) found that when the lowest nine leaves were pruned and discarded from flue-cured tobacco plants nicotine concentration was increased in the remaining leaves.

Numerous studies have dealt with source-sink manipulations in other plant species. Removal of the grain sink of corn (Zea mays L.) caused dramatic increases in the carbohydrate concentration of both upper and lower leaves (Allison and Weinmann, 1970). Pod removal from soybean (Glycine max L. Merr.) increased leaf carbohydrate concentration (McAlister and Krober,1958; Kollmann et al., 1974; Ciha and Brun, 1978; Mondal et al., 1978; Streeter and Jeffers, 1979; Crafts-Brandner et al., 1984), and also increased $N$ and $P$ concentrations in the leaves (Kollman et al., 1974; Crafts-Brandner et al., 1984). Kollmann et al. (1974) further reported that leaf Ca and $\mathrm{K}$ concentrations were decreased due to depodding of soybean. Lawn and Brun (1974) found soybean depodding decreased net photosynthesis. The photosynthetic decline was linked to an accumulation of assimilate in the leaves. Depodding of soybean also has been found to delay leaf senescence (Hicks and Pendleton, 1969; Mondal et al., 1978; Crafts-Brandner et al., 1984). The effects of reproductive sink removal can be summarized to include increased leaf carbohydrate levels with a subsequent decline in net photosynthesis, increase in leaf $\mathrm{N}$ and $\mathrm{P}$ concentrations, decreases in leaf $\mathrm{Ca}$ and $\mathrm{K}$ concentrations, and a delay in the onset of senescence.

Results from leaf removal studies with wheat (Triticum aestivum L.) and oats (Avena sativa $L_{\text {.) }}$ demonstrate that leaf area losses greater than $10 \%$ reduced grain yield (Womack and Thurman, 1962). Grain yield of sorghum (Sorghum bicolor L. Moench) was reduced as defoliation increased (Stickler and Pauli, 1961). Pauli and Stickler 
(1961) found that increases in the percentage of leaves pruned from grain sorghum plants decreased the total carbohydrates in the vegetative tissue and grain. Vegetative tissue $\mathrm{N}$ concentration decreased and grain $\mathrm{N}$ concentration increased as the percentage of defoliation increased. Weber (1955) and McAlister and Krober (1958) found soybean seed yield and size decreased in response to defoliation. The causal mechanism of lower grain yield with defoliation was the loss the total photosynthetic capacity of the plant.

Flue-cured tobacco is managed differently than most other agronomic crops in that the leaves, and not the seed, are harvested. Also, leaves are removed as they mature on the plant. Most source-sink manipulation studies with other crops have dealt with the effects of either the removal of the reproductive sink on leaf and seed characters or the removal of leaves on seed characters. Lower leaf harvesting option studies with flue-cured tobacco have reported total yield and chemical effects only. To ascertain the specific effects of lower leaf harvesting options, a study was designed and implemented to evaluate leaf position responses to five lower leaf harvesting options of flue-cured tobacco plants having exactly 21 leaves. The five lower leaf harvesting options were:

1) Harvest all 21 leaves in a normal manner (control).

2) Prune and discard the lowest 3 leaves, harvest remaining 18 leaves in a normal manner.

3) Do not prune and do not harvest the lowest 3 leaves (leaves were left on the stalk), harvest remaining 18 leaves in a normal manner.

4) Prune and discard the lowest 6 leaves, harvest remaining 15 leaves in a normal manner.

5) Do not prune and do not harvest the lowest 6 leaves (leaves were left on the stalk), harvest remaining 15 leaves in a normal manner.

To maintain the integrity of the leaf positions, the 21 leaves of the plants were partitioned into seven, 3-leaf stalk positions with the lowest three leaves designated 1-3 and progressing up the stalk with the upper-most three leaves designated 19-21.

The objective of the present study was to evaluate the effects of pruning and discarding, not pruning or harvesting, or harvesting in a normal manner, the lowest 
three or six leaves on flue-cured tobacco plants on the leaves above those involved in the the treatments. Leaf number per plant and by harvest was controlled so that any effects due to the treatments could be reported by the position or node on the stalk where leaves were formed. Previous work on this topic indicated positive effects on yield and value by pruning and discarding lower leaves, but negative effects by not pruning or harvesting the same leaves.

The present study involved the measurement of numerous properties of tobacco leaves based on the position or node on the stalk at which leaves were formed. Data are lacking that characterize the agronomic, chemical, and mineral qualities by leaf position of currently-grown flue-cured tobacco cultivars. These data are reported by leaf position for normally-harvested mature leaves and for the same leaf positions over time after topping to maturity to contribute data on the characteristics and the development of the leaves comprising a leaf position. 


\section{CHAPTER 2 \\ CHARACTERIZATION OF FLUE-CURED TOBACCO BY LEAF POSITION PRODUCED UNDER NORMAL HARVESTING METHODS OR MONITORED OVER TIME AFTER TOPPING}

\section{Introduction}

Tobacco (Nicotiana tabacum L.) production, unlike that of most other agronomic crops, involves harvest of the vegetative tissue (leaves), not the reproductive tissue (seeds). Flue-cured tobacco leaves, unlike most other tobacco types, are harvested manually or mechanically as the leaves mature on the plant. Harvest of the flue-cured tobacco leaves progresses with maturity from the lowest to the highest leaves on the plant stalk. This harvest method allows for all leaves to become fully mature if proper production practices are followed. With most other tobacco types, the entire plant is severed in the field at a stage when a majority of the leaves on the plant are judged to be mature. Although the progressive harvest of flue-cured tobacco results in mature leaves, there are considerable physical and chemical differences depending on the position or nodes at which leaves are formed on the stalk (leaf position).

Leaf position (LP) is of considerable importance to the tobacco industry. Tobacco is marketed, graded, and sold according to LP regardless of type. Tobacco companies purchase tobacco based on their needs for a given characteristic most often derived from the inherent differences between LPS. The tobacco is processed and stored based on LP, as well. Tobacco products are manufactured based on certain characteristic properties of the cured leaf. Weybrew et al. (1984) determined that the leaf chemical components of tobacco are influenced most by LP. In general, the LP characteristics of tobacco dictate what type product can be manufactured. 
Because LP is such an important factor in tobacco production and manufacturing, numerous studies over the years have evaluated a wide array of LP properties for tobacco types. Various burley tobacco LP properties have been described by Bowman and Nichols (1968), and Williamson and Chaplin (1981). Flue-cured tobacco LP properties have been described over the years. Agronomic, chemical, and mineral composition data on LPs of flue-cured tobacco can be garnered from reports by Darkis et al. (1936, 1952), Askew et al. (1947), Walker (1968), Brown and Terrill (1972, 1973), Bowman et al. (1973), Nel et al. (1974), Neas et al. (1978), and Campbell et al. (1980). Raper and McCants (1966), Srivastava et al. (1984), and Bruns and Mclntosh (1988) has reported dry matter accumulation data for tobacco, but these studies were based on whole plant sampling with no segregation of the leaves.

One of the most important production and management practices of flue-cured tobacco (Nicotiana tabacum L.) is the removal of the apical meristem (topping). Tobacco is topped to improve yield and quality of the upper leaves. The topping process breaks apical dominance resulting in rapid axilary bud development and generally corresponds to the onset of floral initiation. The axilary buds (suckers), if allowed to develop will reduce yield and quality of the tobacco leaves. Consequently, farmers remove suckers by hand or use growth regulators to suppress their development. The process of topping is also associated with many important developments of the tobacco plant. Topping, for practical purposes, eliminates the traditional source-sink relationship for a tobacco plant. Hurng et al. (1989) found that topping tobacco plants increased leaf dry weight, specific leaf weight, and $\mathrm{P}$ concentration indicating that in the absence of the reproductive sink, the leaves acted as an alternate sink. Wolf and Gross (1937) detailed anatomical changes associated with tobacco topping and found larger, thicker leaves resulted due to an increase in cell size in response to topping. Steinberg and Jeffery (1957) found topping increased root development and nicotine concentration. Nicotine is synthesized in the roots of the tobacco plant and translocated to the leaf (Dawson and 
Solt, 1959). Wolf and Bates (1964) showed that a more extensive tobacco root system resulted in higher leaf nicotine concentrations.

Nicotine is the most unique of all the chemical components of a tobacco leaf, and its accumulation in the leaf as a response to topping is an important event, but, other important processes are associated with topping. Elliot (1975) reported that topping increased, not only nicotine concentration, but also lamina weight, leaf $N$ and reducing sugar concentration, and quality of the cured leaf.

At topping, there is a clear and distinct gradient in leaf age on a tobacco plant. The oldest and most mature leaves will be the lowest on the stalk, and leaf maturity will decline as LP increases to the top of the plant. Wolf and Gross (1937) reported that leaves that were the most mature at topping were least modified, while those that were least mature were profoundly modified. In Florida, topping generally occurs 80 to 90 days after transplantation of seedlings. The topping process often coincides with the first harvest of the mature lowest leaves.

Because the production of flue-cured tobacco involves the harvest of leaves as they mature on the stalk, management of the crop becomes a science of leaf senescence. Weybrew et al. (1984) state that "physiological maturity (of a tobacco leaf) marks the transition from growth to senescence and is usually identified as the point of maximum dry weight attainment." They estimated that a leaf becomes ripe approximately 12 days after physiological maturity. Also, because the leaves emerge sequentially, they will ripen progressively from the lowest leaf, earliest emerged, to the uppermost leaf, latest emerged. Weybrew et al. (1984) proposed that weekly harvests of three leaves per plant would be the optimum way to produce quality tobacco because one leaf should be "ideally" ripe, and the other two leaves would be only two days before or past the "ideally" ripe stage.

Moseley et al. (1963) stated that "as a tobacco leaf approaches maturity, it loses much of its tackiness and acquires a velvety feel. It develops "grain" or mounds between 
the small veins. It becomes more turgid, does not wilt readily, and will snap crisply from the stalk. Both the yellow and green pigments decrease, but the green ones at a faster rate, thus the leaf becomes less green and more yellow in appearance." Moseley et al. (1963) studied the maturity of tobacco leaves at harvest and found chlorophyll decreased at a faster rate than did carotene or xanthophyll. Nicotine concentration increased with maturity. Reducing sugar, $\mathrm{N}$, and $\mathrm{K}$ concentrations, and the $\mathrm{N}$ to nicotine and reducing sugar to nicotine concentration ratios declined as the tobacco leaves matured. Walker (1968) found that as tobacco leaves matured the $\mathrm{Ca}, \mathrm{Mg}$, and $\mathrm{K}$ concentrations declined, and noted inherent concentration differences between leaf positions.

On a more general nature, Leopold (1961) described two positive effects of leaf senescence. As leaves become shaded, senescence allows for organic and inorganic compounds, which had been committed to those leaves during growth and development, to be remobilized to leaves that are actively growing in a more favorable environment. Also, with age and shading, the photosynthetic activity of a leaf declines sharply. The shaded leaves are not parasitic to the plant, rather they are removed through senescence. Thomas and Stoddart (1980) suggested leaf senescence is: 1) controlled genetically, 2) a result of competition for light, space, and nutrients, or 3) a response to environmental factors such as light, temperature, water relations, mineral relations, and diseases.

Sinclair and deWit's (1975) "self-destruct" hypothesis suggested soybean leaf senescence to be a result of $\mathrm{N}$ being transported out of the leaves to supply the developing seed to such an extent the leaves senesce. Flue-cured tobacco leaves ripen or partially senesce as result of $\mathrm{N}$ starvation. In Sinclair and deWit's (1975) hypothesis the $\mathrm{N}$ demand of the developing soybean seed depleted leaf N. However, in flue-cured tobacco production $\mathrm{N}$ is managed such that the plant gradually depletes the soil $\mathrm{N}$ supply, thereby limiting the $N$ availability to the leaves, progressively from the lowest leaves to the top leaves. 
In flue-cured tobacco production, proper $\mathbf{N}$ management is the key to quality cured leaf. Ideally, the $\mathrm{N}$ management scheme would cause the soil $\mathrm{N}$ supply to be depleted when all but the upper-most leaves have fully developed allowing for the remobilization of $\mathrm{N}$ from mature to maturing leaves. This scheme is the objective of every flue-cured tobacco farmer each year, however, environmental factors nearly always make this scheme difficult to achieve.

Numerous studies have detailed nutrient and dry matter accumulation for various tobacco types over time (Grizzard et al., 1942; Raper and McCants, 1966; Sims and Atkinson, 1971,1973, and 1974; Atkinson and Sims, 1977; Raper et al., 1977; Srivatava et al., 1984; Bruns and Mclntosh, 1988). In all the above mentioned studies, composite samples were acquired and data were reported on a whole plant basis. Studies are lacking that detail the effects of time on the development of individual LPS.

Data are lacking that describe the characteristics of leaves by position on the stalk of currently grown flue-cured tobacco cultivars. In the present study, agronomic, chemical, and mineral data were collected from two flue-cured tobacco cultivars ('NC37NF' and 'K-358') topped to 21 leaves. The purpose of this study was to provide information on tobacco leaf characteristics based upon the position or node on the stalk at which leaves were formed. Data on LP characteristics over time are presented because changes in the characteristics of individual LPS have been described in few previous studies.

\section{Materials and Methods}

Field experiments were conducted in 1989 and 1990 at the University of Florida's Green Acres Agronomy Farm near Gainesville, FL. Two flue-cured tobacco cultivars, 'NC37NF' and 'K-358', were grown in an Arredondo fine sand (fine-sandy siliceous, Hyperthermic Grossarenic Paleudult) (Carlisle et al., 1989) for both years. 
Plants were spaced $41 \mathrm{~cm}$ apart in rows spaced $121 \mathrm{~cm}$ apart. Transplanting dates were 10 March 1989 and 2 April 1990.

Prior to transplanting in 1989 , weed and soil-borne pest management consisted of $6.73 \mathrm{~kg}$ (a.i.) ha-1 fenamifos (nematicide) \{Ethyl 3-methyl-4-(methylthio) phenyl(1-methylethyl)phosphoramidate\}, $2.26 \mathrm{~kg}$ (a.i.) ha-1 chlorpyrifos (insecticide) \{0,0-Diethyl O-(3,5,6-trichloro-2-pyridinyl)-phosphorothioate $\}$, $4.46 \mathrm{~kg}$ (a.i.) ha-1 pebulate (herbicide) \{S-Propyl butylethylthiocarbamate\}, and 0.58 $\mathrm{kg}$ (a.i.) ha-1 pendimethalin (herbicide) $\{\mathrm{N}$-(1-ethylpropyl)-3,4-dimethyl-2,6dintro-benzenamine\}. These pesticides were broadcast and then incorporated into the soil by disking. The same pre-transplant pest management treatments were used in 1990, except that $56.0 \mathrm{~L} \mathrm{ha}^{-1}$ of 1,3 dichloropene (nematicide) was used rather than fenamifos. Acephate (0.83 kg (a.i.) ha-1) \{O,S-Dimethyl acetylphosphoramidothiate was used as needed to control foliage-feeding insects.

Fertilization for both years consisted of $448 \mathrm{~kg} \mathrm{ha}^{-1}$ of a $6-6-18\left(\mathrm{~N}, \mathrm{~K}_{2} \mathrm{O}, \mathrm{P}_{2} \mathrm{O}_{5}\right)$ fertilizer formulated for tobacco and $168 \mathrm{~kg} \mathrm{ha-1}$ 15-0-14 (sodium-potassium nitrate) at transplanting, $448 \mathrm{~kg} \mathrm{ha}^{-1} 6-6-18$ at first cultivation, and $448 \mathrm{~kg} \mathrm{ha}^{-1} 6-6-18$ at last cultivation. All fertilizer was banded to the sides of the plants. Total application of the primary and secondary nutrients was $106 \mathrm{~kg} \mathrm{ha}^{-1} \mathrm{~N}, 81 \mathrm{~kg} \mathrm{ha}^{-1} \mathrm{P}_{2} \mathrm{O}_{5}, 266 \mathrm{~kg} \mathrm{ha}^{-1}$ $\mathrm{K}_{2} \mathrm{O}, 54 \mathrm{~kg} \mathrm{ha}^{-1} \mathrm{Ca}, 54 \mathrm{~kg} \mathrm{ha}^{-1} \mathrm{Mg}$, and $148 \mathrm{~kg} \mathrm{ha}^{-1} \mathrm{~S}$. In 1990, due to leaching of $\mathrm{N}$ and $\mathrm{K}, 112 \mathrm{~kg} \mathrm{ha}-1$ of $15-0-14$ was hand-applied to plots three weeks after the last cultivation.

Leaf position (LP) will be defined as the leaves associated with a consecutive grouping of nodes along the stem. To maintain the integrity of a designated LP, all plants were topped to 21 leaves (each plant's leaves were counted). Suckers (axilary buds) were chemically controlled by pouring $25 \mathrm{ml}$ of a solution consisting of $20 \mathrm{ml} \mathrm{L}^{-1}$ flumetralin (2-chloro-N-[2,6-dinitro-4-(trifluoro-methyl)phenyl]-N-ethyl-6flouro-benzene-methanamine) and $40 \mathrm{ml} \mathrm{L}^{-1}$ fatty alcohol (hexanol $0.5 \%$, octonol $42 \%$, 
decanol 56\%, dodecanol 1.5\%) down the stalk at topping. The 21 leaves were partitioned into seven, 3-leaf stalk positions for harvesting purposes.

A normal harvest study, so called because it most closely approximated the normal production practices of flue-cured tobacco, was used to evaluate the responses of the leaves when they were mature. A whole plant harvesting study was used to evaluate the responses of individual LPs over time. These two studies will be described separately because of the differences in design and layout in the field and the methods by which the data were managed.

\section{Normal Harvest Study}

Ten plants comprised a plot and each plot was replicated four times each year. Seven weekly leaf harvests were taken from 3-leaf stalk positions, beginning one week after topping. Weybrew et al. (1984) suggested that flue-cured tobacco leaves should mature at a rate of one leaf every two days. Based on their statement, harvesting three leaves per week should ensure that mature tobacco was harvested each week. The lowest three leaves were taken first, and subsequent harvests progressed up the plant until the final harvest of the last three leaves that remained on the plants. The lowest three leaves were designated LP 1-3, and uppermost three leaves designated LP 19-21, with appropriate designations for the intermediate leaves.

Thirty leaves constituted a harvest on a given date (three leaves from each of 10 plants). On harvest days, 15 of the 30 leaves were measured for leaf area using a LiCor 3100 leaf area meter. The 15 leaves for leaf area measurement always came from the same five plants to minimize variation between plants and to ensure that the 15 leaves were composed of an equal number of leaves from each of the three leaf groups per plant. To facilitate accurate leaf area measurement, individual leaves were severed down the midrib and each leaf half was passed through the leaf area meter. Once leaf area measurement was completed on the 15 leaves, fresh weight was determined using an Ohaus 8000 digital scale. Fresh weight was also taken on the intact 15 leaves. Once leaf 
area and fresh weight measurements were completed, the leaves were cured in the normal flue-curing manner. The cut and intact samples were kept separate in the curing barn so that the cured weights could be obtained on the leaf area samples for specific cured leaf weight calculation. Once the leaves had been cured, the cut and intact leaves were measured for cured weight. These weights were composited for the total plot yield of cured tobacco.

Cured (intact) leaves from all samples were evaluated by United States Department of Agriculture tobacco graders. Each sample was assigned a grade. These grades were used to determine the value per hectare or kilogram, using the 1989 or 1990 Georgia-Florida flue-cured tobacco (Type 14) market average for the respective grades. The numerical index for each grade (Bowman et al., 1988) was used to determine a grade index for each LP. The grade index reported in this study for each LP is the mean of the grade indices for the tobacco that was in the designated LP. Eight cured leaves were selected from each sample of each LP for chemical or mineral analyses. The midribs were removed from the lamina. The lamina was ground to $1 \mathrm{~mm}$ using a Wiley mill. Total N, nicotine, and reducing sugar analyses were performed by R.J. Reynolds Tobacco Company in Winston-Salem, N.C. For Ca, Mg, K, and P analyses, samples were prepared by the ashing and acid digestion method described by Walsh (1971). The resulting solutions were analyzed by Inductively Coupled Argon Plasma (ICAP) in the University of Florida's Institute of Food and Agricultural Science Extension Soil Testing Laboratory by methods described by Hanlon and Devore (1989).

A split-split-plot design was used for statistical analysis with years being main plots, cultivars being sub-plots, and leaf positions being sub-sub-plots. Analysis of variance and Fisher's Least Significant Difference (LSD) were carried out by methods described by Gomez and Gomez (1984). For most variables, interactions were either not significant, or were determined not to be of practical importance. No differences between cultivars or years were found. The data reported were averaged across 
cultivars and years. For clarity, only the LP effects are discussed because they were of the greatest significance for each variable.

\section{Whole Plant Harvest Study}

This study was designed to monitor changes in LP characteristics for the duration that each leaf position remained on the plant prior to normal harvest. Seven weekly harvests were taken of all LPS that remained on the stalk, beginning one week after topping. A set of samples was taken at topping to establish a baseline for all LPS. Because this study was designed to monitor LP changes over time, LPs that were harvested in the normal harvest study were removed from all plots that were to be used for future harvest date analysis. The progression of the LPS as they were harvested is illustrated in Table $2-1$.

Table 2-1. The leaf positions removed per plant by harvest date in the days after topping study.

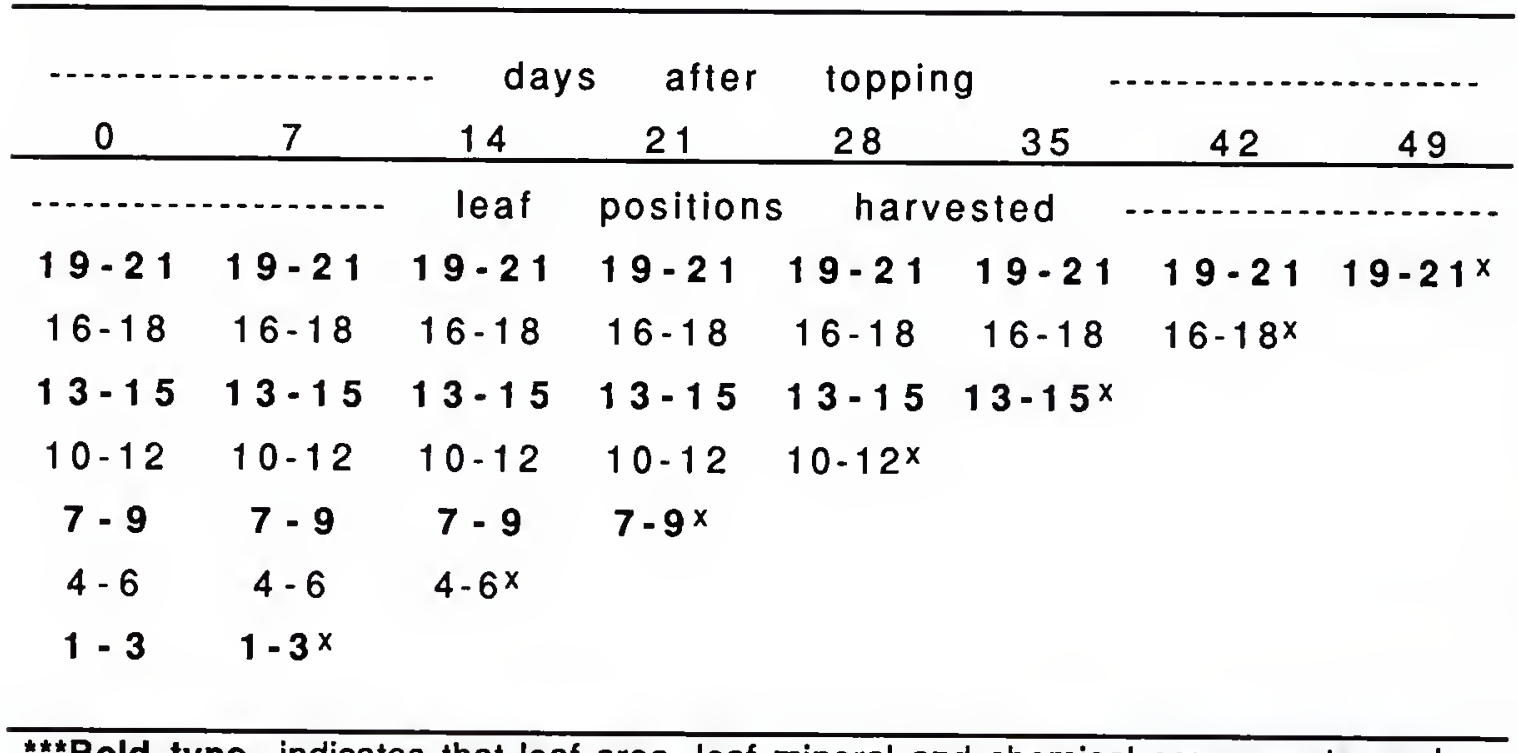

***Bold type indicates that leaf area, leaf mineral and chemical components, and total non-structural carbohydrates (TNC) were measured on those leaf positions.

$x$ Indicates leaf positions which were harvested normally on this date.

The data discussed herein were extracted from a larger study dealing with the effects of lower leaf harvesting options on the same characters described in this paper. Analysis of variance revealed that three treatments: 1) harvest all 21 leaves, 2) prune 
the lowest 3 leaves, and 3) do not prune or harvest the lowest three leaves, had few if any differences (discussed in Chapters 3 and 4). Most flue-cured tobacco farmers practice one of these three treatments. Because of the lack of differences between treatments, the data from the three treatments were combined, thereby increasing sample size from 12 to 36 observations.

Each plot consisted of two plants occupying an area of 1 square meter. All LPs were removed from the designated plants for a given harvest date as illustrated in Table 2-1. Each LP harvested consisted of six leaves (2 plants $X$ a 3-leaf position). Fresh weight was taken on all LPs using an Ohaus 8000 digital scale. Leaf area was measured using a Li-Cor 3100 leaf area meter on LPs 1-3, 7-9, 13-15, and 19-21. To facilitate accurate leaf area measures, each leaf was severed down the midrib and each leaf half passed through the leaf area meter. All leaf samples were cured in the normal flue-curing manner. After curing, the dried leaf samples were rehydrated for handling purposes, and cured weights were taken on all LPS.

The six leaves from LPs $1-3,7-9,13-15,19-21$ of each plot were used for leaf chemical or mineral analyses. The samples for chemical or mineral analyses were processed the same as described in the normal havest study above.

Total non-structural carbohydrate (TNC) data reported herein were derived from separate plants than those used for leaf mineral and chemical analyses, but the progression of harvesting LPS was identical to that indicated in Table 2-1. The TNC samples were obtained from a single plant that was adjacent to those used for the agronomic and mineral analyses. Because a single plant was used, total sample size was three leaves per LP harvested. The lamina was severed from the midrib and placed in a paper bag. The sampling and cutting of leaves was done in the field. When the samples were obtained, bags containing samples were placed in a large plastic bag in a cooler containing ice. This procedure was followed so that the leaf metabolism would be slowed, conserving as much of the leaf carbohydrate as possible. Once all samples had been 
taken, samples were transported to drying facilities. A Blue $M$ forced air dryer was used to desiccate samples. Prior to sampling, the dryer was set to $100 \mathrm{C}$, so that the temperature would be at the desired level upon arrival at the drying facility. The paper bags containing the leaf lamina were quickly placed in the dryer. The temperature was maintained at $100 \mathrm{C}$ for $1 \mathrm{hr}$ to arrest lamina metabolism. After $1 \mathrm{hr}$ at $100 \mathrm{C}$, the temperature was reduced to $70 \mathrm{C}$ for the duration of lamina drying. This drying method was the best alternative to freeze-drying (Heberer et al., 1985). The elapsed time between sampling initiation and arrival at the drying facilities was generally between 1 and $2 \mathrm{hr}$, depending on the number of samples that were to be harvested. Sample acquisition always progressed from replication 1 to replication 4 , so that any effects due to sampling time could be accounted for. There were no appreciable differences in replications indicating samples were processed in a timely manner. The TNC was analyzed by a modified procedure of the methods described by Smith (1974).

Leaf chemical and mineral data are reported for leaf lamina only. Midribs were not evaluated, and previous studies indicated that their chemical and mineral constituents were different from the lamina (Darkis et al., 1952).

The treatments were arranged in a split-split-split-plot design in the field with cultivars being main plots, lower leaf harvesting options being sub-plots, leaf position being sub-sub-plots, and harvest dates being sub-sub-sub-plots. Analysis of the entire data set was not possible due to lack of balance. With each harvest date there was a loss of one LP (Table 2-1). Consequently, for harvest date evaluation, each harvest date was analyzed individually. The statistical model was also a split-split-split-plot design with years being main plots, cultivars being sub-plots, treatments being sub-subplots, and leaf positions being sub-sub-sub-plots. The LSD values for LP comparison given in the tables were calculated from the individual harvest date analysis of variance. Data from each LP were regressed separately over the time period during which the given LP remained on the plant. The model used was the same as that used for the 
individual harvest date analysis except that harvest dates (days after topping) were sub-sub-sub-plots. Analysis of variance, Fisher's Least Significant Difference (LSD) and regression analysis of LP means were carried out by methods described by Gomez and Gomez (1984). All regression equations reported were significant at the five-percent level or greater $(p>0.05)$. For most variables, interactions (except for leaf position $X$ harvest dates) were either not significant, or were determined not to be of practical importance. For clarity, only the leaf position $X$ harvest date effects are discussed because they were of the greatest significance for each variable.

\section{Results and Discussion}

Each 3-leaf LP comprises $14.3 \%$ of the 21 total number of leaves that were evaluated per plant. Fresh weights (FW) observed at the seven LPs during the normal harvesting scheme were similar except for those at LPs 1-3 and 19-21 (Fig. 2-1). Fresh weight accumulation of a given LP over time was dramatically influenced by leaf age at topping (Fig. 2-2a and Fig. 2-2b.) At topping, the oldest leaves are those nearest the bottom of the plant (i.e. LP 1-3), and leaf age declines progressively toward the the top of the plant. The youngest and least mature LP at topping, 19-21, was initially the lowest in FW, but increased in FW the most over time. The more mature LPs increased the least in FW over time. The FW of the uppermost three LPs (or nine leaves), being the least mature at topping, increased over time (Fig. 2-2a). However, the FW of the lowermost four LPs (or 12 leaves) did not increase over time (Fig. 2-2b). This observation quantified the suggestion by Wolf and Gross (1937) that more mature leaves at topping would have fewer changes over time.

The cured weight (CW) of leaves harvested when they were mature was influenced more by LP than was FW (Fig. 2-3). The highest two LPs, 16-18 and 1921 , contributed $37.1 \%$ of the total cured weight of $4141 \mathrm{~kg} \mathrm{ha}^{-1}$, while the lowest two LPs, $1-3$ and $4-6$, contributed only $19.9 \%$ of the total CW. Under good growing conditions like those encountered in the present study, the upper leaves typically will 


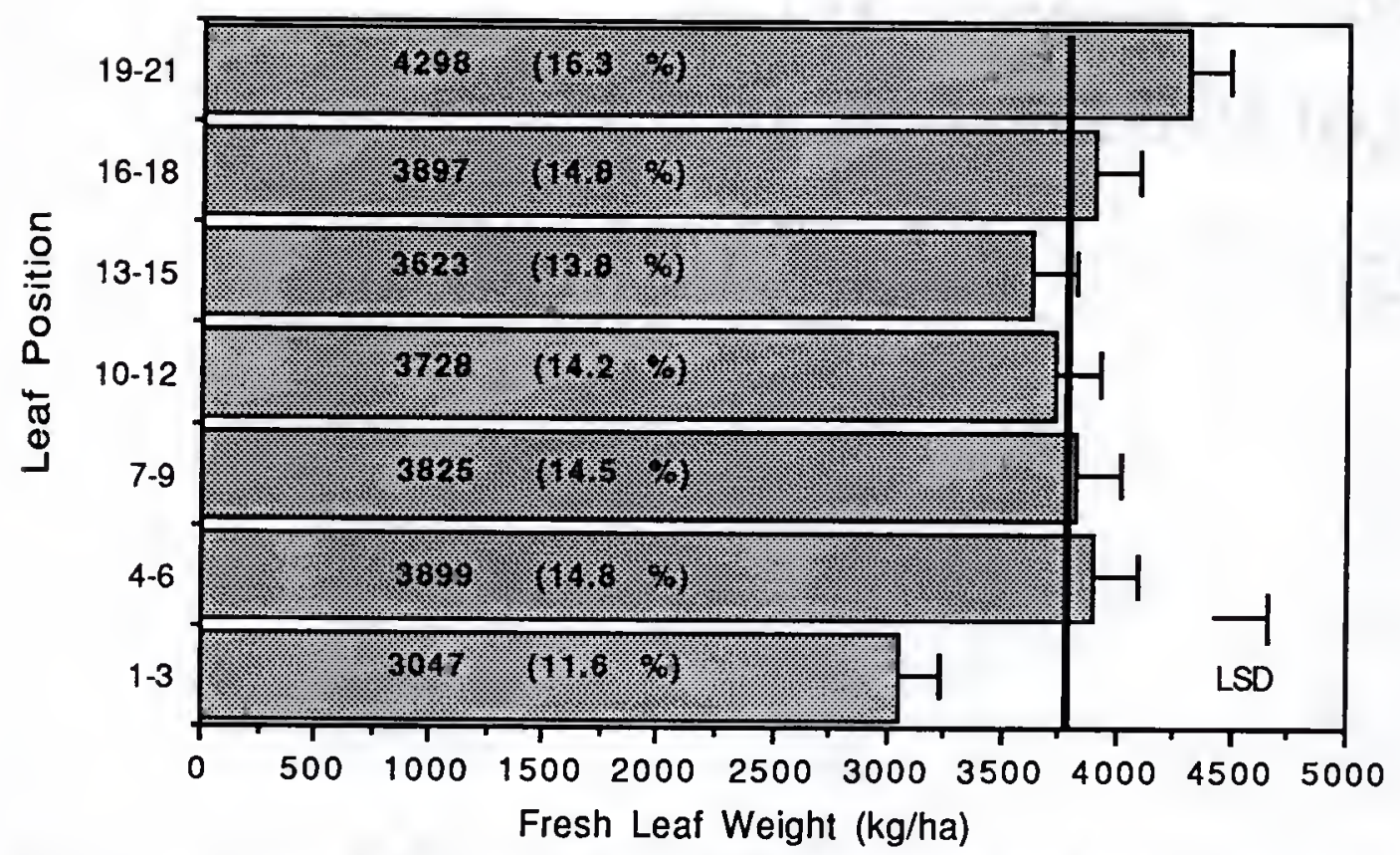

Fig. 2-1. Fresh weight of flue-cured tobacco as influenced by leaf position (LP) (LSD $0.05=193$ ). Vertical line represents mean across all LPs. Numerical values within bars are means $(n=16)$ of each LP and $(\%)$ is that LP's contribution to the total yield of $26317 \mathrm{~kg} / \mathrm{ha}$. 


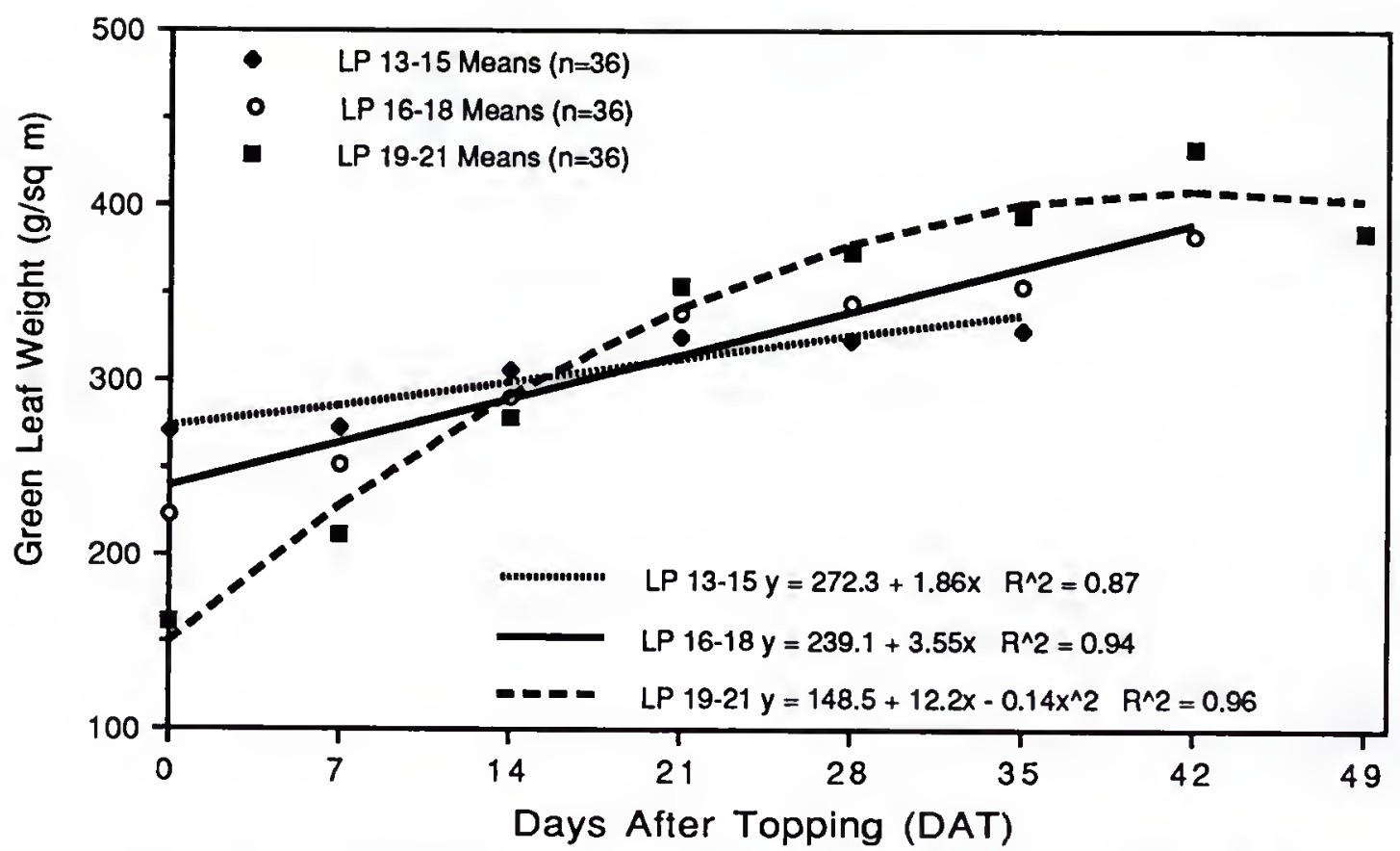

Fig. 2-2a. Fresh weight of flue-cured tobacco upper stalk leaf positions (LP) in response to days after topping. LSDs (0.05) for comparison of LPS at $0,7,14$, $21,28,35$, and 42 DAT are $30,16,14,14,15,10$, and 15 , respectively.

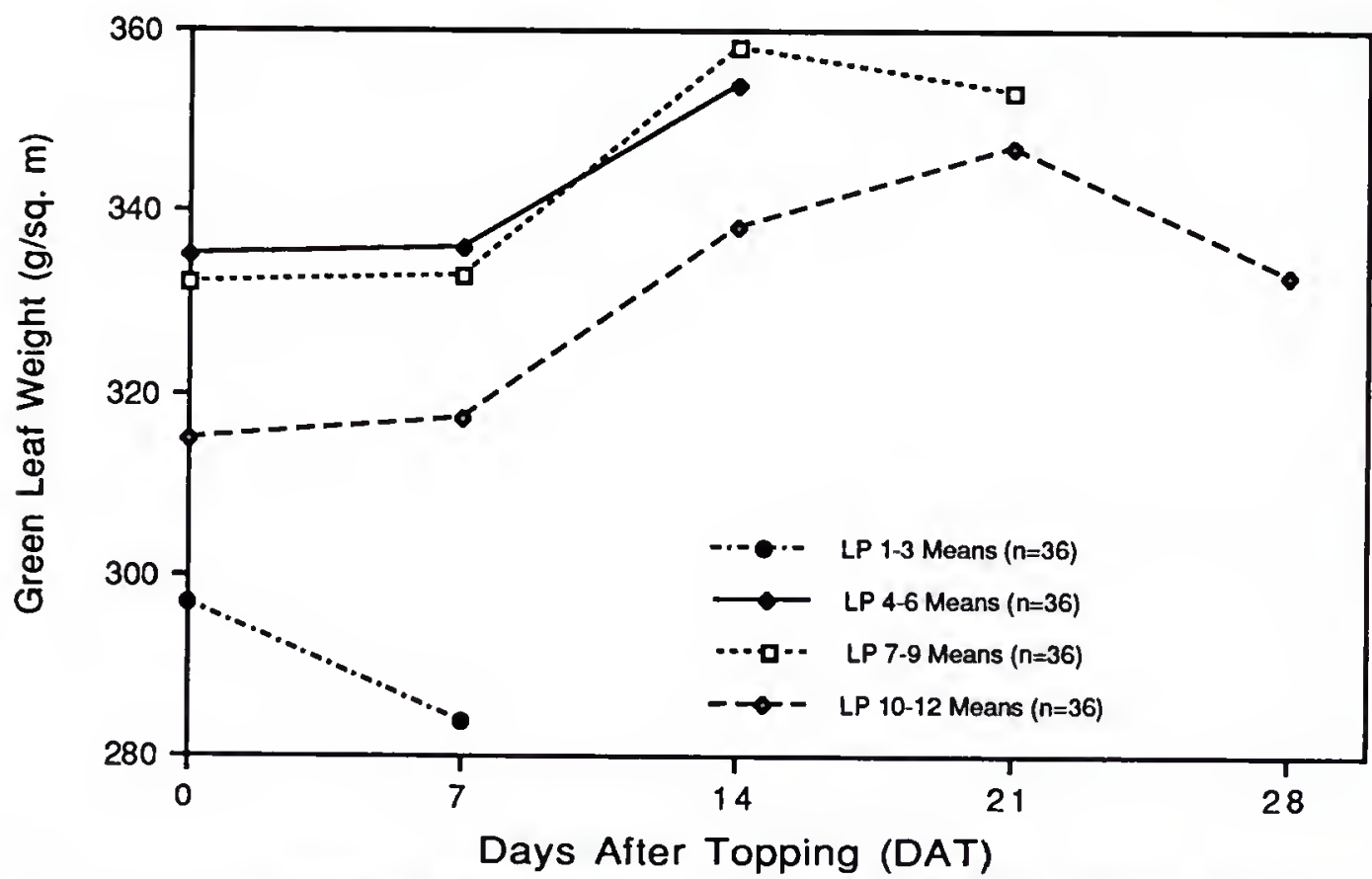

Fig. 2-2b. Fresh weight of flue-cured tobacco lower stalk leaf positions (LP) in response to days after topping. LSDs (0.05) for comparison of LPS at $0,7,14$, and 21 DAT are $30,16,14$, and 14 , respectively. 


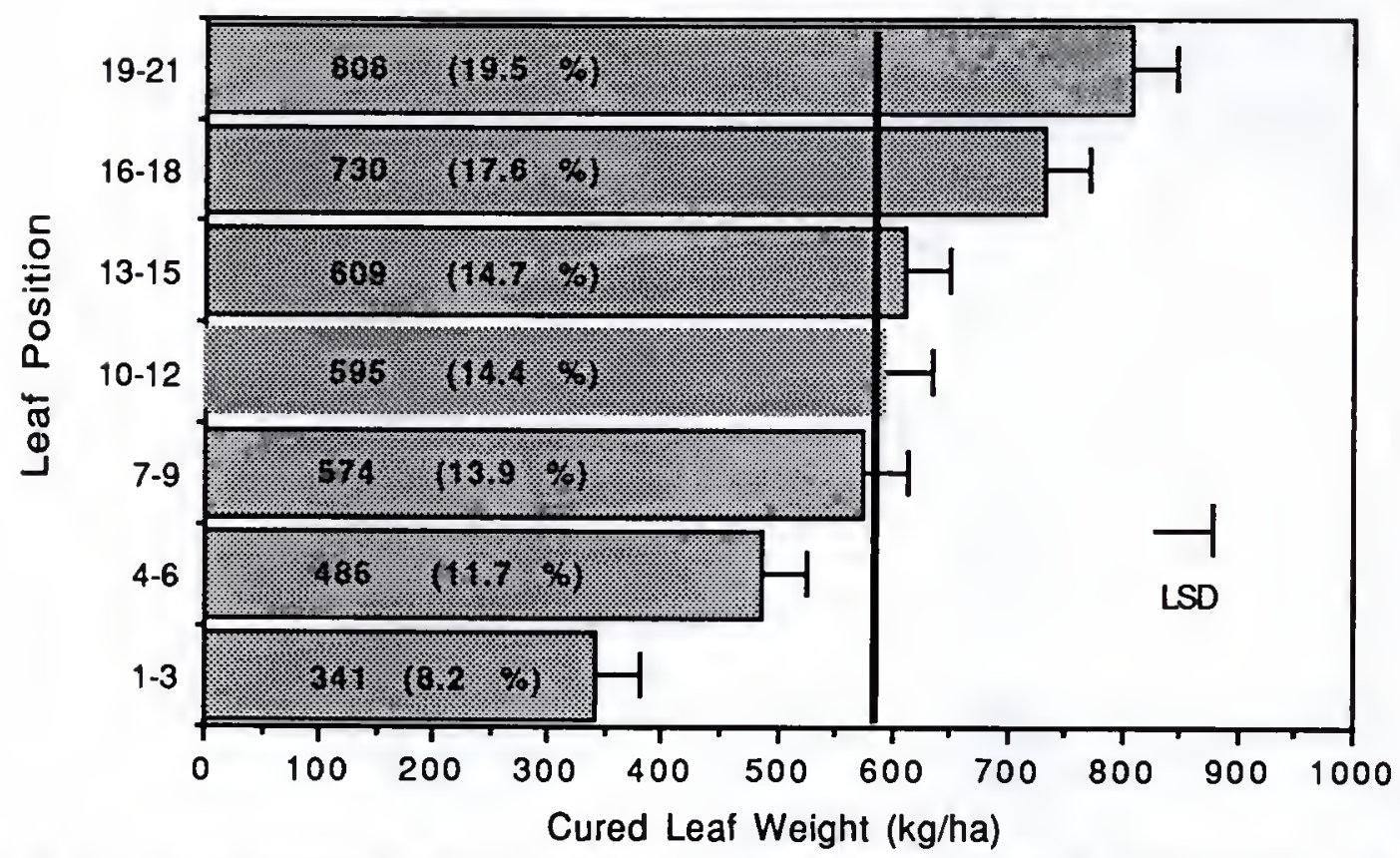

Fig. 2-3. Cured weight of flue-cured tobacco as influenced by leaf position (LP) (LSD $0.05=40$ ). Vertical line represents mean across all LPS. Numerical values within bars are means $(n=16)$ of each LP and (\%) is that LP's contribution to the total yield of $4141 \mathrm{~kg} / \mathrm{ha}$. 
contribute the highest CW of all leaves (Brown and Terrill, 1972; Darkis et al., 1936, 1952). Over time after topping, the CW increases observed for individual LPs were a result of the inherent differences in age of the leaves which comprised that LP (Fig. 2$4 a$ and $2-4 b$ ). The influence of leaf age on $C W$ increases over time was similar to that previously discussed for FW, except that the CW of LP 10-12 also increased with time after topping (Fig. 2-4b). Only the lowest three LPS (or nine leaves) did not significantly increase in $\mathrm{CW}$ over time.

Cured weight yield (CWY) is the percentage cured leaf that results from a given amount of freshly harvested leaf after the curing process. Cured weight yield generally increased from the lowest LPS to the highest LPs (Fig. 2-5). The CWY of other tobacco crops was also shown to increase as LP increased (Suggs et al., 1987). It is desirable to have a high CWY because the costs per unit of curing and handling are reduced due to the higher return of salable product. The CWY for an individual LP over time was driven by the differential in leaf age of the LPS at topping. The CWY response to time after topping was similar to that observed with $\mathrm{CW}$ in that the upper four LPS (or 12 leaves) increased in CWY over time (Fig. 2-6a), while the the lowest three LPs (or nine leaves) did not (Fig. 2-6b). Handling costs per LP would be similar on a FW basis. However, because CWY and CW increased progressively with higher LPS, the net returns per LP likely would increase as LP advanced up the plant.

Leaf area was highest at the lower LPs and lowest at the highest LPs (Fig. 2-7). This leaf area distribution is expected since the lowest leaves are formed prior to or shortly after the seedlings are transplanted. The first leaves formed in the field after transplanting are normally the largest with the upper leaves being smaller giving most flue-cured tobacco cultivars their characteristic conical shape. Lower topping heights than those used in this study can result in larger upper leaves, and some cultivars produce large upper leaves. Turner and Incoll (1971) reported $80 \%$ of the leaf area of a tobacco plant was contained in the $20 \mathrm{~cm}$ to $80 \mathrm{~cm}$ sections on the stalk. The stalk 


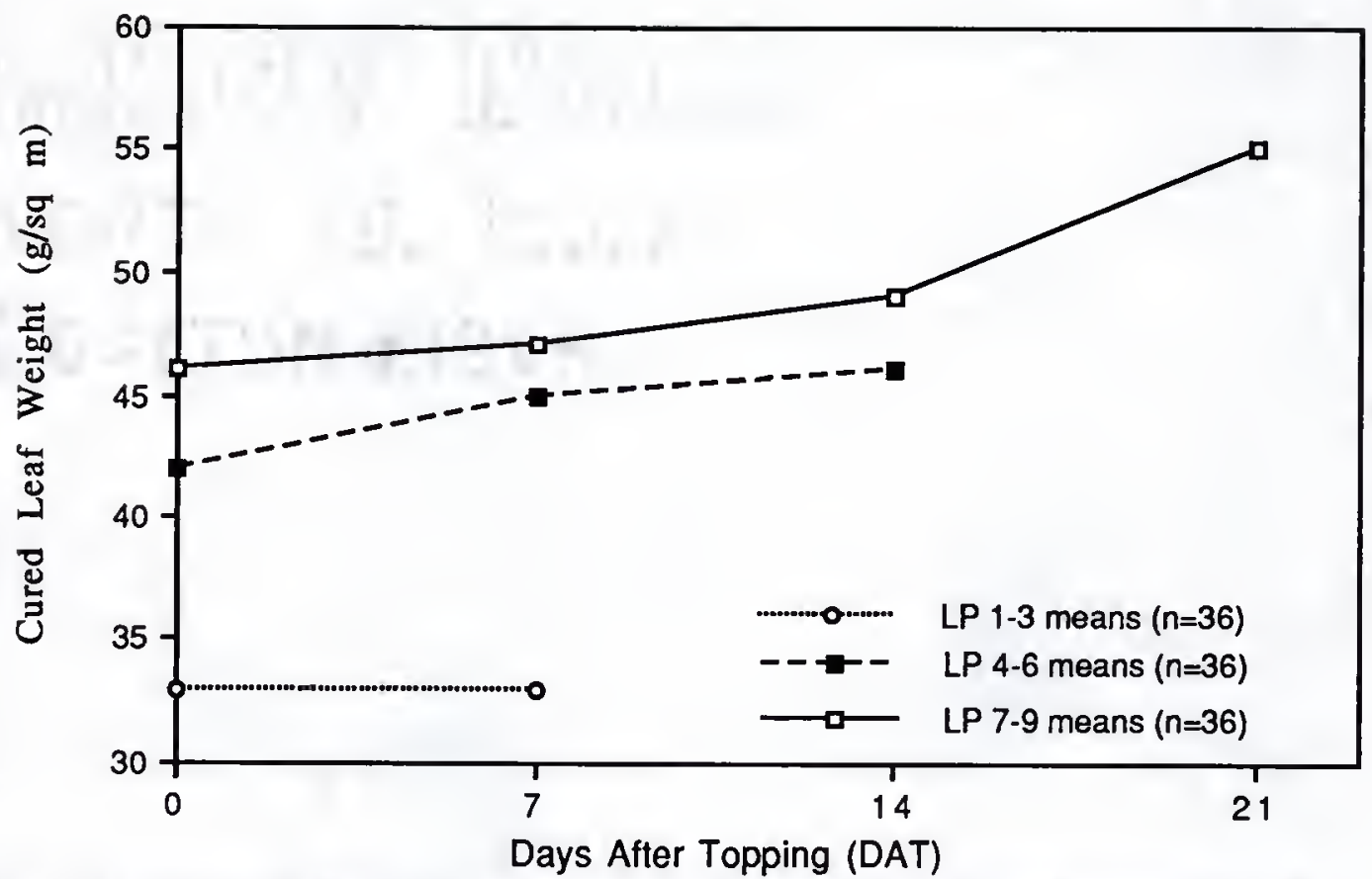

Fig. 2-4a. Cured weight of flue-cured tobacco lower stalk leaf positions (LP) in response to days after topping. LSDs $(0.05)$ for comparison of LPS at 0,7 , and 14 DAT are 3,2 , and 2, respectively.

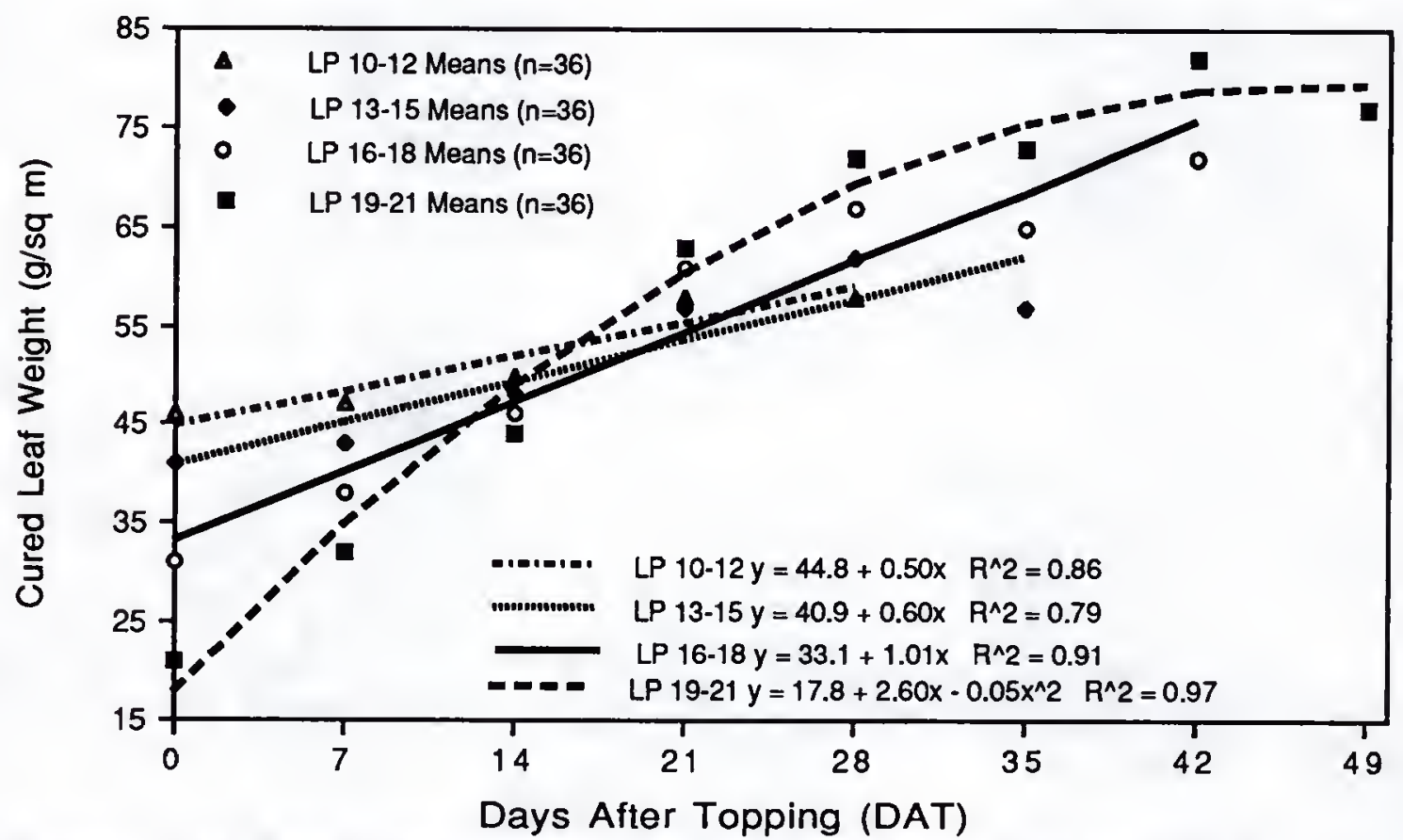

Fig. 2-4b. Cured weight of flue-cured tobacco upper stalk leaf positions (LP) in response to days after topping. LSDs (0.05) for comparison of LPS $0,7,14$, $21,28,35$, and 42 DAT are $3,3,2,3,3,3$, and 4 , respectively. 


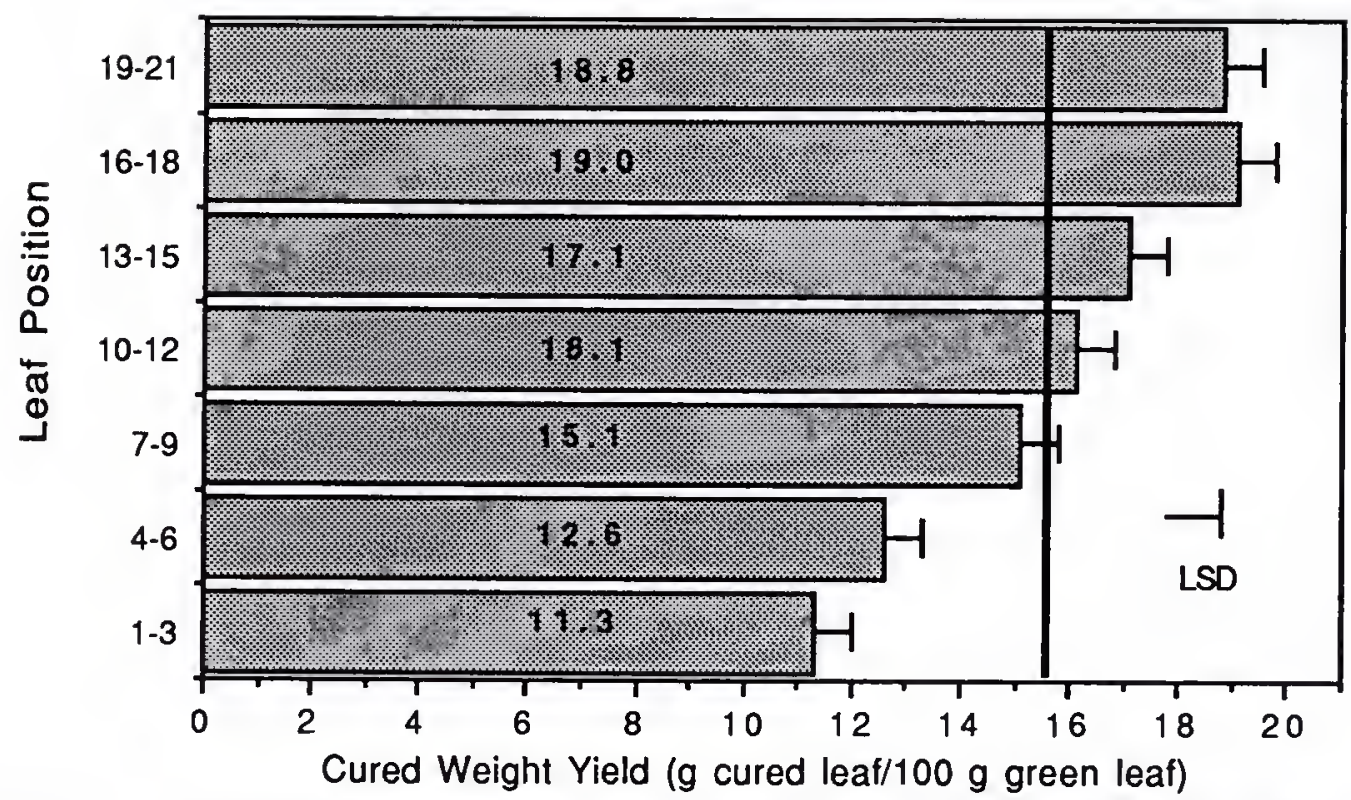

Fig. 2-5. Cured weight yield of flue-cured tobacco as influenced by leaf position (LP) (LSD $0.05=0.7$ ). Vertical line represents mean across all LPs. Numerical values within bars are means $(n=16)$ of each LP. 


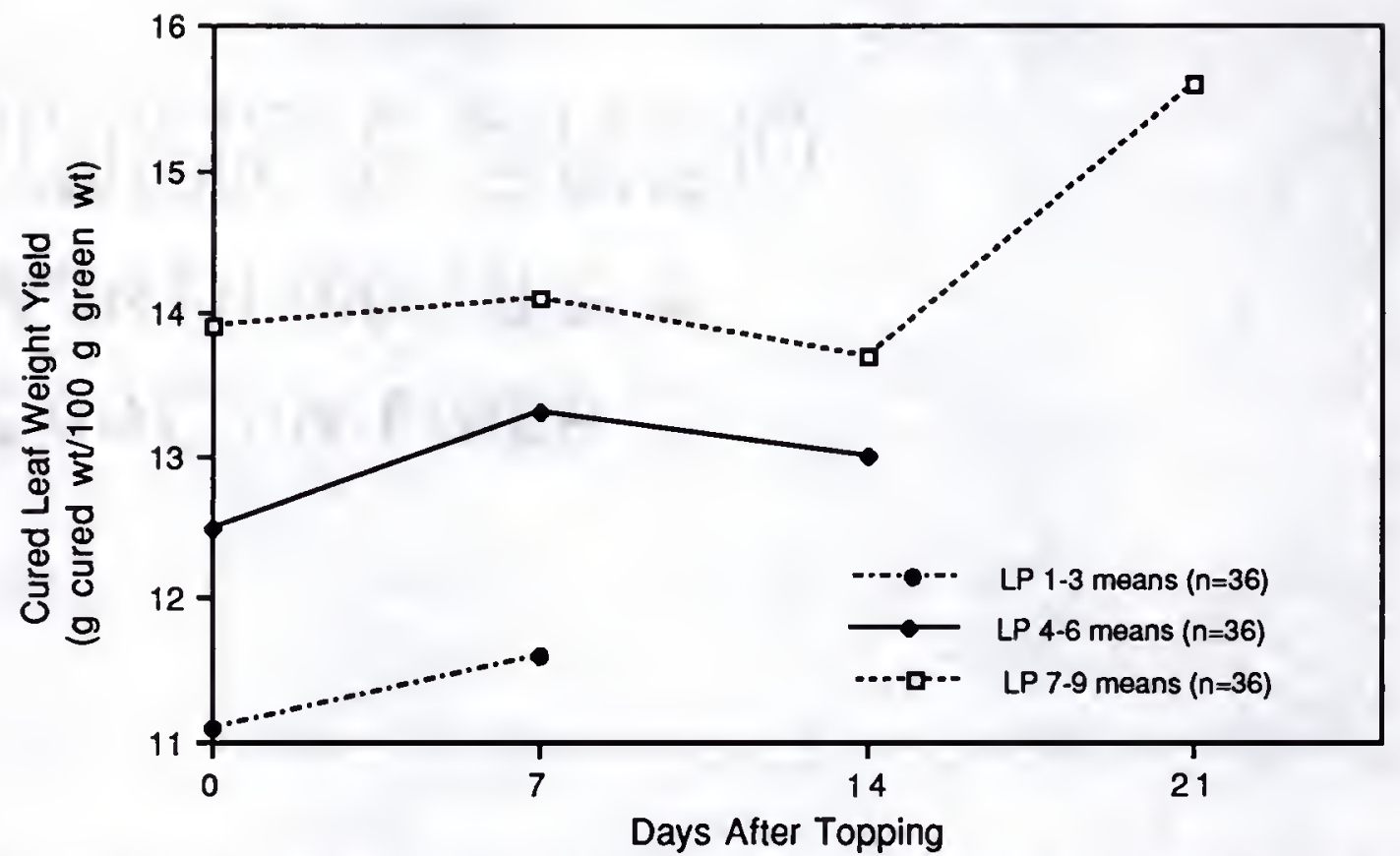

Fig. 2-6a. Cured weight yield of flue-cured tobacco lower stalk leaf positions (LP) in response to days after topping. LSDs (0.05) for comparison of LPS at 0,7 , and 14 DAT are $1.0,0.4$, and 0.5 , respectively.

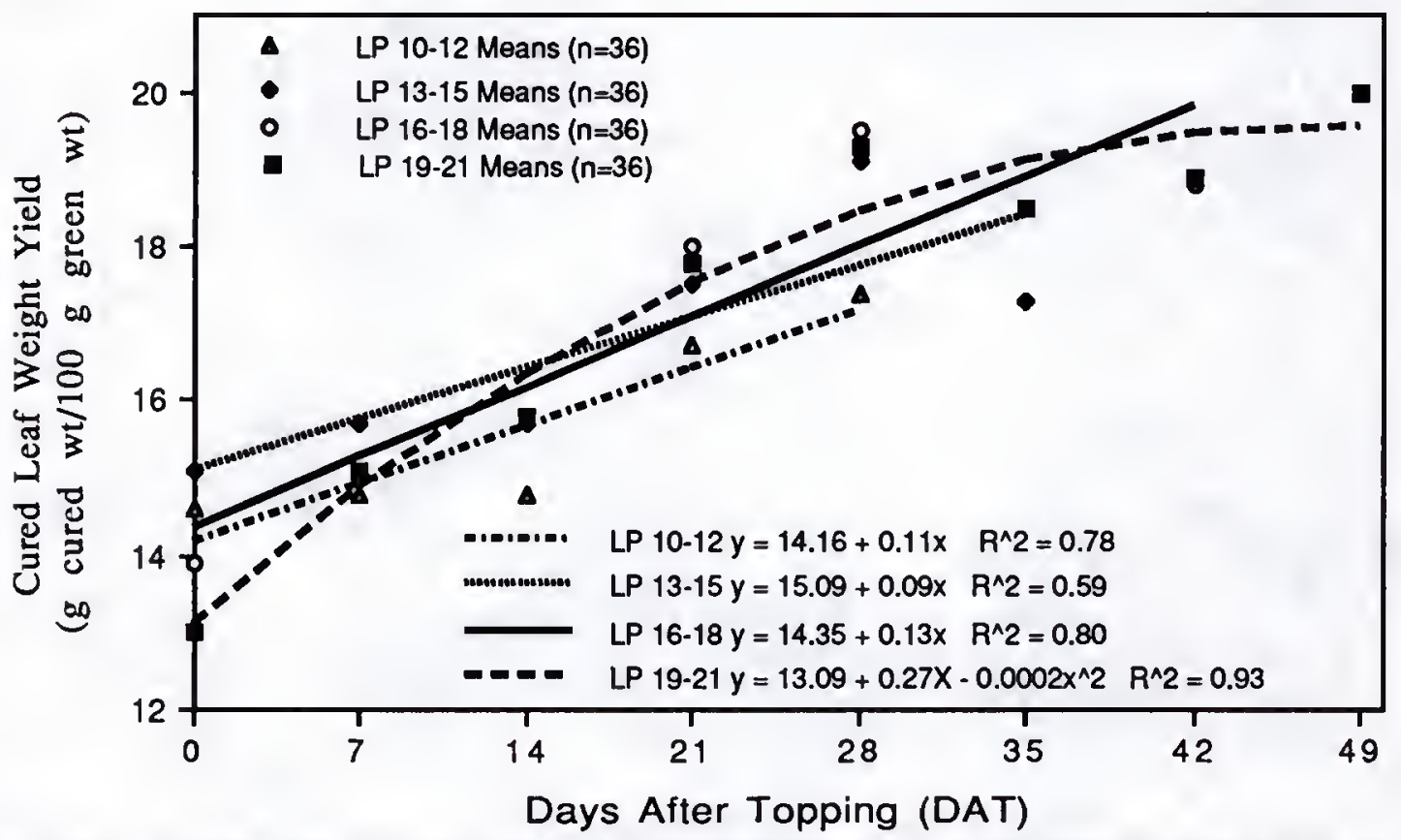

Fig. 2-6b. Cured weight yield of flue-cured tobacco upper stalk leaf positions (LP) in response to days after topping. LSDs $(0.05)$ for comparison of LPs at $0,7,14$, $21,28,35$, and 42 DAT are $1.0,0.4,0.5,0.5,0.8,0.5$ and 0.5 , respectively. 


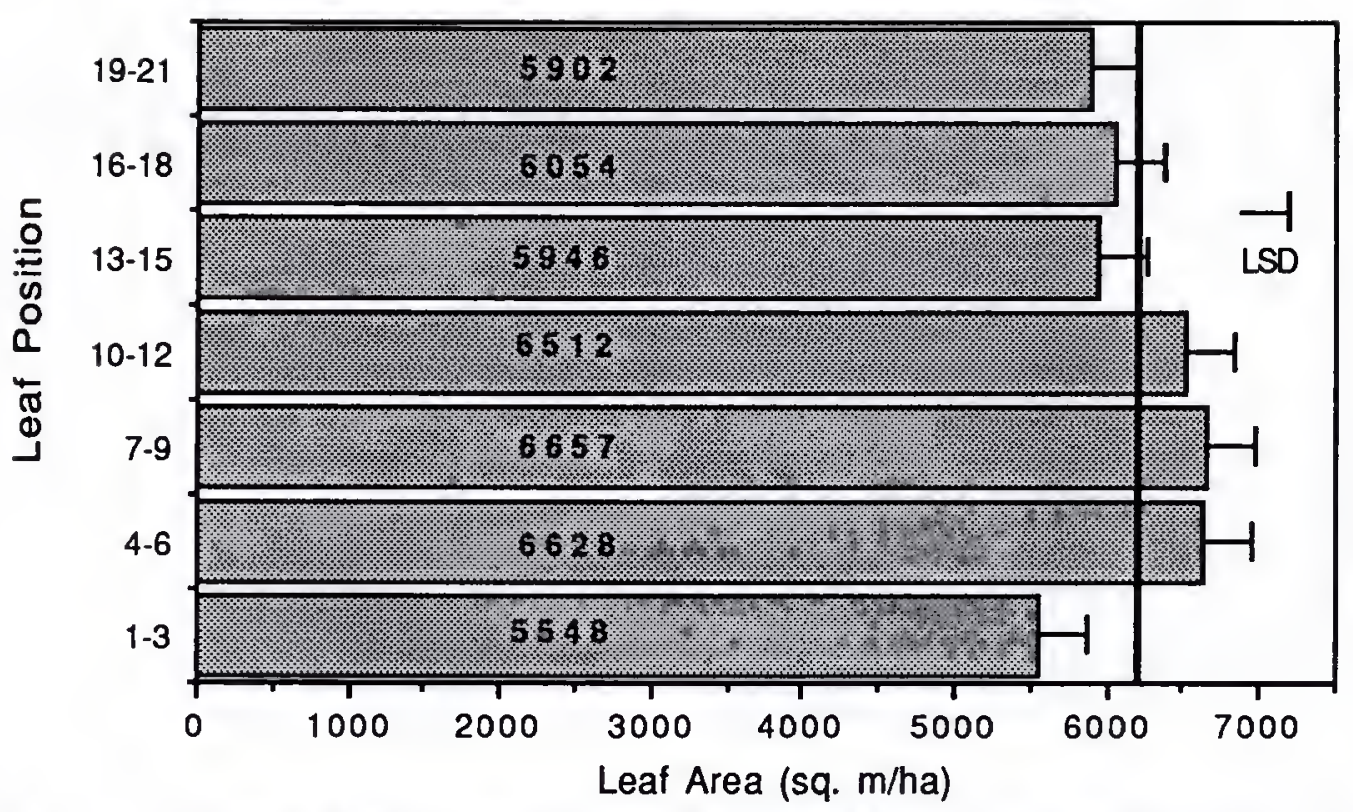

Fig. 2-7. Leaf area of flue-cured tobacco as influenced by leaf position (LP) (LSD 0.05 $=322$ ). Vertical line represents mean across all LPs. Numerical values within bars are means $(n=16)$ of each LP. 
heights for the plants used in the present study were about $100 \mathrm{~cm}$. Each leaf should occupy about $5 \mathrm{~cm}$ on the stalk. The middle five LPs, which contributed $74 \%$ of the total leaf area, would fall in the $20 \mathrm{~cm}$ to $80 \mathrm{~cm}$ sections on the stalks of these plants. A true measure of leaf area index (LAI) was not possible because the leaves were harvested as they matured, however, the composite LAI was 4.32 for the data given here. Only LPs $1-3,7-9,13-15$, and 19-21 were measured over time, but the leaf area development was similar to the responses for the other parameters previously discussed. The leaf areas for those LPS that were measured were influenced by leaf age and maturity over time (Fig. 2-8).

Specific cured leaf weight (SCLW) is a measure of $C W$ per unit of leaf area. Specific cured leaf weight increased with each LP (Fig. 2-9), ranging from a low of $6.13 \mathrm{mg}$ of $\mathrm{CW} \mathrm{cm}-2$ leaf area at LP $1-3$ to a high of $13.69 \mathrm{mg}$ of $\mathrm{CW} \mathrm{cm}-2$ leaf area at LP 19-21. The SCLW may be a useful measure for interpreting differences in CW between LPs. Cured weight yield is simply a ratio of the $\mathrm{CW}$ from a given amount of $\mathrm{FW}$. The CWY is largely the difference in water concentration. However, SCLW measures the CW per unit of leaf area thereby negating to some extent the influence of water concentration between a group of leaves. At LP 19-21, the CW was 2.36 times higher than that at LP 1-3, while the SCLW at LP 19-21 was 2.23 times higher than that at LP 1-3. Based on the SCLW measures observed in this study, there may be a higher proportion of structural tissue at higher LPs. Specific cured leaf weight of the individual LPS responded to time (Fig. 2-10) in a similar manner as did the parameters previously discussed.

Value per kilogram (Fig. 2-11) increased as LP progressed from the lowest to the highest leaves on the plant. Value per hectare (Fig. 2-12), being a function of $\mathrm{CW}$ and value per kilogram, also increased at higher LPs. The uppermost LP (leaves 1921) contributed $19.9 \%$ of the total value $\left(\$ 15315 \mathrm{ha}^{-1}\right)$ of the tobacco crop, while the lowest LP (leaves 1-3) contributed only $7.4 \%$ of the total value. Brown and Terrill 


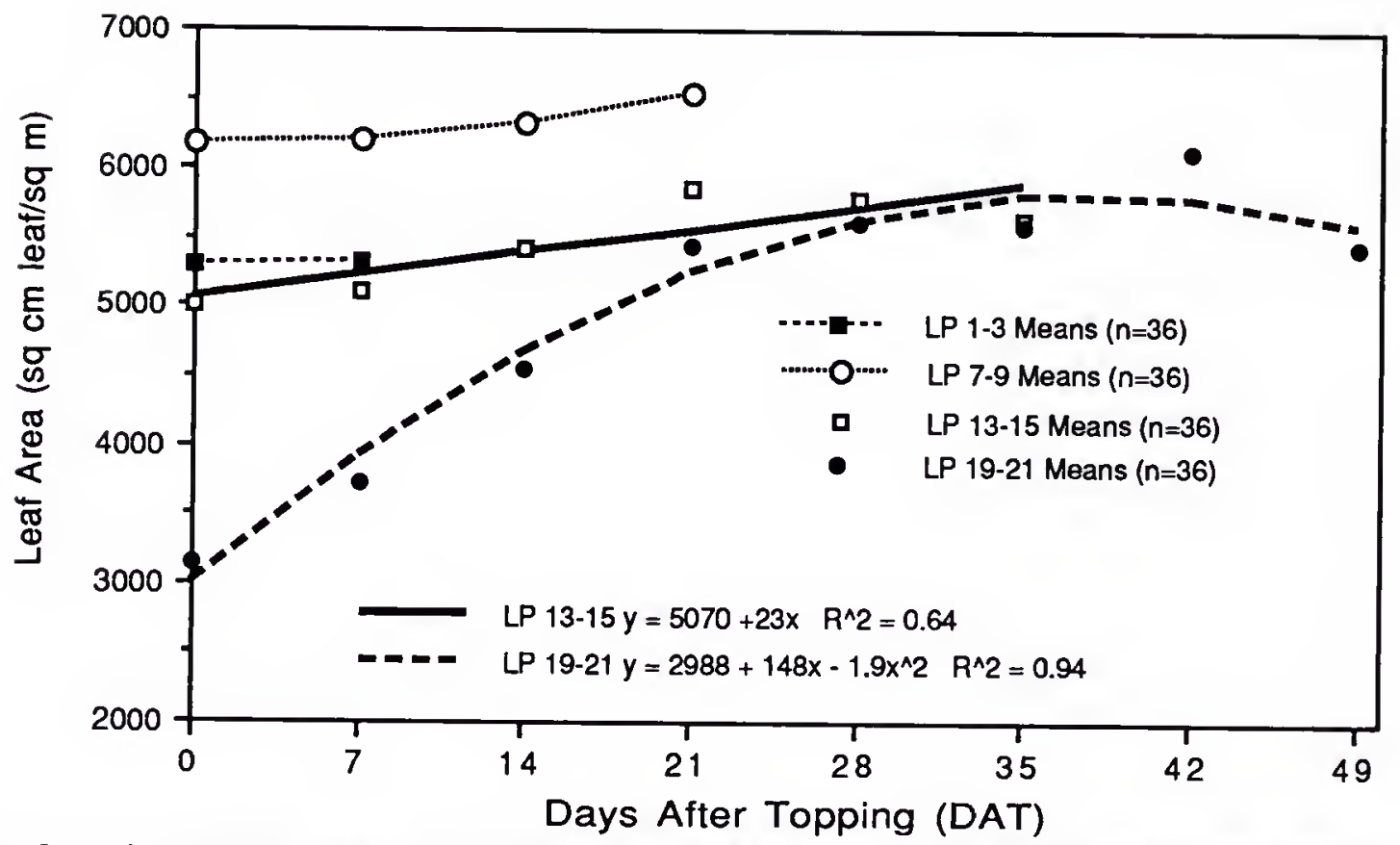

Fig. 2-8. Leaf area of flue-cured tobacco leaf positions (LP) in response to days after topping. LSDs (0.05) for comparison of LPS at $0,7,14$, and 21 DAT are 503, 316,253 , and 218 , respectively. DAT 28 and 35 are not significant. 


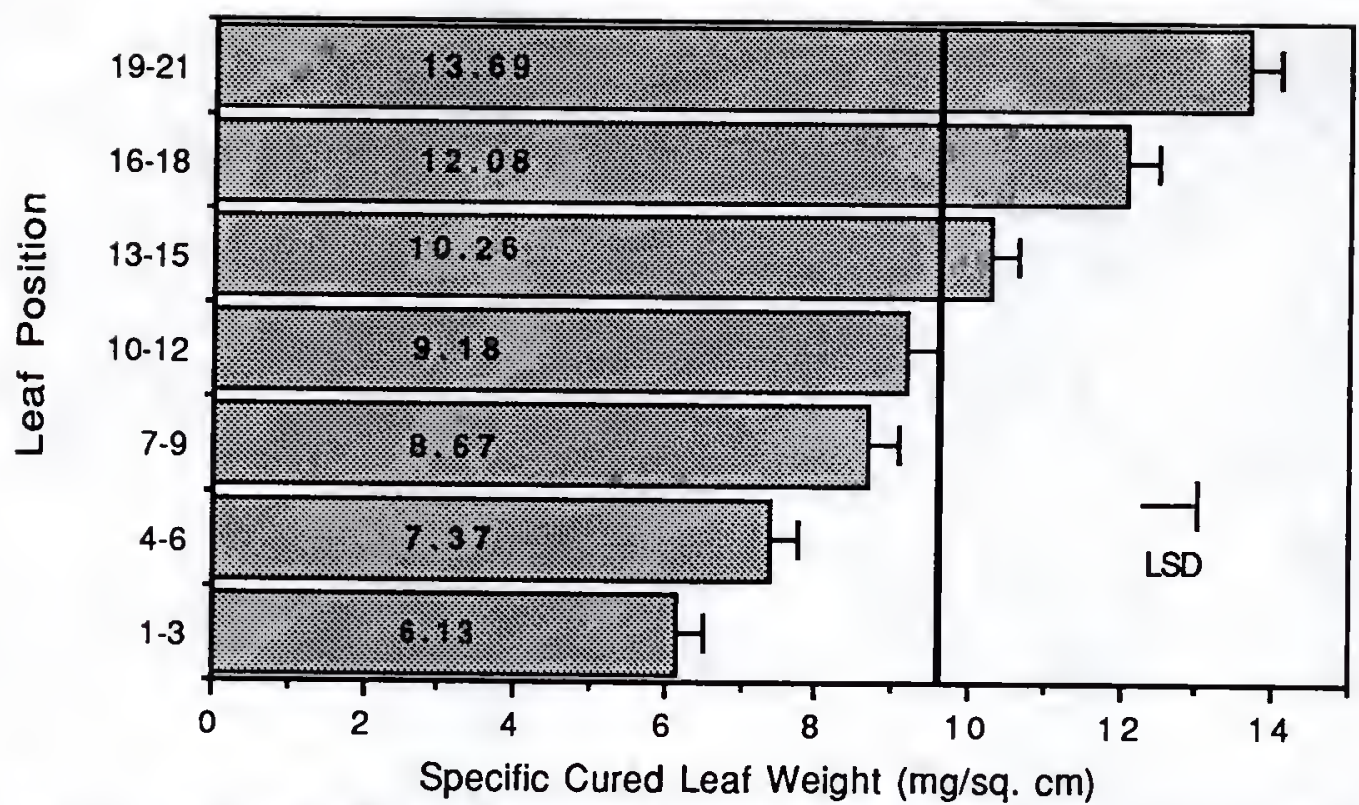

Fig. 2-9. Specific cured leaf weight of flue-cured tobacco as influenced by leaf position (LP) (LSD $0.05=0.4$ ). Vertical line represents mean across all LPS. Numerical values within bars are means $(n=16)$ of each LP.

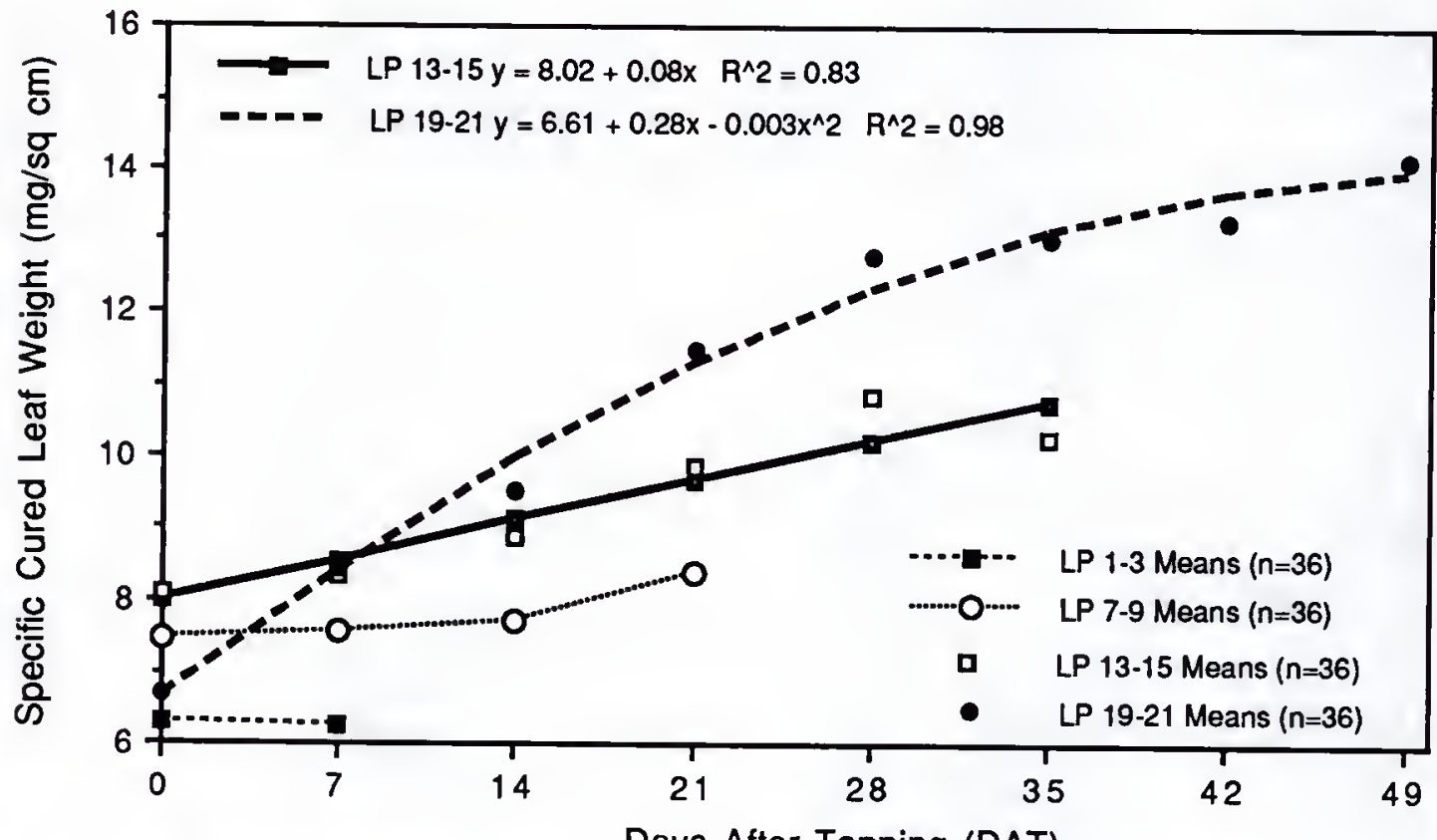

Days After Topping (DAT)

Fig. 2-10. Specific cured leaf weight of flue-cured tobacco leaf positions (LP) in response to days after topping. LSDs $(0.05)$ for comparison of LPs at $0,7,14$, 21,28 , and 35 DAT are $0.48,0.28,0.34,0.38,0.56$, and 0.47 , respectively. 


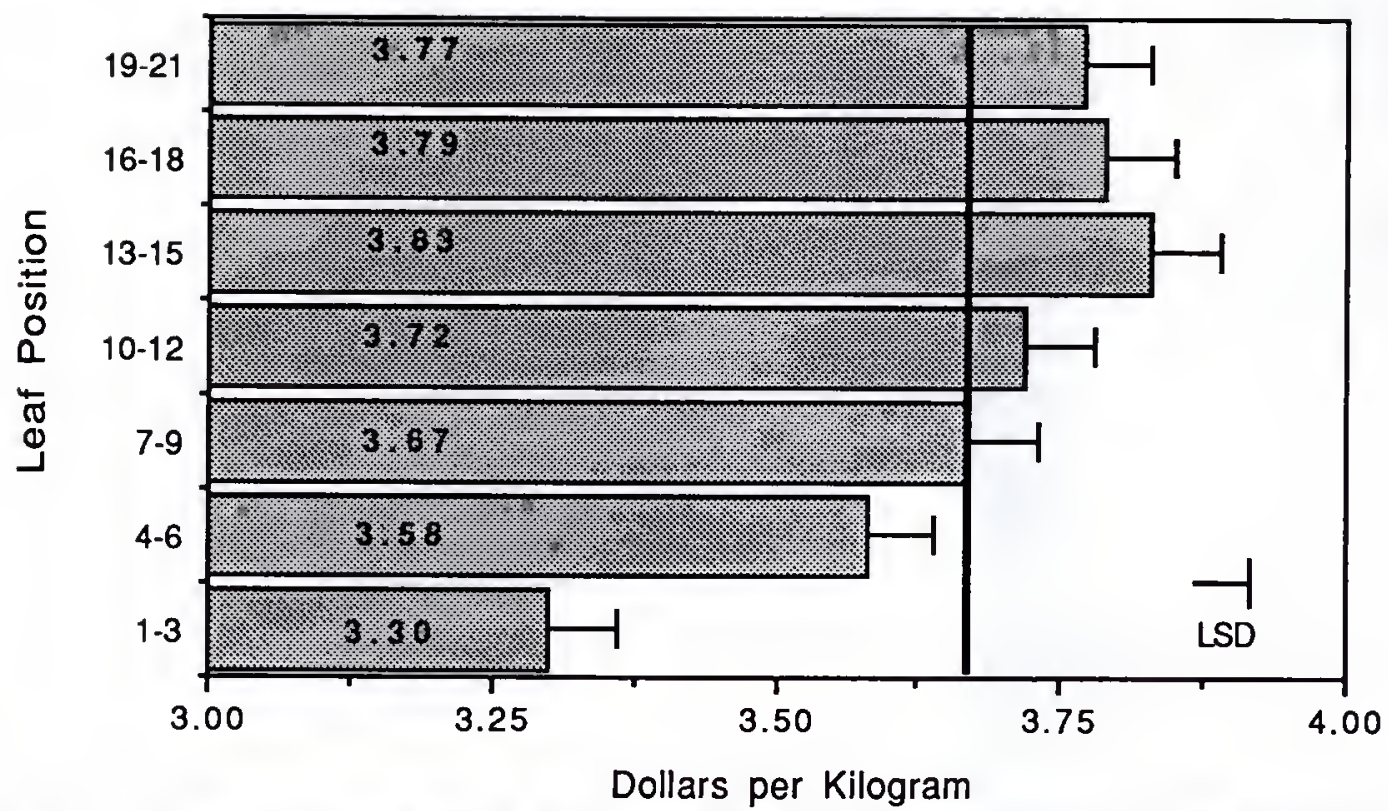

Fig. 2-11. Value per kilogram of flue-cured tobacco as influenced by leaf position (LP) (LSD $0.05=0.06)$. Vertical line represents mean across all LPs. Numerical values within bars are means $(n=16)$ of each LP.

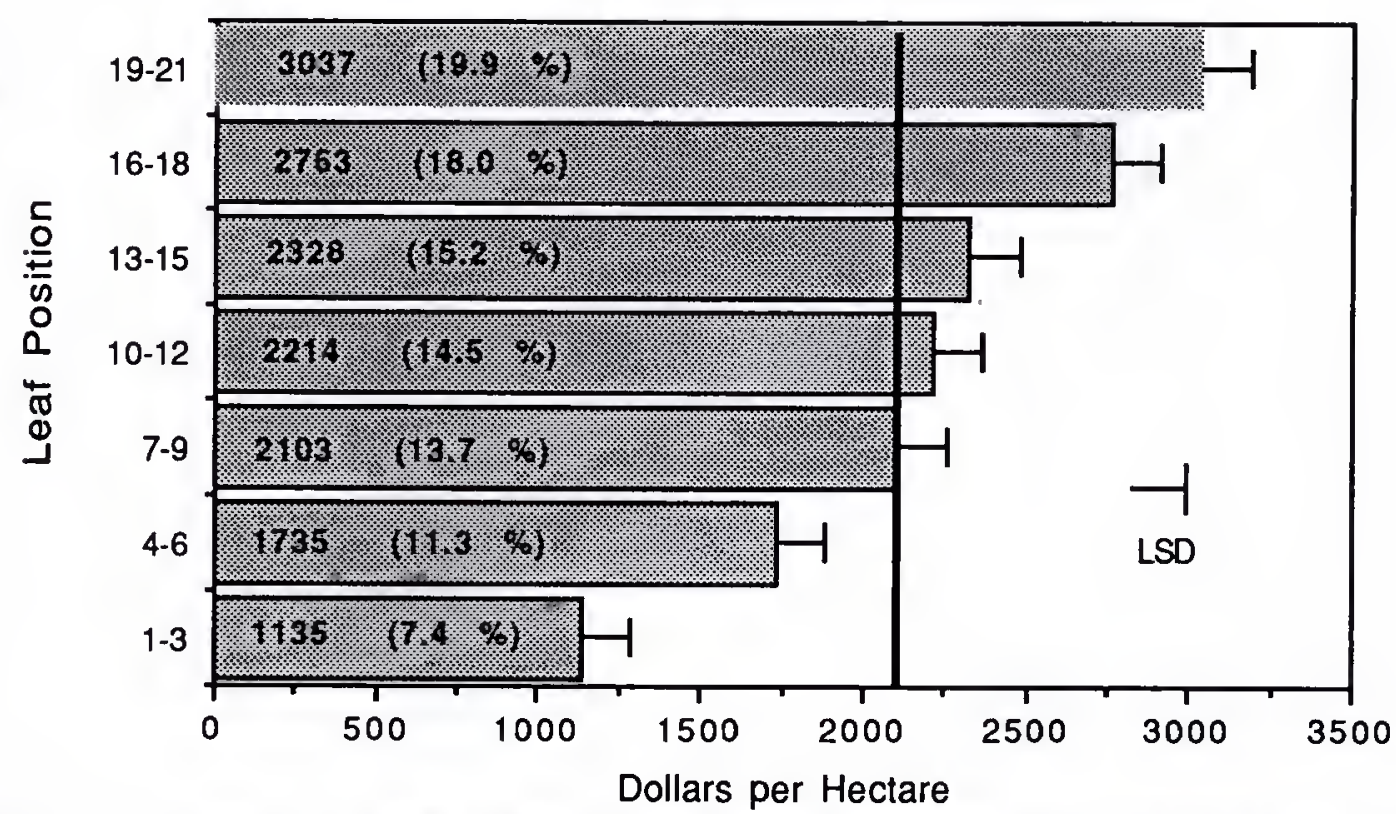

Fig. 2-12. Value per hectare of flue-cured tobacco as influenced by leaf position (LP) (LSD $0.05=152$ ). Vertical line represents mean across all leaf positions. Numerical values within bars are means $(n=16)$ of each LP and (\%) is that LP's contribution to the total value of $15315 \$ / \mathrm{ha}$. 
(1972) found the middle and upper leaves of flue-cured tobacco contributed the most value to the total value of the crop. The higher value of the upper LPs would support the suggestion that management practices should strive to protect the upper leaves from pests late in the harvesting season so as to derive the maximum yield and value from those leaves.

The numerical grade index of flue-cured tobacco (Bowman et al., 1988) is based on the USDA flue-cured tobacco grading system which considers several leaf characteristics including position on the stalk, maturity, color and quality of the cured leaf. Based on the grades received for the tobacco evaluated in this study, the lowest five LPs were equal in grade index with the upper two LPs being lower in grade index (Fig. 2-13). The grade index values reported for the lower five LPs indicated ripe and mature tobacco, while the upper leaf grade index values were indicative of unripe and/or immature leaf. Suggs (1986) reported a high correlation of grade index to unit price of tobacco crops. However, based on the data for grade index and value per kilogram by LP reported in this study there was a poor relationship between price and grade index across LPs. The grade indices typically reported are a weighted average across all LPs. Higher quality tobacco, and subsequently higher value tobacco will have a higher grade index. However, the prices paid per grade of tobacco from a given LP are determined by market demand, and may not correlate as well with the grade indices from that LP. Leaf Chemical Characteristics

Lamina N concentration (Fig. 2-14) generally increased as LP progressed up the stalk. Brown and Terrill (1973), Nel et al. (1974), Neas et al. (1978), Darkis et al. $(1936,1952)$ also found $N$ concentration increased as LP advanced up the stalk. The age of the leaves contained within a given LP influenced the $N$ concentration of that LP over time (Fig. 2-15). The least mature LPs at topping were the highest in $\mathrm{N}$ concentration, but as those immature LPS increased in CW and leaf area, the $\mathrm{N}$ concentration declined rapidly. Raper and McCants (1966) reported that flue-cured tobacco plants had 


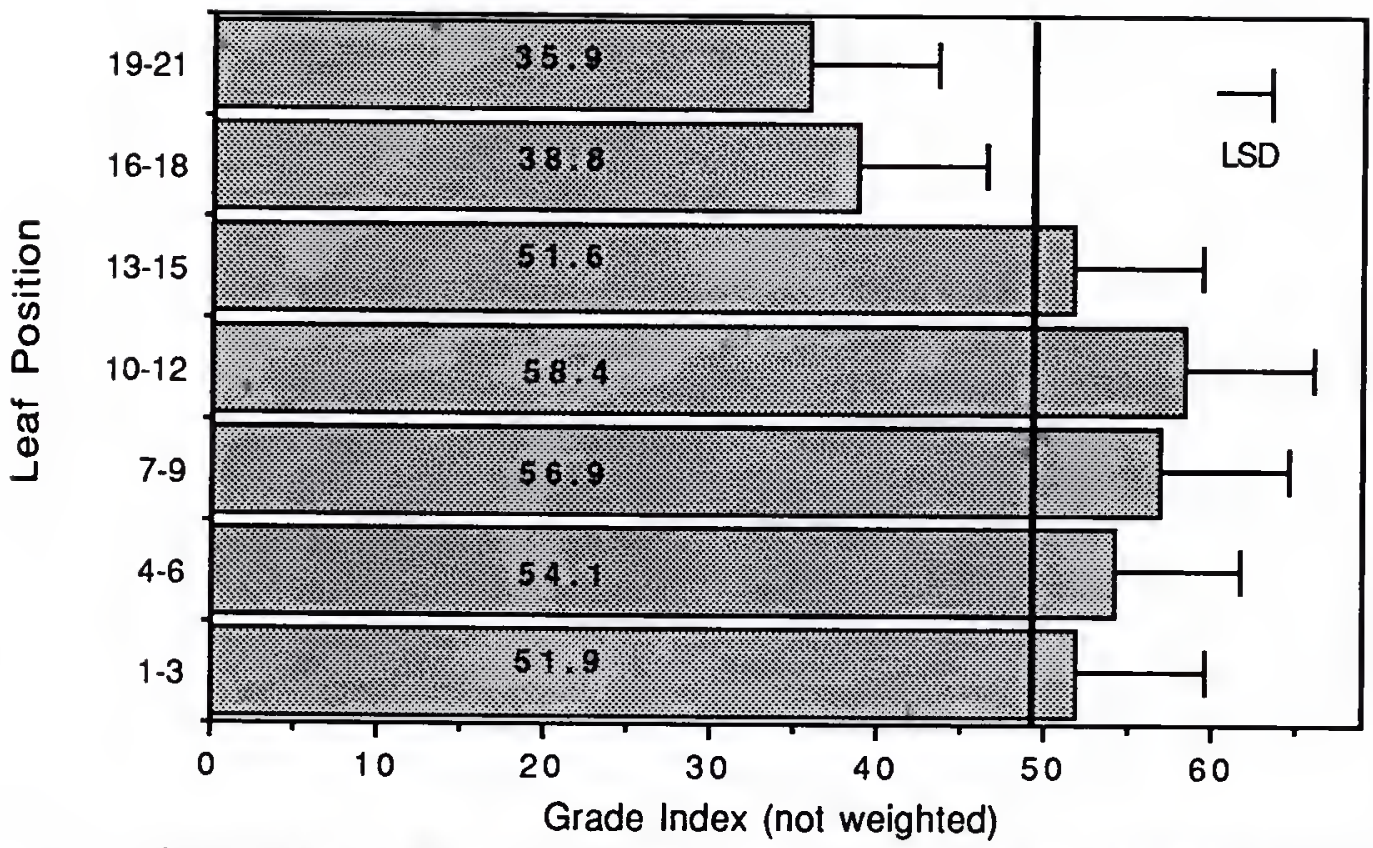

Fig. 2-13. Grade index of flue-cured tobacco as influenced by leaf position (LP) (LSD $0.05=7.7$ ). Vertical line represents mean across all LPS. Numerical values within bars are means $(n=16)$ of each LP. 


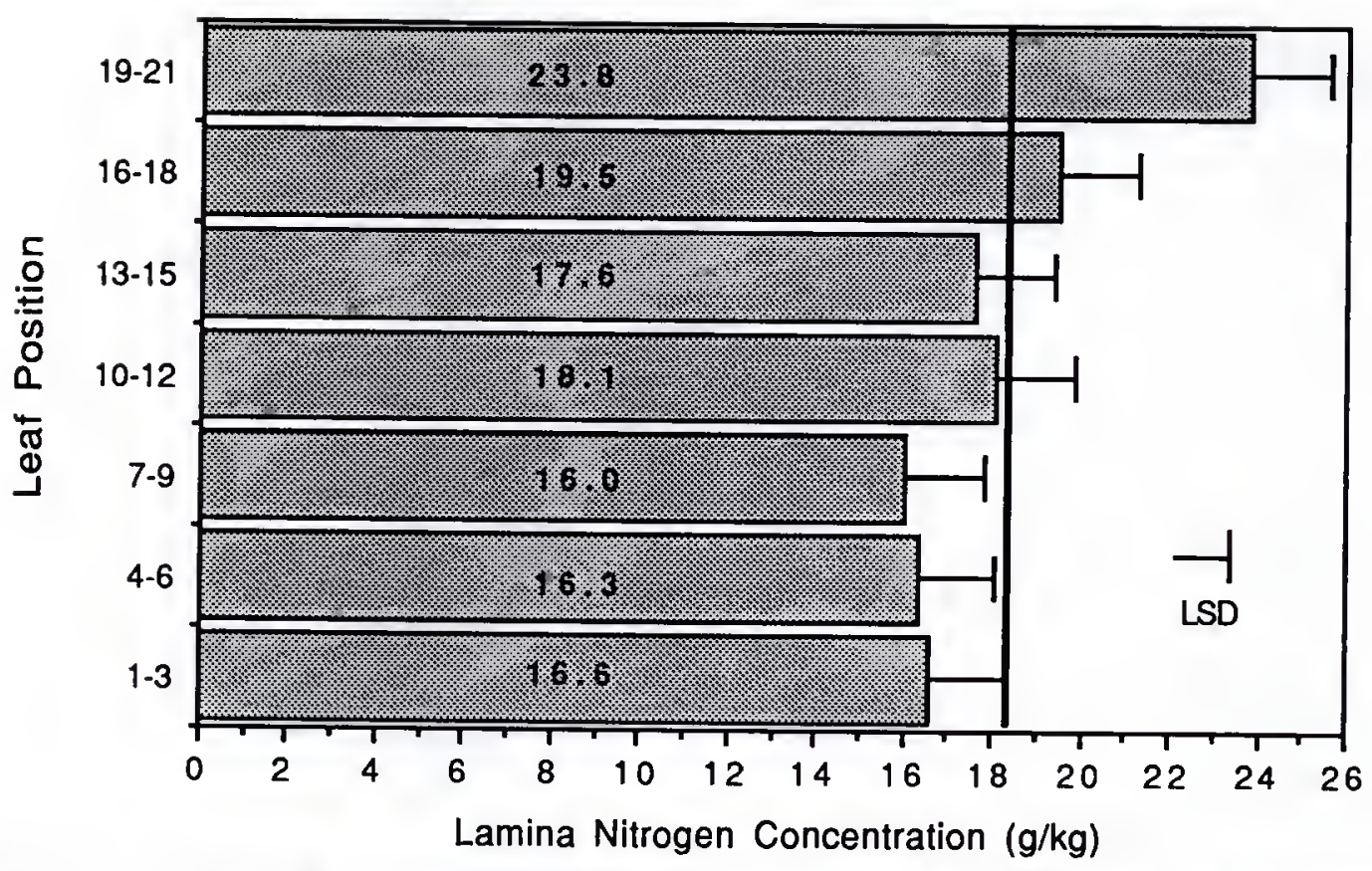

Fig. 2-14. Lamina $N$ concentration of flue-cured tobacco as influenced by leaf position (LP) $($ LSD $0.05=1.8)$. Vertical line represents mean across all LPs. Numerical values within bars are means $(n=16)$ of each LP.

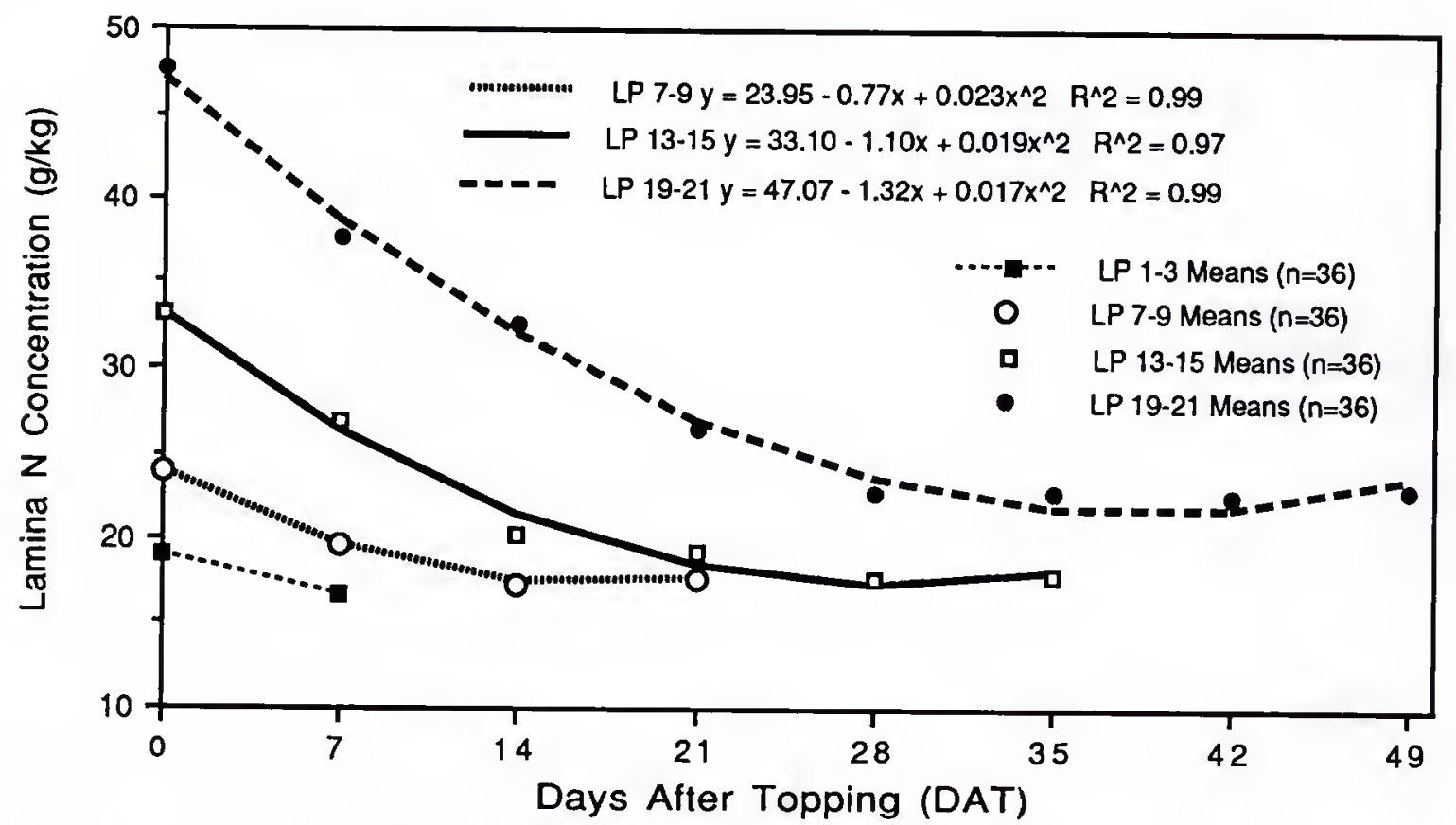

Fig. 2-15. Lamina $\mathrm{N}$ concentration of flue-cured tobacco leaf positions (LP) in response to days after topping. LSDs (0.05) for comparison of LPS at $0,7,14$, 21,28 , and 35 DAT are $3.1,2.6,1.0,1.7,1.4$, and 0.6 , respectively. 
accumulated $89.5 \%$ of the total $\mathrm{N}$ uptake 77 days after the seedlings were transplanted. This period of time approximates the topping time in the present study. The total $\mathrm{N}$ uptake was not measured in the present study. However, the rapid decline in $\mathrm{N}$ concentration at the immature LPs may indicate that most of the $N$ had been taken up by the plants at topping and was diluted as the leaves expanded and accumulated dry matter.

Nicotine concentration (Fig. 2-16) was influenced by LP. Nicotine concentration declined from the lowest LP to the middle LPS, then increased again to the upper LPS. This nicotine concentration by LP pattern was similar to that reported by Walker (1968) and $\mathrm{Nel}$ et al. (1974), however, other studies dealing with flue-cured tobacco found nicotine concentration increased with higher LPs (Brown and Terrill, 1973; Neas et al., 1978; and Darkis et al., 1936, 1952). Nicotine concentration increased with leaf maturity (Fig. 2-17). Srivastava et al. (1984) reported that nicotine accumulation of Dixie Shade Wrapper tobacco was only $18.4 \%$ of the total accumulation 70 days after seedlings were transplanted. Nicotine is synthesized in the roots (Dawson and Solt, 1959), and the topping process is believed to stimulate root growth (Steinberg and Jeffery, 1957). Nicotine concentration increase in the tobacco leaf is a most important response to topping and leaf maturity (Steinberg and Jeffery, 1957; Moseley et al., 1963; Walker, 1968; Elliot, 1975). Topping established a set leaf number per plant and assuming root growth was stimulated, nicotine concentration should increase as the leaves mature.

Total non-structural carbohydrates (TNC) are the energy reserves the plant has accumulated which can be used for new plant growth (Smith, 1981). The concentration of TNC in leaves changed over time after topping (Fig. 2-18). The rapid increases in TNC concentration at LPs $13-15$ and 19-21 were probably due to both topping and leaf maturity. The decline in the TNC concentration at the LPS as the final harvest neared was likely due to a reduction in the photosynthetic capacity of the ageing leaves in combination with some respiration of the TNC fraction due to maturity, ripening, and 


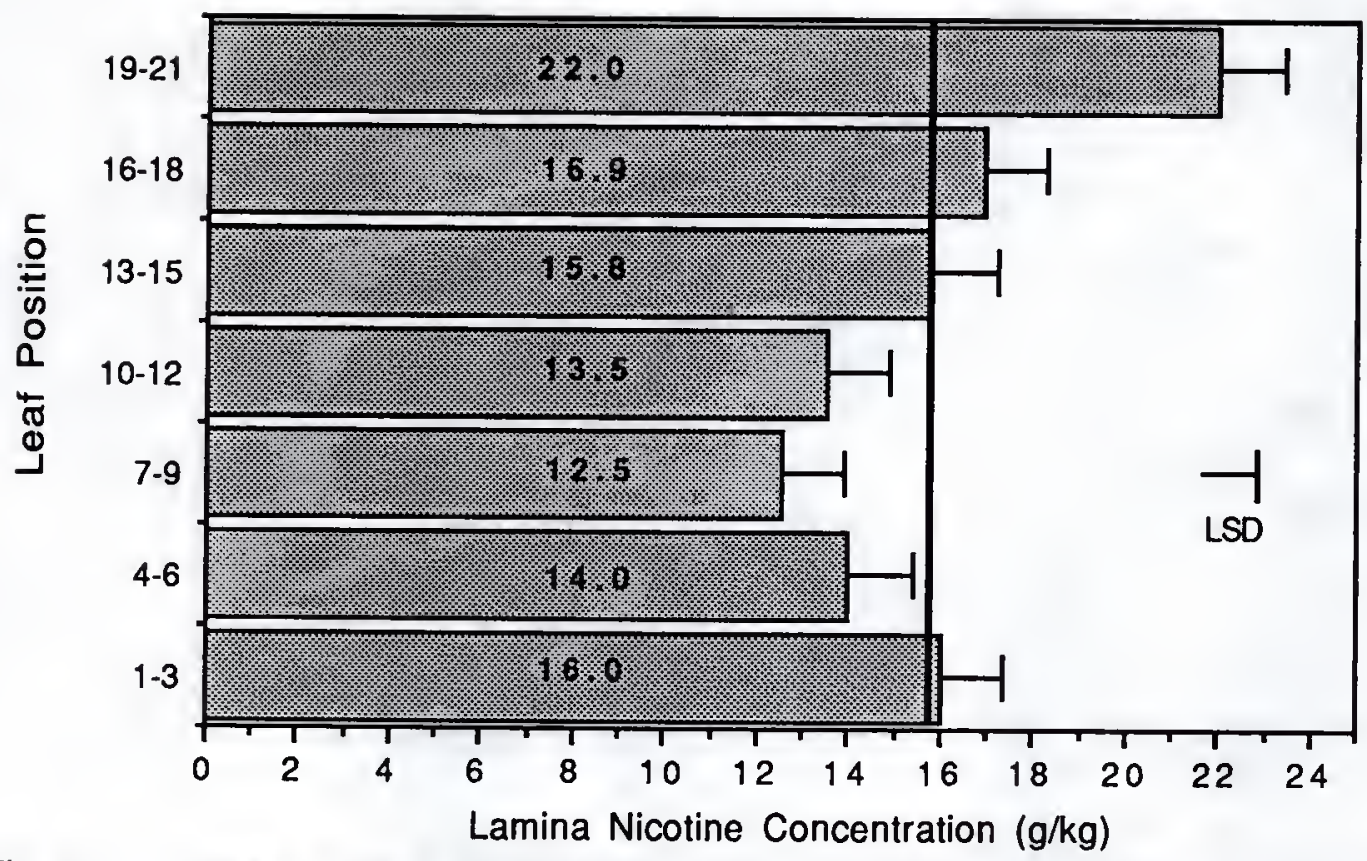

Fig. 2-16. Lamina nicotine concentration of flue-cured tobacco as influenced by leaf position (LP) (LSD $0.05=1.4)$. Vertical line represents mean across all LPs. Numerical values within bars are means $(n=16)$ of each LP.

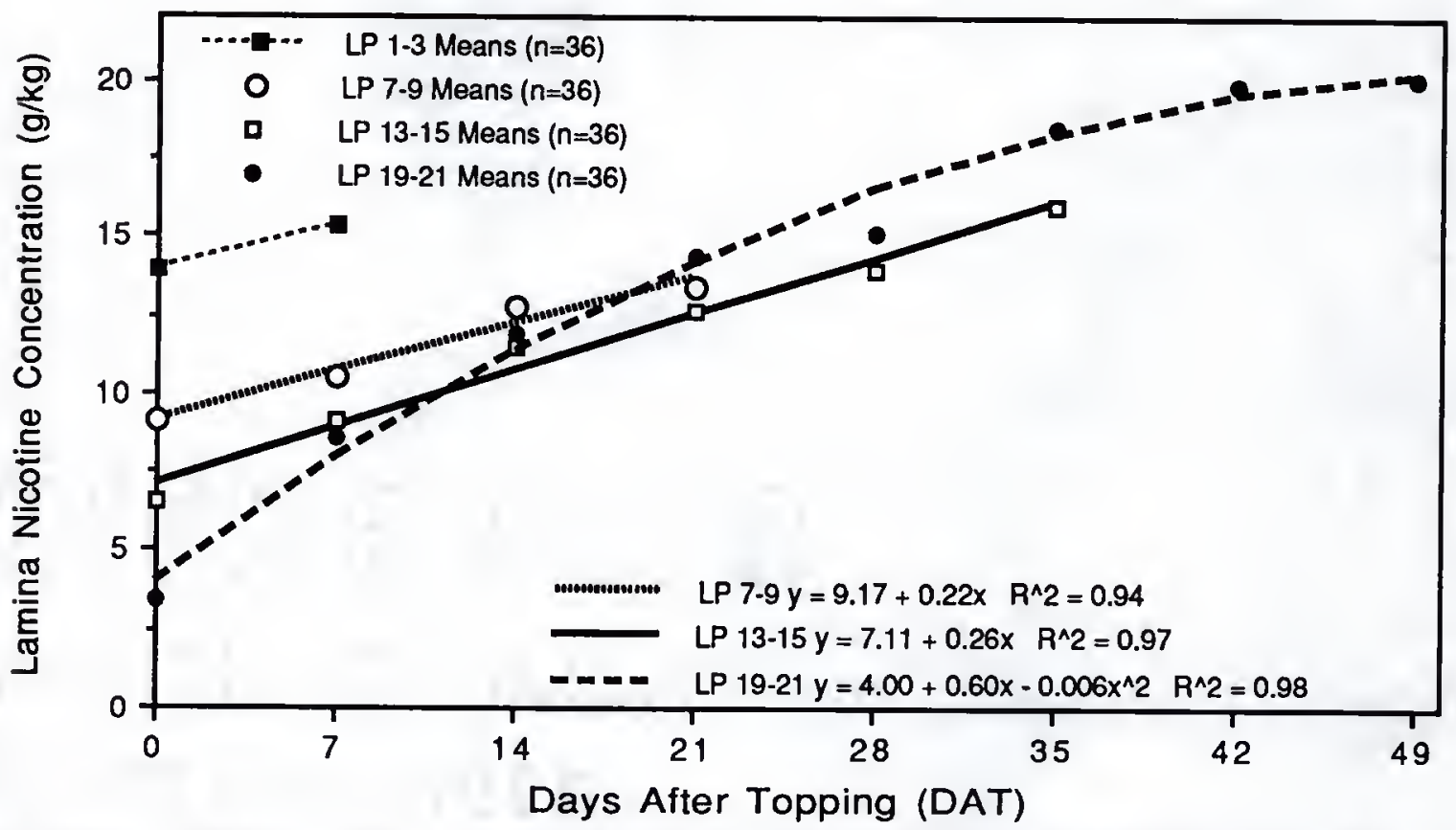

Fig. 2-17. Lamina nicotine concentration of flue-cured tobacco leaf positions (LP) in response to days after topping. LSDs $(0.05)$ for comparison of LPS at $0,7,14$, 21,28 , and 35 DAT are $0.9,0.7,0.4,0.5,0.6$, and 0.7 , respectively. 


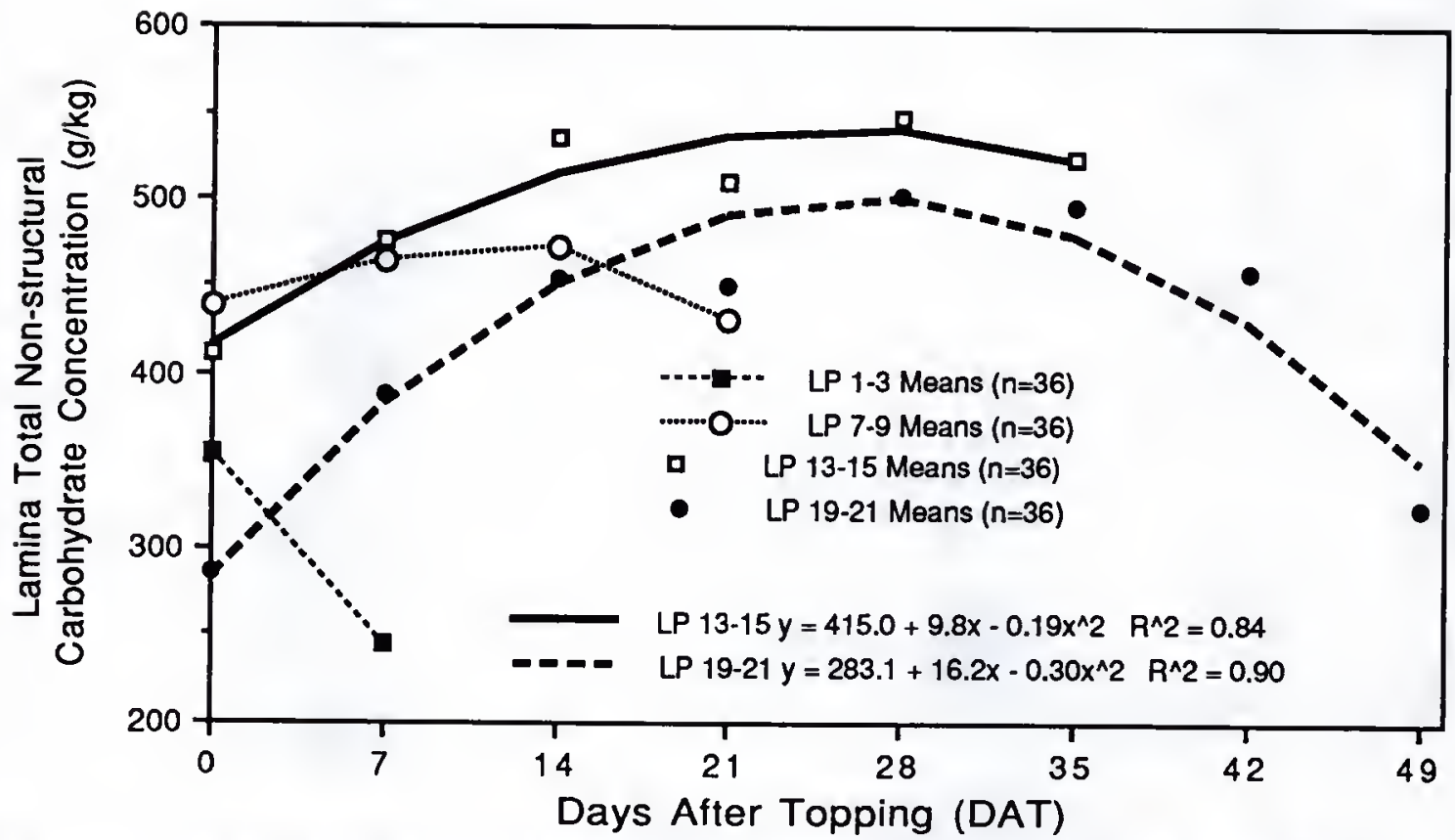

Fig. 2-18. Lamina total non-structural carbohydrate concentration of flue-cured tobacco leaf positions (LP) in response to days after topping. LSDs (0.05) for comparison of LPS at $0,7,14,21,28$, and 35 DAT are $70.3,54.4,49.8,50.3$, 37.5 , and 24.3 , respectively. 
senescence of the leaves. The leaves taken for the final harvests in the present study were judged to be mature to ripe. Kakie and Sugizaki (1970) and Kakie (1972) reported that flue-cured tobacco leaves declined in total carbohydrate concentration as the leaves progressed from maturity to over-maturity. The total carbohydrate decline was associated with a decrease in starch concentration and an increase in the soluble sugar fraction. But, there was some respiration of starch because the soluble sugar increase was not equal to the starch decrease.

Reducing sugar concentration is important to the quality of flue-cured tobacco. The reducing sugars are a product of starch (mostly TNC) metabolism induced during the curing process (Askew and Blick, 1947). Kakie (1972) reported that total carbohydrate concentration of mature green tobacco leaves ranged from $340 \mathrm{~g} \mathrm{~kg}^{-1}$ to $416 \mathrm{~g} \mathrm{~kg}^{-1}$ with a starch concentration ranging from $190 \mathrm{~g} \mathrm{~kg}^{-1}$ to $370 \mathrm{~g} \mathrm{~kg}^{-1}$. The ratio of starch to total carbohydrates was $56 \%$ to $89 \%$. The higher proportion of starch occurred when the leaves were progressing from immaturity to maturity, while the lower proportion of starch occurred as the leaves were progressing from maturity to over-maturity. Reducing sugar concentration of flue-cured tobacco leaves will vary greatly depending on the location, cultivar, and ultimately seasonal climatic conditions. However, a concentration range generally from $150 \mathrm{~g} \mathrm{~kg}^{-1}$ to $280 \mathrm{~g} \mathrm{~kg}^{-1}$ has been reported. The starch concentration of cured leaves is usually less than $30 \mathrm{~g} \mathrm{~kg}^{-1}$ (Neas et al., 1978; Nel et al., 1974) if mature leaves are harvested and cured properly. Reducing sugar concentration was highest in the leaves from the middle LPs (Fig. 2-19). The middle leaves of flue-cured tobacco are nearly always the highest in reducing sugar concentration (Brown and Terrill, 1973; Nel et al., 1974; Neas et al., 1978; Darkis et al., 1936, 1952; Walker, 1968). Over time after topping, the reducing sugar concentration (Fig. 2-20) followed a similar pattern to that of TNC concentration. This result would be expected because the TNC is metabolized to reducing sugars in the curing process. The reducing sugar concentrations at LPS 13-15 and 19- 


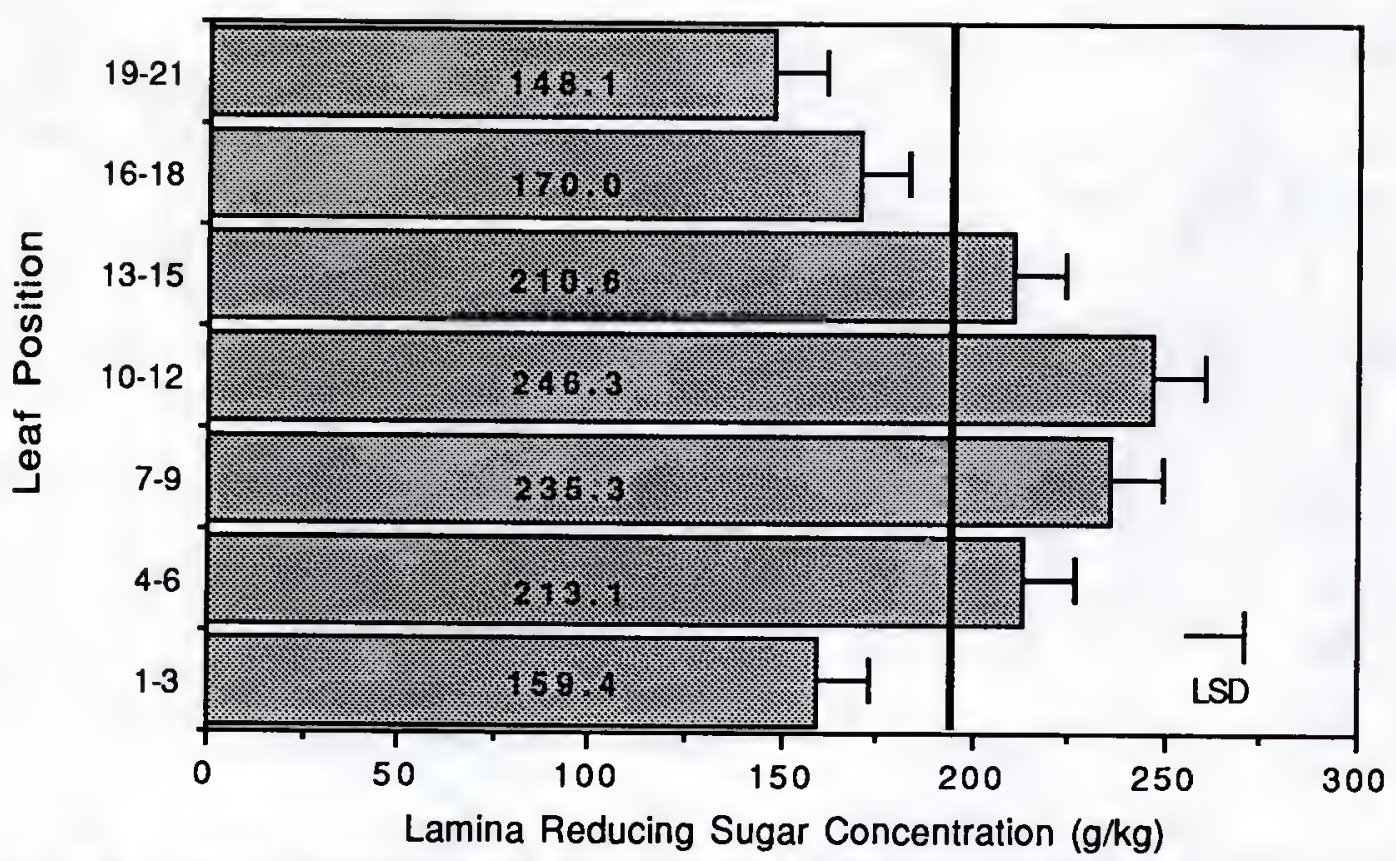

Fig. 2-19. Lamina reducing sugar concentration of flue-cured tobacco as influenced by leaf position $(L P)(L S D 0.05=13.5)$. Vertical line represents mean across all LPs. Numerical values within bars are means $(n=16)$ of each LP.

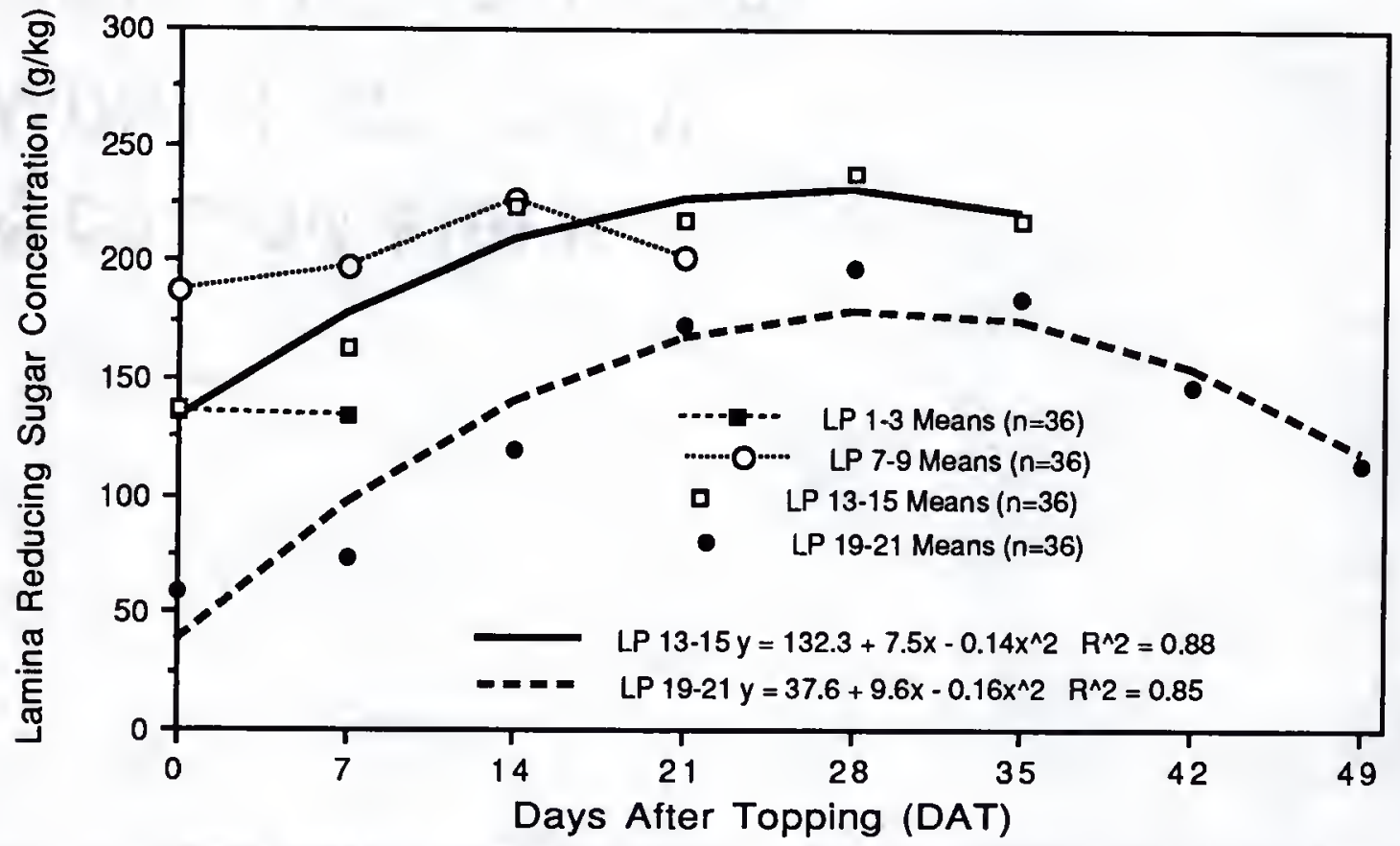

Fig. 2-20 Lamina reducing sugar concentration of flue-cured tobacco leaf positions

(LP) in response to days after topping. LSDs (0.05) for comparison of LPs at 0 , $7,14,21,28$, and 35 DAT are 33.3, 10.6, 10.4, 15.2, 11.3, and 6.0, respectively. 
21 changed proportionally with the TNC concentration of the same LPs (Fig. 2-21). A poor relationship of reducing sugar to TNC concentration was found at LPs $1-3$ and 7-9.

The $\mathrm{N}$ to nicotine (N:Nic) and reducing sugars to nicotine (Sug:Nic) concentration ratios have been used to evaluate the potential smoking quality of flue-cured tobacco (Moseley et al., 1963; Tso, 1972). The N:Nic (Fig. 2-22) was influenced by LP. The lower N:Nic ratio values at LPs 1-3, 4-6, 13-15, 16-18, and 19-21 were within the ranges found of other tobaccos for similar LPs (Brown and Terrill, 1973; Darkis et al., 1952; Walker, 1968), however, the higher N:Nic values for LPS 7-9 and 10-12 exceeded published values for similar LPs. Tso (1972) determined that an N:Nic approximating 1:1 was the most desirable. The N:Nics of the LPs evaluated over time after topping were different because of the differences in leaf age at topping (Fig. 223). Maturation of tobacco leaves results in lower concentrations of $\mathrm{N}$ and higher concentrations of nicotine (see Figs. 2-15 and 2-17). Moseley et al. (1963) reported maturation of tobacco leaves resulted in lower N:Nic. The Sug:Nic ratio (Fig. 2-24) also varied by LP. The Sug:Nic was highest at the middle LPs with lower Sug:Nic observed at the upper and lower LPs. Brown and Terrill (1973) reported increasing Sug:Nic up to the middle LPS, then a decline to the upper LPS, but their values for the middle LPs were lower than the ones reported in the present study. Florida flue-cured tobacco is typically higher in reducing sugar concentration and lower in nicotine than tobacco from other states. Over time, each LP declined in the Sug:Nic (Fig. 2-25) indicating that nicotine concentration was increasing proportionally higher than the reducing sugar concentration. Moseley et al. (1963) found a reduction of the Sug:Nic was characteristic of maturing tobacco leaves. 


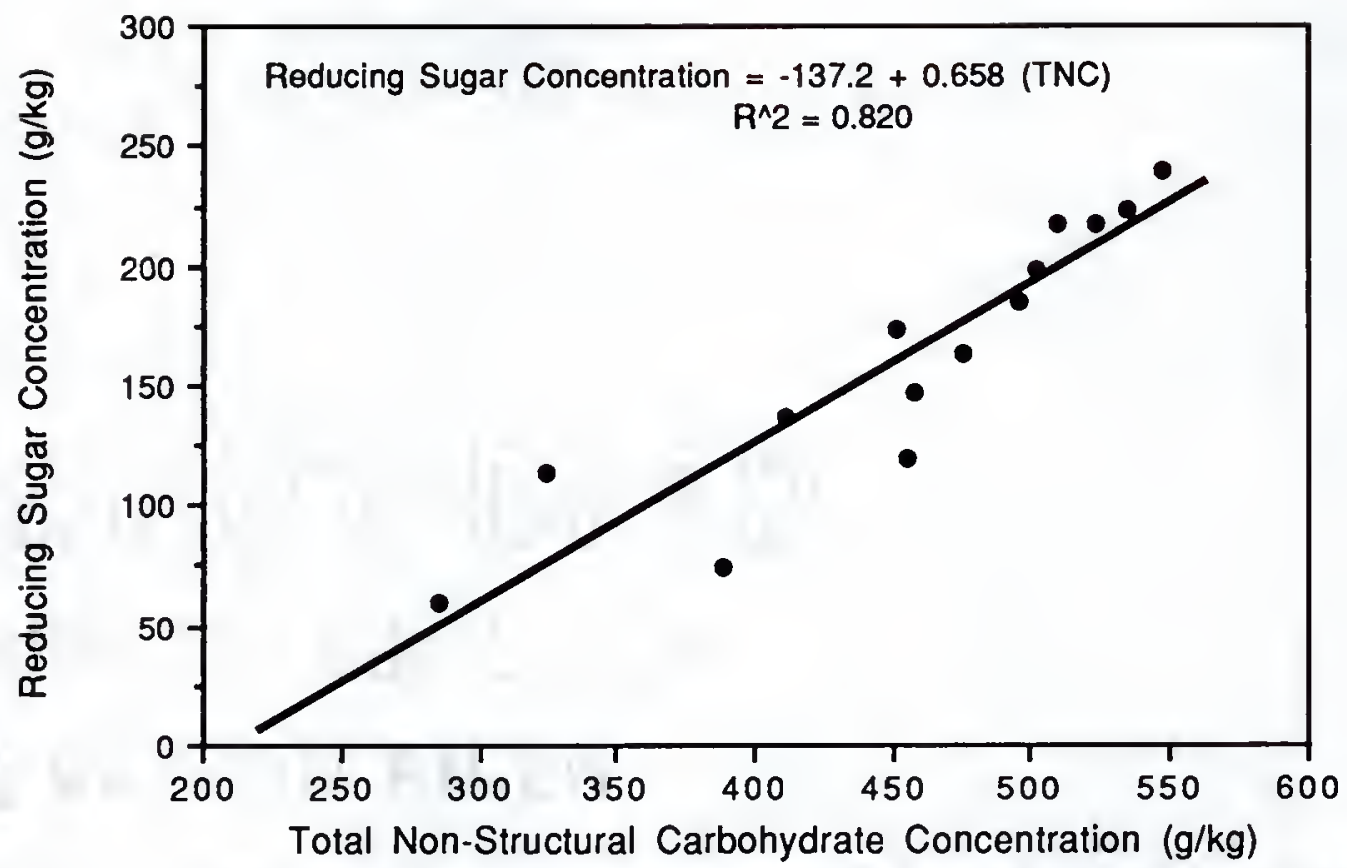

Fig. 2-21. Relationship ( $p=0.001$ ) between the total non-structural carbohydrate (TNC) concentration of rapidly dried leaf lamina and the reducing sugar concentration of cured leaf lamina from flue-cured tobacco leaf positions 13-15 and 19-21. 


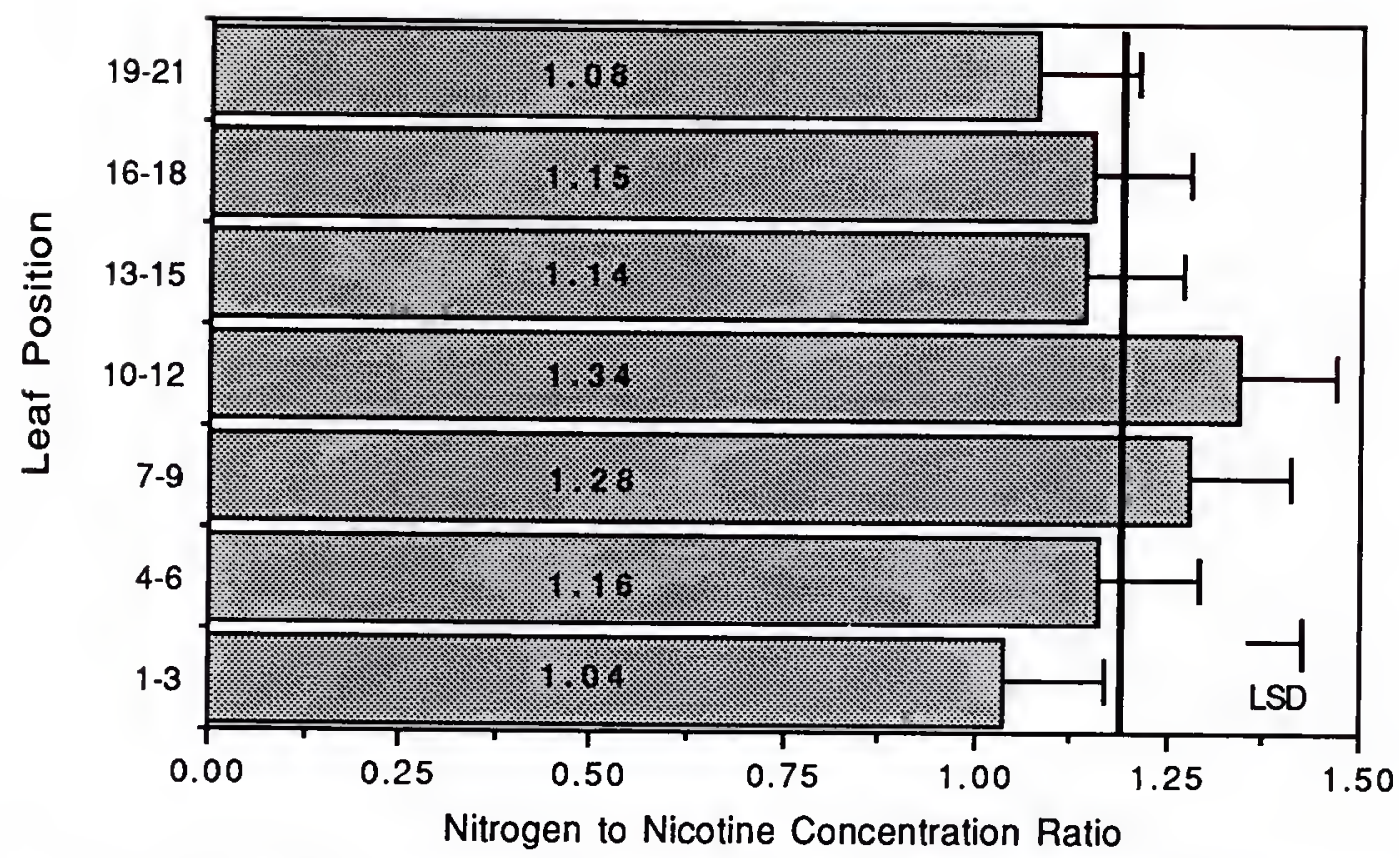

Fig. 2-22. Lamina $\mathrm{N}$ to nicotine concentration ratio of flue-cured tobacco as influenced by leaf position (LP) (LSD $0.05=0.13$ ). Vertical line represents mean across all LPs. Numerical values within bars are means $(n=16)$ of each LP.

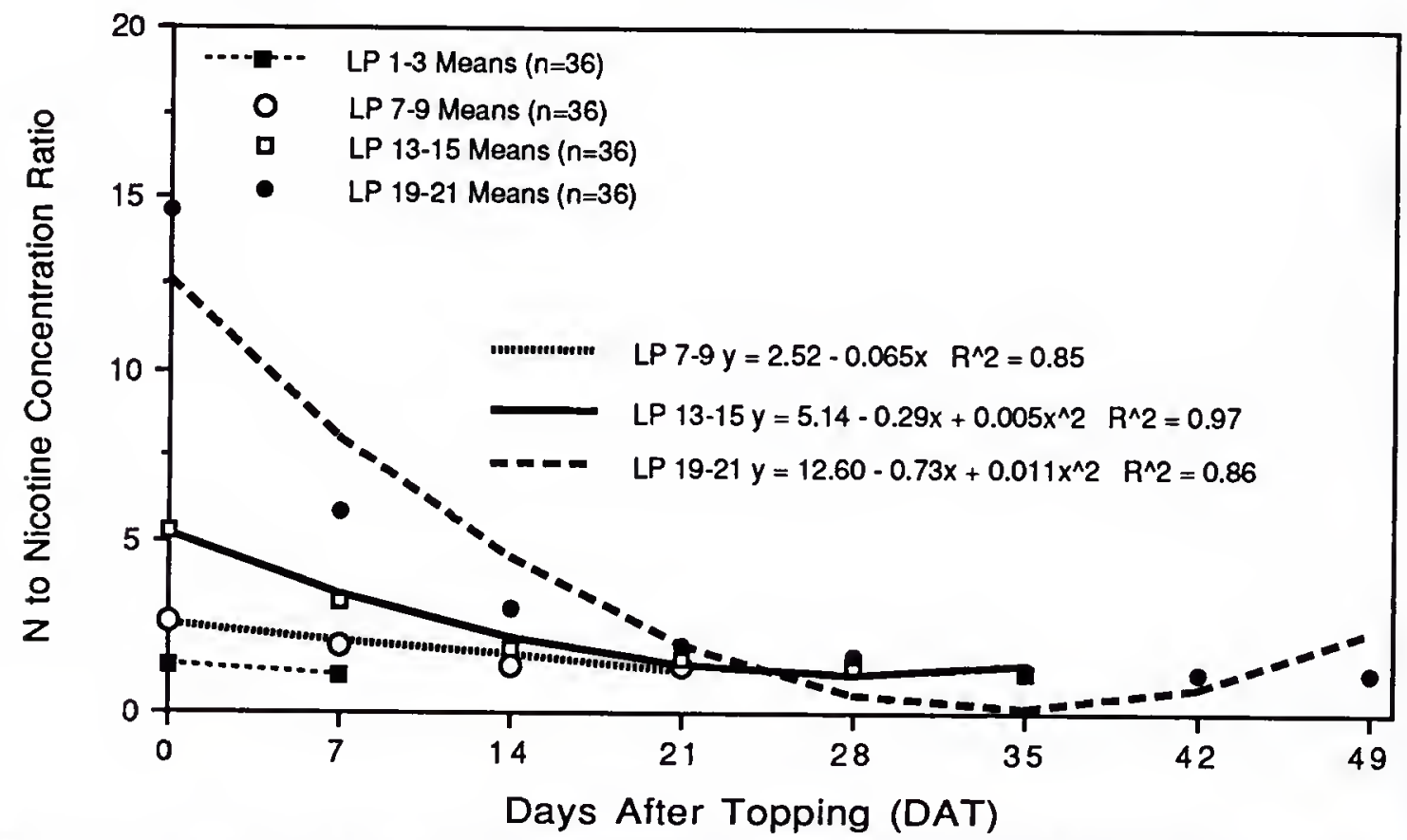

Fig. 2-23. Lamina $\mathrm{N}$ to nicotine concentration ratio of flue-cured tobacco leaf positions (LP) in response to days after topping. LSDs $(0.05)$ for comparison of LPs at 0 , $7,14,21,28$, and 35 DAT are $2.35,1.18,0.18,0.12,0.08$, and 0.07 , respectively. 


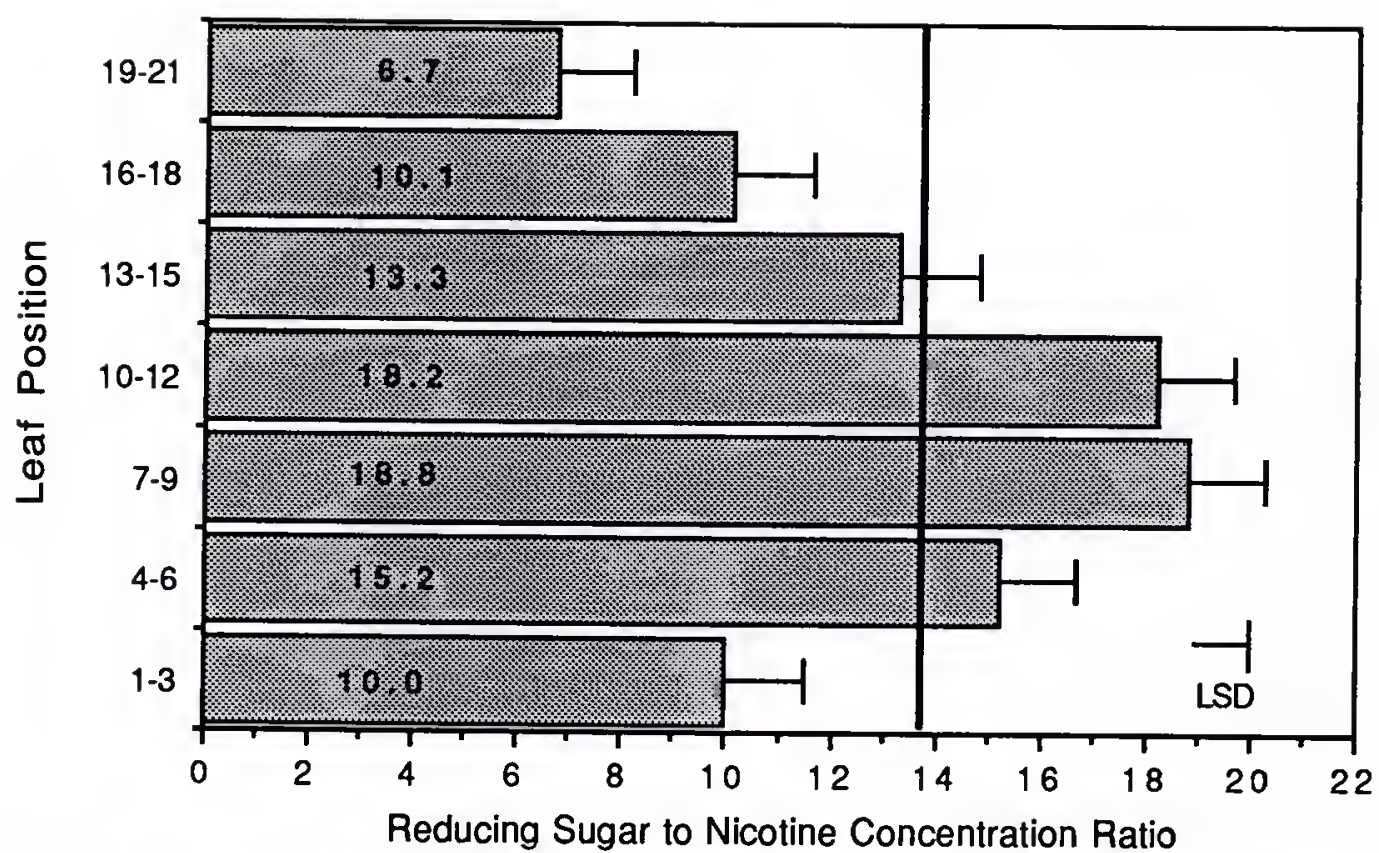

Fig. 2-24. Lamina reducing sugar to nicotine concentration ratio of flue-cured tobacco as influenced by leaf position (LP) (LSD $0.05=1.5$ ). Vertical line represents mean across all LPs. Numerical values within bars are means $(n=16)$ of each LP.

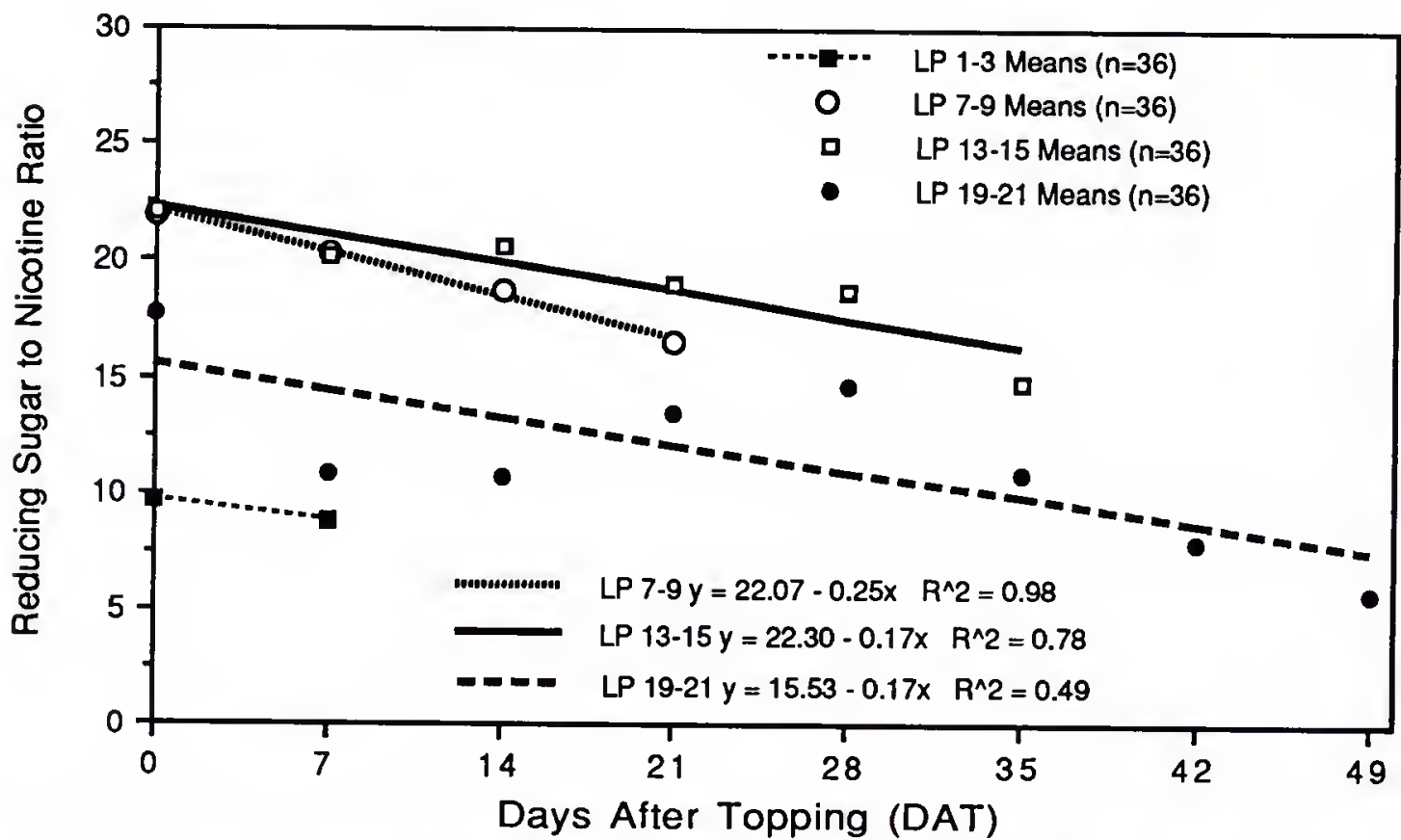

Fig. 2-25. Lamina reducing sugar to nicotine concentration ratio of flue-cured tobacco leaf positions (LP) in response to days after topping. LSDs (0.05) for comparison of LPS at $0,7,14,21,28$, and 35 DAT are 3.6, 1.7, 1.4, 1.5, 1.3, and 1.3 , respectively. 


\section{Leaf Mineral Characteristics}

Lamina Ca concentration (Fig. 2-26) was highest in the lowest LPS. This result was expected because $\mathrm{Ca}$ is considered to be non-mobile in plants (Tisdale and Nelson, 1975). Calcium concentrations have been found to be highest in the lower leaves of tobacco in previous studies as well (Darkis et al., 1936, 1952; Askew et al., 1947; Walker, 1968; Neas et al.,1978). Calcium concentrations changed little over time after topping for all LPS (Fig. 2-27). Raper and McCants (1966) found that flue-cured tobacco plants had accumulated $81.8 \%$ of the total Ca uptake 77 days after seedling transplantation. One possible interpretation of these data is that Ca uptake continued at a fairly constant rate after topping because for the leaves within the given LPs to maintain the Ca concentration in response to $\mathrm{CW}$ increases a considerable amount of $\mathrm{Ca}$ must be taken up by the roots and translocated to the leaves. Raper and McCants (1966) based their total uptake percentages on the composition of plants harvested 91 days after seedlings were transplanted. Data collection for the present study continued until 130 days after the seedlings had been transplanted.

Lamina Mg concentration by LP (Fig. 2-28) followed an almost identical pattern as that of $\mathrm{Ca}$. A similar distribution of $\mathrm{Mg}$ concentration in leaves has been reported by Askew et al. (1947), Darkis et al. (1952), and Walker (1968). The Mg concentration by LP over time after topping was constant (Fig. 2-29), much like that observed for Ca. Raper and McCants (1966) reported that 77 days after the seedlings were transplanted tobacco plants had accumulated $90.0 \%$ of the total $\mathrm{Mg}$ that was accumulated after 91 days in the field. Because $\mathrm{Mg}$ and $\mathrm{Ca}$ concentration patterns, not the actual concentrations, were similar over time, the same argument previously made about $\mathrm{Ca}$ concentration over time should be valid for $\mathrm{Mg}$. It also could be argued, based on the observations in the present study, that had Raper and McCants (1966) continued to take samples after 91 days after transplanting the total uptake of $\mathrm{Mg}$ and $\mathrm{Ca}$ may have been different. This suggestion is supported by observations by Srivastava et al. (1984) who found that 


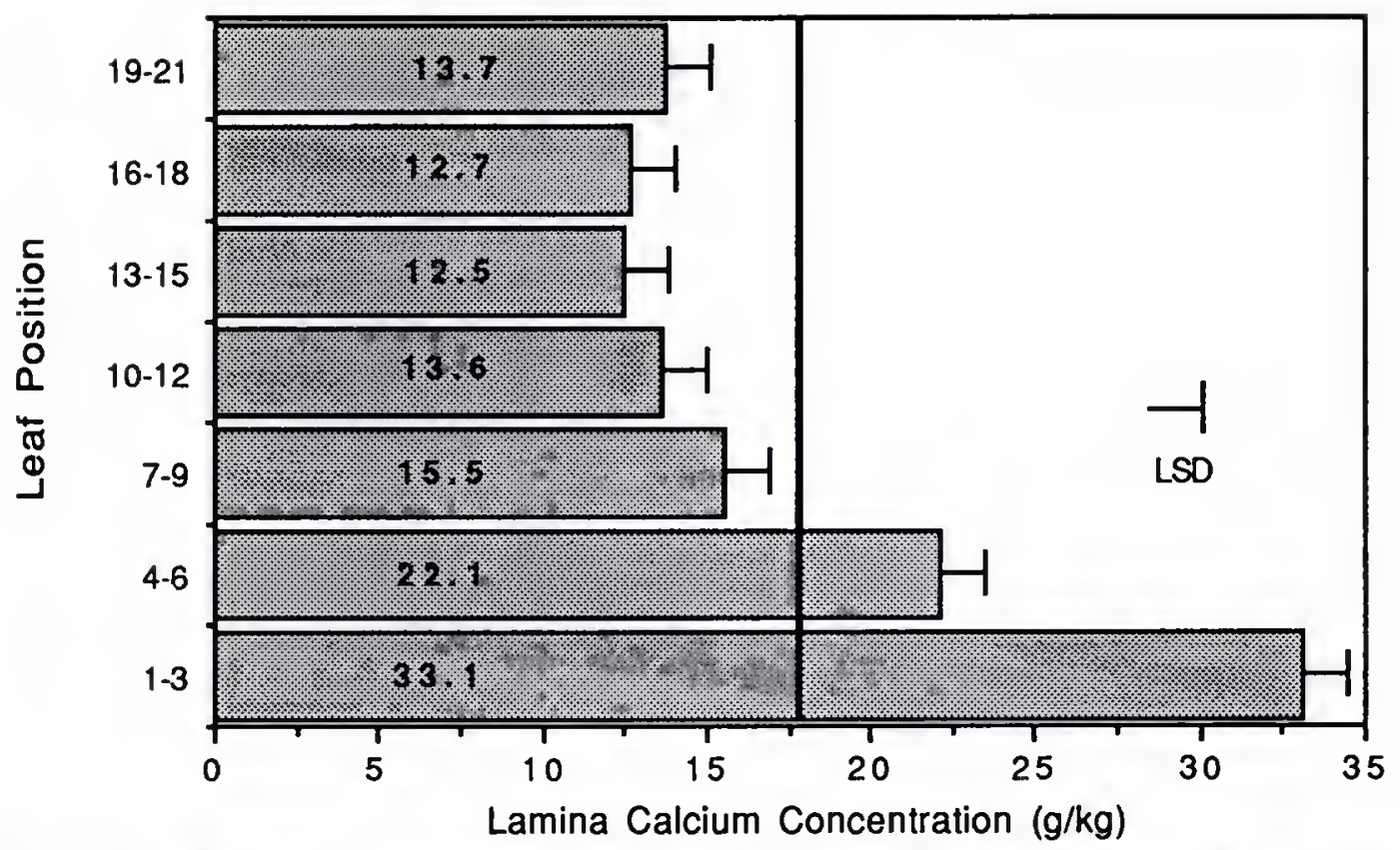

Fig. 2-26. Lamina $\mathrm{Ca}$ concentration of flue-cured tobacco as influenced by leaf position (LP) (LSD $0.05=1.4)$. Vertical line represents mean across all LPs.

Numerical values within bars are means $(n=16)$ of each LP.

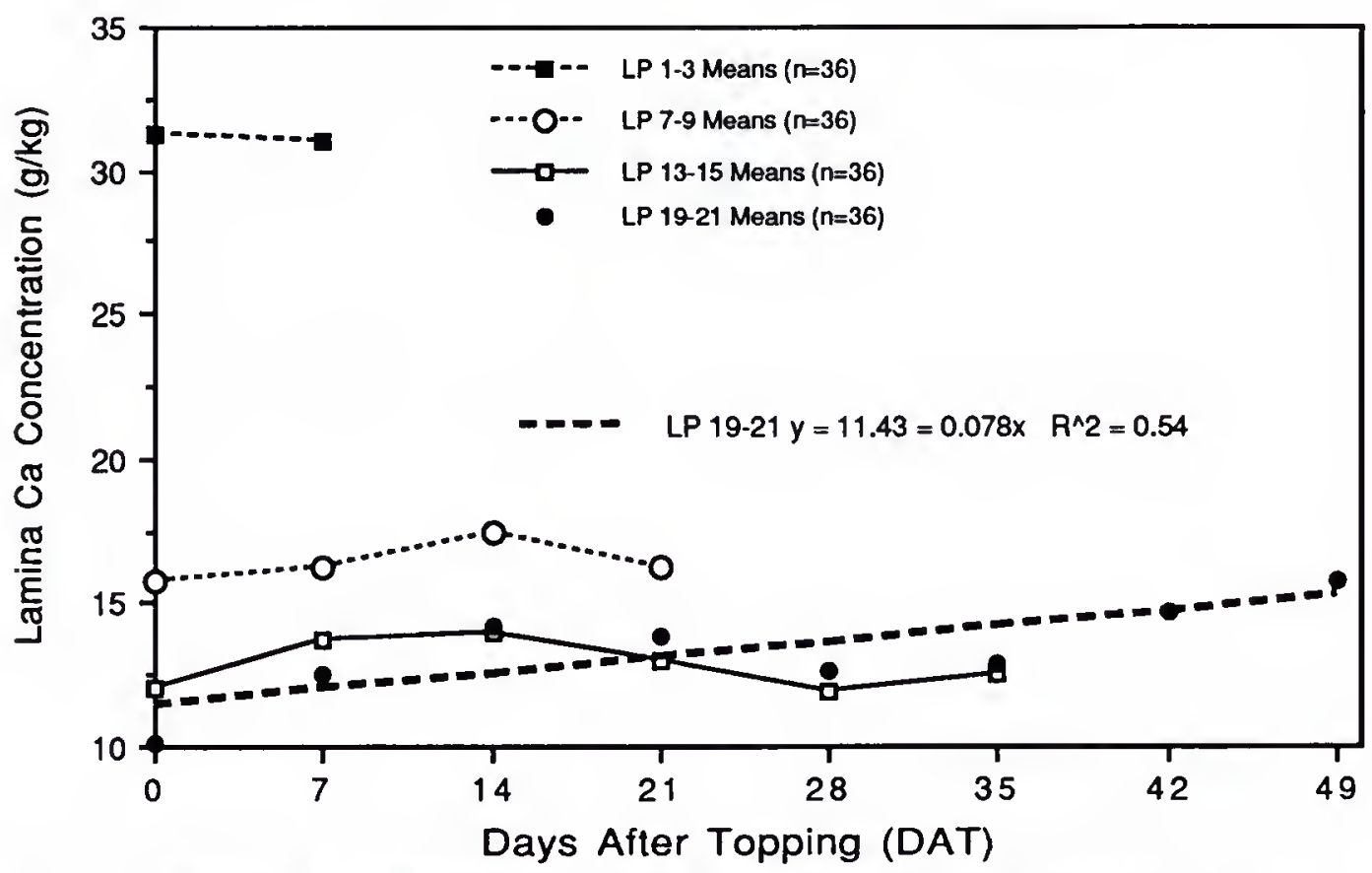

Fig. 2-27. Lamina Ca concentration of flue-cured tobacco leaf positions (LP) in response to days after topping. LSDs $(0.05)$ for comparison of LPS at $0,7,14$, 21,28 , and 35 DAT are $2.5,0.6,0.8,0.8,0.5$, and 0.7 , respectively. 


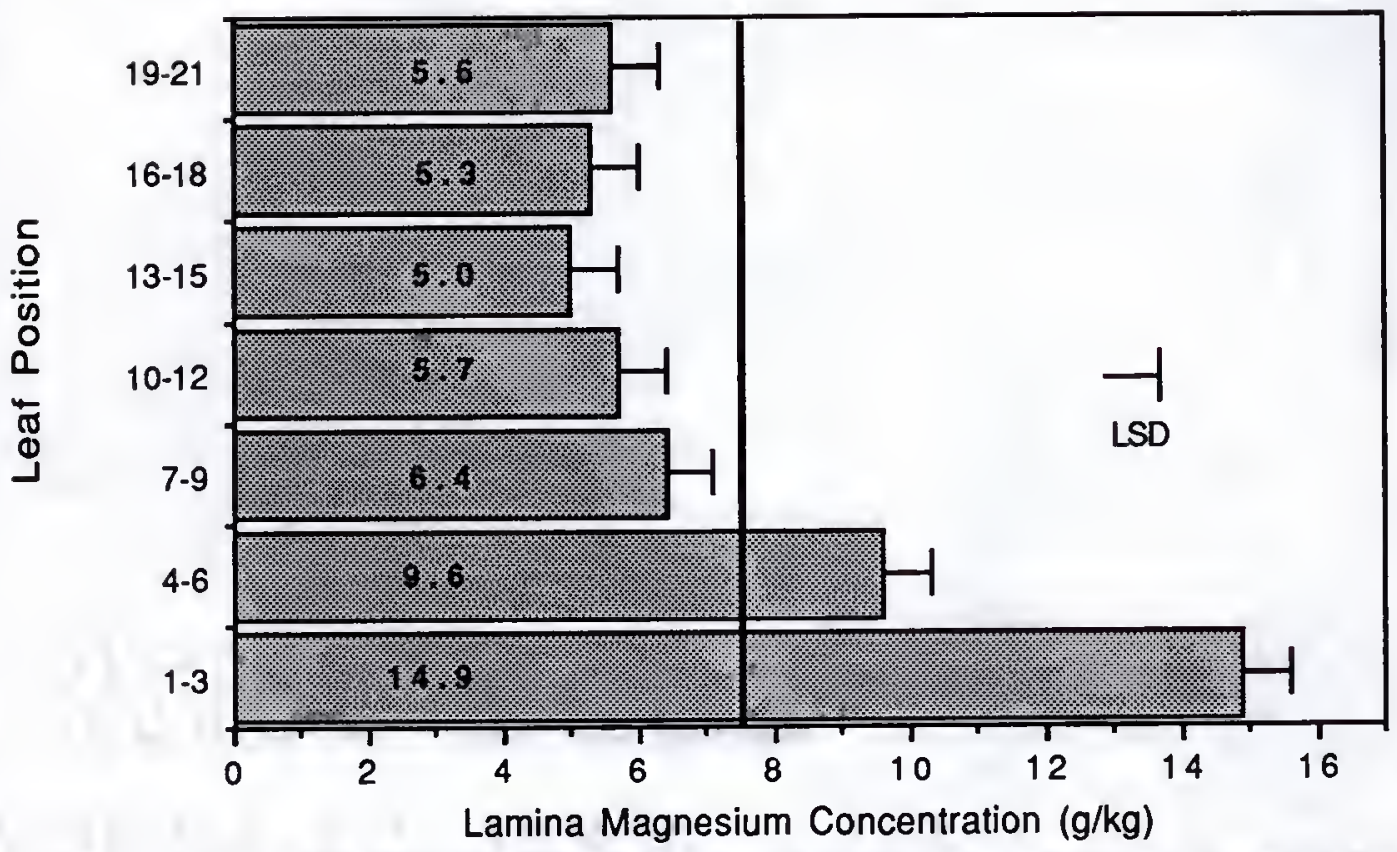

Fig. 2-28. Lamina $\mathrm{Mg}$ concentration of flue-cured tobacco as influenced by leaf position (LP) (LSD $0.05=0.7)$. Vertical line represents mean across all LPs. Numerical values within bars are means $(n=16)$ of each LP.

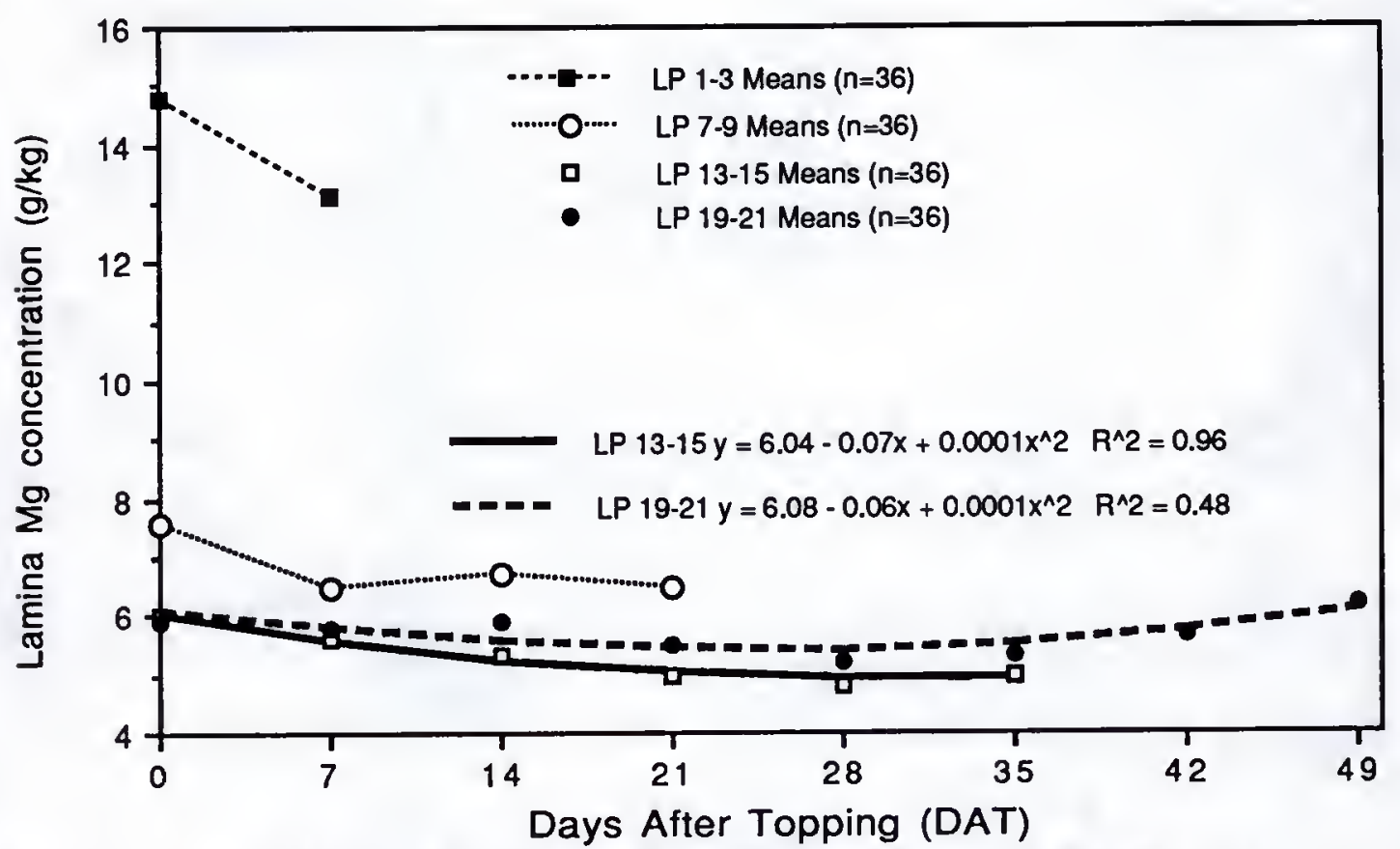

Fig. 2-29. Lamina $\mathrm{Mg}$ concentration of flue-cured tobacco leaf positions (LP) in response to days after topping. LSDs (0.05) for comparison of LPs at $0,7,14$, 21,28 , and 35 DAT are $1.3,0.3,0.3,0.4,0.2$, and 0.2 , respectively. 
Dixie Shade Wrapper tobacco had taken up only $54.2 \%$ and $42.7 \%$ of the total $\mathrm{Ca}$ and $\mathrm{Mg}$, respectively, 80 days after seedling transplantation. They compared the percentage uptake to final harvest values taken 120 days after transplanting.

Lamina $\mathrm{K}$ concentration (Fig. 2-30) was highest at the lower LPs and lowest at the upper LPs. Potassium is generally considered to be a mobile element in plants (Tisdale and Nelson, 1975). However, the fact that lower $\mathrm{K}$ concentrations in upper leaves than lower leaves have been reported by Darkis et al. (1936, 1952), Askew et al. (1947), Walker (1968), and Neas et al. (1978) may indicate that $K$ is not as mobile in the tobacco plant as in other plants. The change in $\mathrm{K}$ concentration over time was influenced by the age of the leaves within an LP (Fig. 2-31). Raper and McCants (1966) reported that flue-cured tobacco plants had accumulated $97.4 \%$ of all $\mathrm{K} 77$ days after transplanting. Srivastava et al. (1984) found Dixie Shade Wrapper tobacco had taken up only $55.4 \%$ of all $\mathrm{K} 80$ days after transplanting. Atkinson et al. (1977) found Burley tobacco plants had accumulated $95.1 \%$ of all $K 73$ days after seedling transplantation. The tobacco plants in the present study may have accumulated most of the $K$ at topping because the $K$ concentrations at the least mature LPs declined after topping, while $\mathrm{K}$ concentrations at the more mature LPs remained about the same.

Lamina P concentration (Fig. 2-32) differed little at LPs. Differences existed between some LPS, but unlike other leaf mineral components previously discussed, these $P$ concentration data differed from other published reports. Askew et al. (1947), Darkis et al. (1952), and Nel et al. (1974) found P concentrations to be higher at higher LPs. Of all the leaf parameters evaluated over time, the most dynamic relationship existed for $P$ concentration by LP (Fig. 2-33). These differences between LPs existed due to the inherent differences in leaf age at topping. The least mature LP at topping, 19-21, had the highest $P$ concentration and most likely had the highest metabolic activity. The most interesting aspect of the $P$ concentration changes over time was that the P concentrations at LPs 7-9, 13-15, and 19-21 increased over the 21 


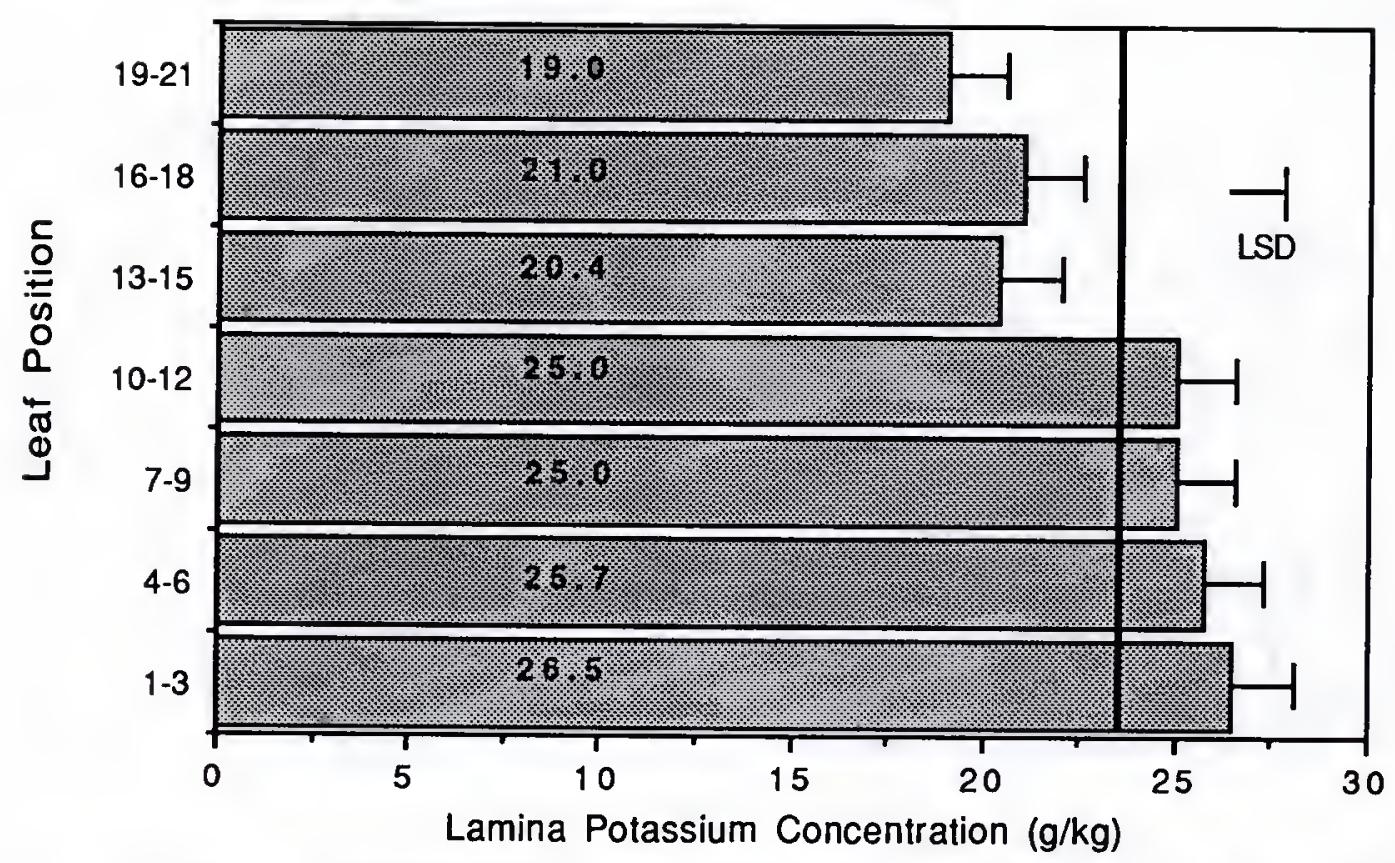

Fig. 2-30. Lamina $K$ concentration of flue-cured tobacco as influenced by leaf position (LP) (LSD $0.05=1.6$ ). Vertical line represents mean across all LPs. Numerical values within bars are means $(n=16)$ of each LP.

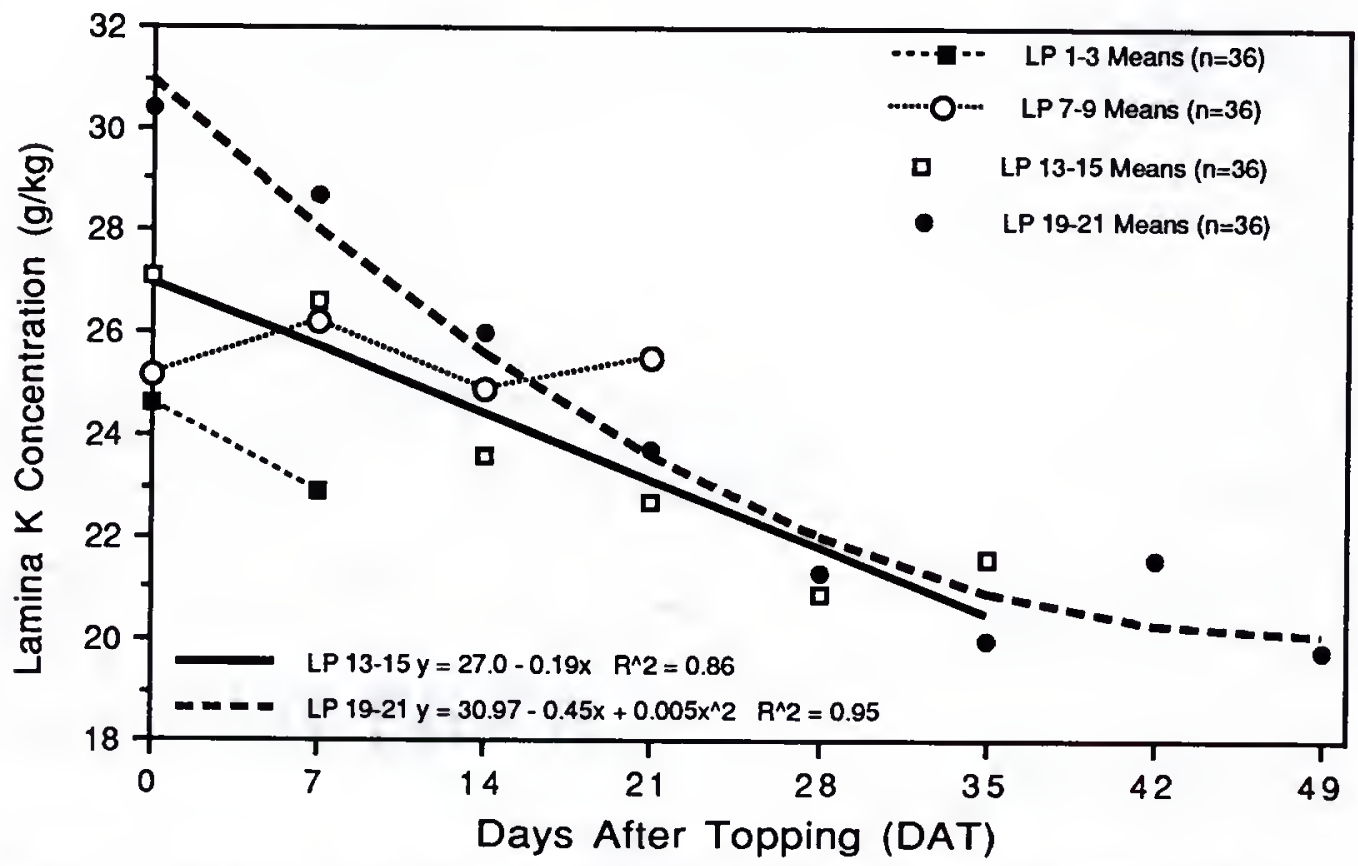

Fig. 2-31. Lamina $\mathrm{K}$ concentration of flue-cured tobacco leaf positions (LP) in response to days after topping. LSDs (0.05) for comparison of LPs at $0,7,14$, 21,28 , and 35 DAT are $3.1,1.5,1.5,1.5,0.8$, and 1.3 , respectively. 


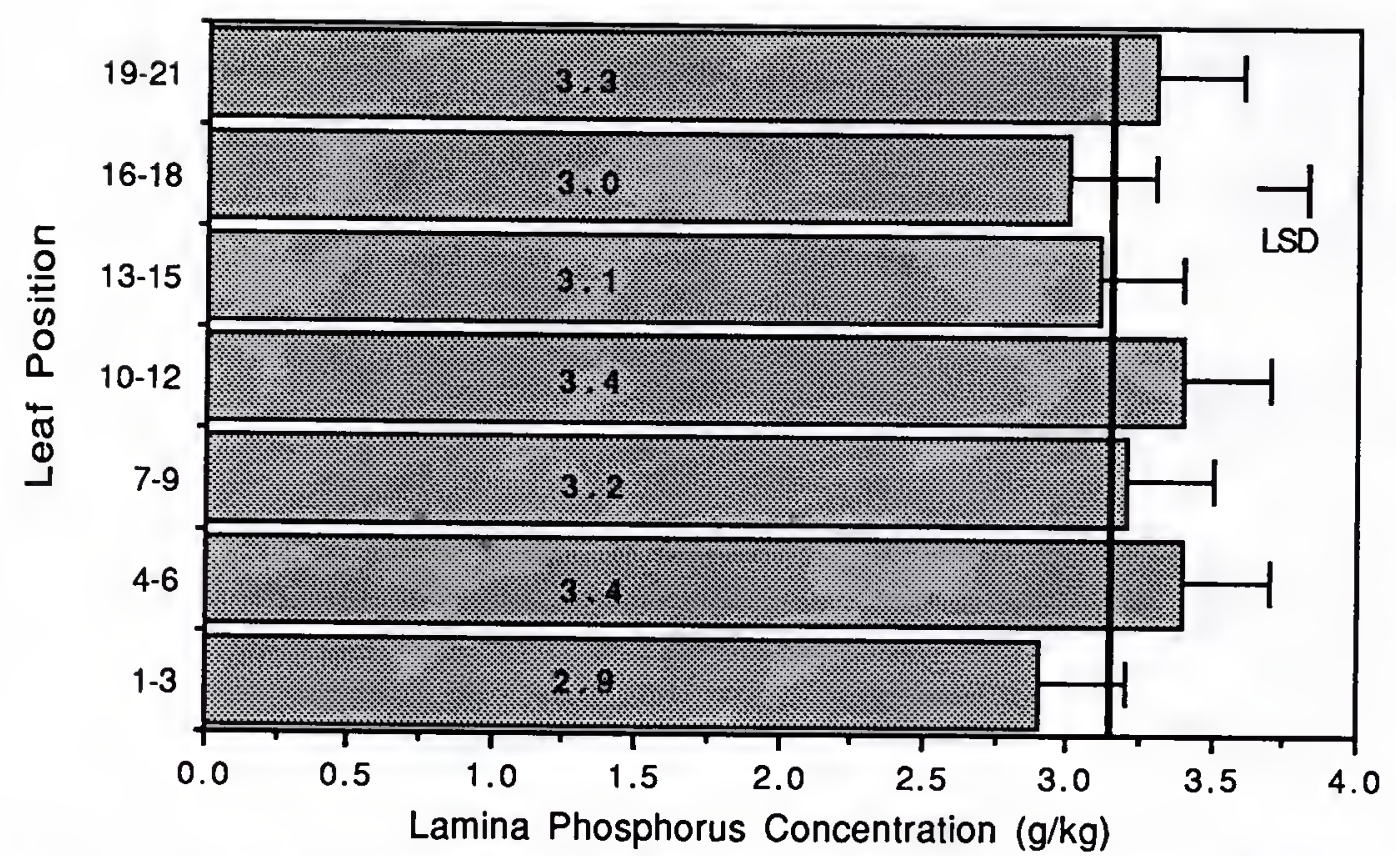

Fig. 2-32. Lamina $P$ concentration of flue-cured tobacco as influenced by leaf position (LP) $($ LSD $0.05=0.3)$. Vertical line represents mean across all LPs. Numerical values within bars are means $(n=16)$ of each LP.

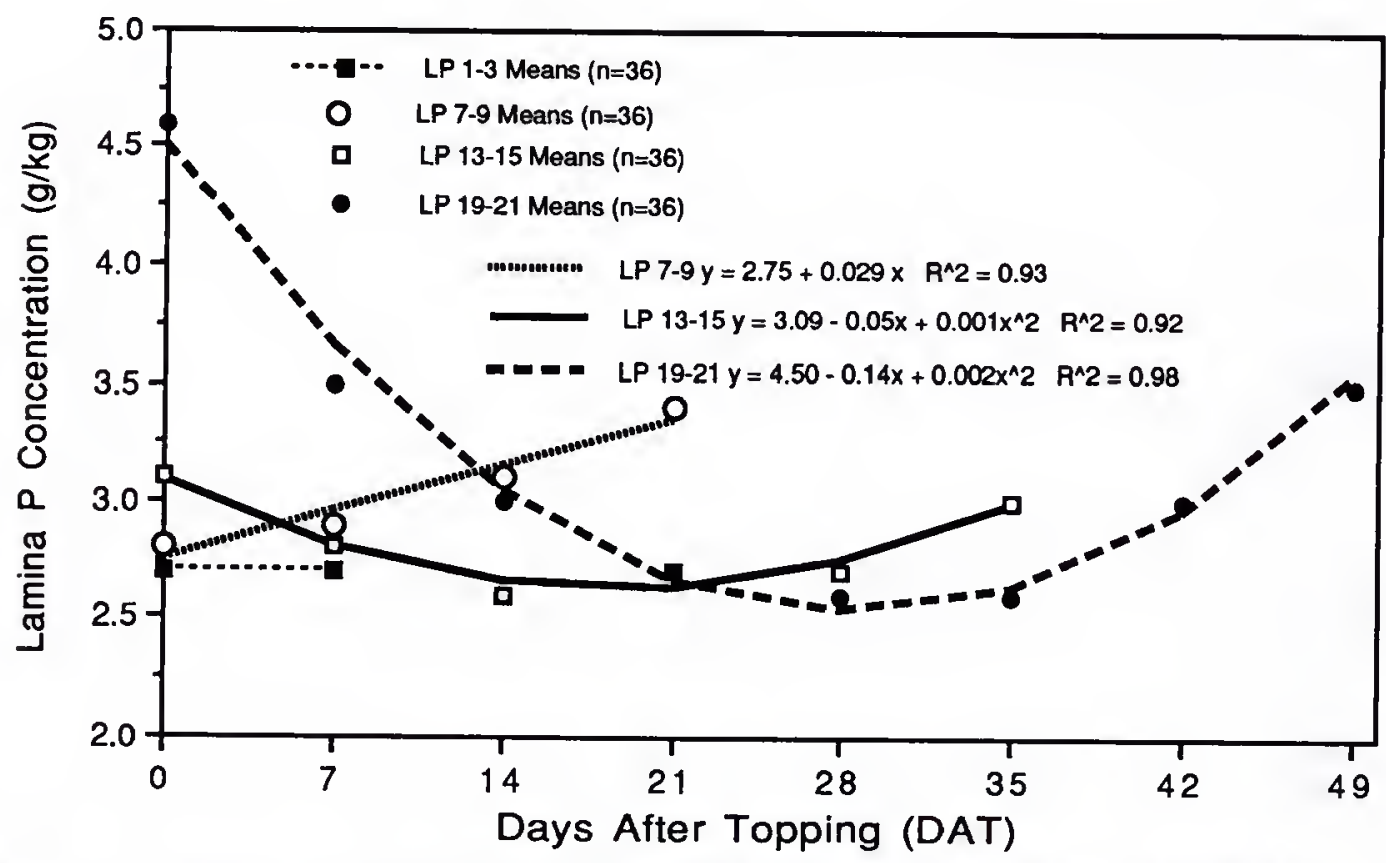

Fig. 2-33. Lamina $P$ concentration of flue-cured tobacco leaf positions (LP) in response to days after topping. LSDs (0.05) for comparison of LPs at $0,7,14$, 21,28 , and 35 DAT are $0.4,0.2,0.2,0.2,0.2$, and 0.2 , respectively. 
days prior to final harvest. Because the leaves comprising LP 19-21 were the most recently formed and were on the plant for the longest period of time, the most information was accumulated for this LP. However, when viewing the concentration curves for LPs 7-9 and 13-15, it may be suggested that had these LPs been sampled over the same stages of development as was LP 19-21, their respective relationships would look similar. This theory may be supported by the lowest $\mathrm{P}$ concentration points, which were about $2.6 \mathrm{~g} \mathrm{~kg}^{-1}$, on the respective curves that were similar at all three LPS. The final P concentrations also were nearly equal for each LP which agreed with the data reported for the individual LPs in Fig. 2-32.

\section{Cenclusions}

Flue-cured tobacco is harvested by LP as the leaves mature. Differences existed for agronomic, chemical, and mineral characteristics based on the position or node on the tobacco stalk at which leaves were formed. The highest yield and value were found at the highest LPs. At topping, differences in the agronomic, chemical, and mineral characteristics at LPs were a result of leaf age and previous development. The yield and chemical and mineral concentrations of the lowest nine leaves did not change over time after topping indicating that those leaves were essentially mature at topping. However, the yield, chemical, and mineral characteristics of the upper 12 leaves (or 4 LPS) did change over time, with the largest changes evident in the uppermost leaves. The observation that characteristics of flue-cured tobacco leaves are different based on the position or node at which the leaves are formed would support continuation of the current practices by which leaves are harvested and marketed based on LP. 


\section{CHAPTER 3 \\ LOWER LEAF HARVESTING EFFECTS ON AGRONOMIC \\ CHARACTERISTICS OF FLUE-CURED TOBACCO}

\section{Introduction}

Federal programs dictate how much flue-cured tobacco (Nicotiana tabacum L.)

can be marketed. A combination of area allotments and weight quotas is assigned to each farm. New tobacco cultivars and improved cultural practices enable many tobacco growers to exceed their weight quotas on less than the area allotted to produce the tobacco. Consequently, some farmers choose not to plant their entire area allotment, since they cannot sell the tobacco produced in excess of the weight quota. This management decision is sound under good growing conditions, where yields can be predicted with reasonable accuracy.

Lower leaf harvesting options are available that may allow farmers opportunities to increase their net income from tobacco. If the upper leaves are substantially more valuable in price than the lower leaves, the farmer may wish to produce his weight quota with the upper leaves. Consequently, the lower leaves could be discarded.

Lower leaf pruning of flue-cured tobacco became an issue in the mid 1970's when an over-supply of lower stalk tobacco pushed prices downward causing receipts of this type tobacco to be increased by the farmer-owned Flue-Cured Tobacco Cooperative Stabilization Corporation (FCTCS) (Wernsman and Matzinger, 1980). The FCTCS purchases tobacco that does not receive bids of more than one cent above the designated United States Department of Agriculture price support. Because of the large receipts of this lower leaf tobacco, the federal tobacco program was amended in 1978 to allow 
farmers to plant $10 \%$ more acreage if they would prune or not harvest the lowest four leaves of their tobacco crop. This program was known as the "four leaf program."

Studies dealing with lower leaf harvesting options have resulted in mixed conclusions with respect to effects on yield. Currin and Pitner (1980) reported that pruning and discarding the lowest four leaves did not lower yields or affect the leaf chemical component balance of the remaining leaves, when compared to harvesting all the leaves. Leaving the lowest four leaves on the stalk and not harvesting them, reduced yield compared to the treatments involving either pruning and discarding the lowest four leaves or harvesting all leaves. Stocks (1988) found that pruning and discarding the lowest three or four leaves resulted in equal yields and an increase in the price per kilogram when compared to harvesting all leaves. But, not removing and not harvesting the same lower leaves reduced yields. Currin and Stanton (1989) and Stocks (1988) reported that pruning more than four leaves had a negative impact on yield and value of flue-cured tobacco.

Court and Hendel (1989) evaluated leaf number management by several topping height and lower leaf pruning regimes. Eighteen leaves per plant was the control. Reduction in leaf number harvested from 18 to 15 to 12 resulted in a reduction in yield and value of the crop for each reduction in leaf number. Pruning the lower leaves or topping down to the desired leaf number produced similar reductions in yield and value. Suggs (1972) evaluated a wide array of leaf pruning treatments and concluded that yield and value decreased with an increase in the number of leaves pruned. However, the lowest three leaves could be pruned with little decrease in yield. Crop value declined as the number of lower leaves pruned exceeded three. Wernsman and Matzinger (1980) found that yield reductions due to lower leaf pruning of mammoth cultivars could be compensated for by topping to a higher leaf number.

In the above-mentioned studies, there are discrepancies regarding the effects of lower leaf pruning. Results from studies conducted in the Southeastern U.S. (Suggs, 
1972; Currin and Pitner, 1980; Stocks, 1988; Currin and Stanton, 1989) suggested that pruning the lowest three or four leaves of flue-cured tobacco did not reduce yield or value appreciably. However, in a study conducted in Southern Canada, Court and Hendel (1989) did find yield losses associated with lower leaf pruning. The present study evaluated the influence of five lower leaf harvesting options on tobacco plants topped to exactly 21 leaves. Because results from some previous work suggests that the tobacco plant compensates in some manner for the cured weight lost due to lower leaf pruning, the 21 leaves on each plant were partitioned into seven, 3-leaf stalk positions so that yield by leaf position could be evaluated to determine where any "yield compensation" may occur.

\section{Materials and Methods}

The location, cultivars, and management practices for the present study were identical to those previously discussed in Chapter 2. Only methods used in the present study that differ from those discussed in Chapter 2 are discussed below.

Five lower leaf harvesting options were evaluated in this study. These treatments were as follows: 1) harvesting all 21 leaves (LPs 1-3 to 19-21)(control), 2) prune and discard the lowest three leaves on the stalk, harvest 18 leaves (LPS 4-6 to 19-21), 3) do not prune or harvest the lowest three leaves, harvest 18 leaves (LPs 46 to 19-21), 4) prune and discard the lowest six leaves on the stalk, harvest 15 leaves (LPs 7-9 to 19-21), and 5) do not prune or harvest the lowest six leaves, 15 leaves harvested (LPS 7-9 to 19-21). Leaves were removed from plants of the pruning treatments at topping when leaf number was established. Currin and Pitner (1980) found pruning the lower leaves at early topping produced the highest yields. The topping time used in the present study would be considered early topping. The pruned leaves were cured in the normal manner to evaluate what their contributions to yield and value would have been. 
A split-plot arrangement of treatments was utilized in the field with cultivars being main plots and lower leaf harvesting treatments being sub-plots. But, the addition of the leaf position variable resulted in a split-split-plot design with leaf position being the sub-sub-plot. Four replications of the cultivars and lower leaf harvesting treatments were evaluated each year.

A split-split-split-plot design was used for statistical analysis with years being main plots, cultivars being sub-plots, lower leaf harvesting options being sub-subplots, and leaf positions being sub-sub-sub-plots. Analysis of variance and Fisher's Least Significant Difference (LSD) were carried out by methods described by Gomez and Gomez (1984). The factors of primary interest in this study were lower leaf harvesting options and leaf positions, and their interaction. There were no significant interactions between harvesting options and leaf position, year, or cultivar for the agronomic variables, so the following discussion focuses on the effects of harvesting options effects across years and cultivars. Total yields were computed by summing yields of all leaf positions and analysis of variance was performed on all data to determine significant effects due to havesting options. A split-split-plot design with years being main plots, cultivars being sub-plots, and lower leaf harvesting options being sub-sub-plots was used for the analysis. A second analysis was also performed on yield data which included weights of pruned leaves in order to evaluate the contributions of the pruned leaves. The LSD values computed from the two statistical analyses were very similar. Therefore, another analysis including the two treatments with the pruned leaves added was carried out. No differences were found in how the harvesting options were segregated by means comparison from the individual analyses. For simplification, the LSD values given in the figures were computed from the combined analysis of treatments, otherwise two LSD values of numerical value would have been necessary. 


\section{Results and Discussion}

Lower leaf harvesting treatments did not influence the fresh weight, cured weight, leaf area, or value at the LPs above those that were either pruned or were left on the plant and not harvested (data not shown). Suggs (1972), Currin and Pitner (1980), and Stocks (1988) found equivalent yields and economic values from treatments involving pruning of the lower three or four leaves or harvesting all of the leaves. Furthermore, Currin and Pitner (1980) and Stocks (1988) found that leaving the lowest three or four leaves on the plant and not havesting them reduced yields and values when compared to pruning and discarding those leaves or harvesting them normally. From those studies it may be inferred that pruning treatments increased yield and economic value in the leaves above those pruned, while not pruning or harvesting the lower leaves did not influence the yield or values at the higher LPs.

Fresh weight (FW) (Fig. 3-1), cured weight (CW) (Fig. 3-2), and leaf area index (LAI) (Fig. 3-3) were reduced as a result of the lower leaf harvesting treatments. Pruning or not pruning per se had no effect on these parameters; rather, the number of harvested leaves per treatment was responsible for the observed results. Court and Hendel (1989) also noted that reduced leaf number per plant reduced yield parameters, either by lower leaf pruning or topping to a lower leaf number.

In the present study, the pruned leaves were saved and cured normally to evaluate the effects of the early harvesting by pruning compared to normal harvesting of the same leaves. When the FW, CW, and LA of the pruned leaves were added back to the yields of the corresponding pruning treatments (Figs. 3-1, 3-2, 3-3), no differences in FW, CW, or LAl were found between the pruning treatments (computed with 21 total leaves) and the control treatment (21 leaves harvested). This observation supports the view that at topping the lower leaves which were pruned had reached maturity. In Chapter 2, it was also noted that the lowest nine leaves had reached maturity at topping. 


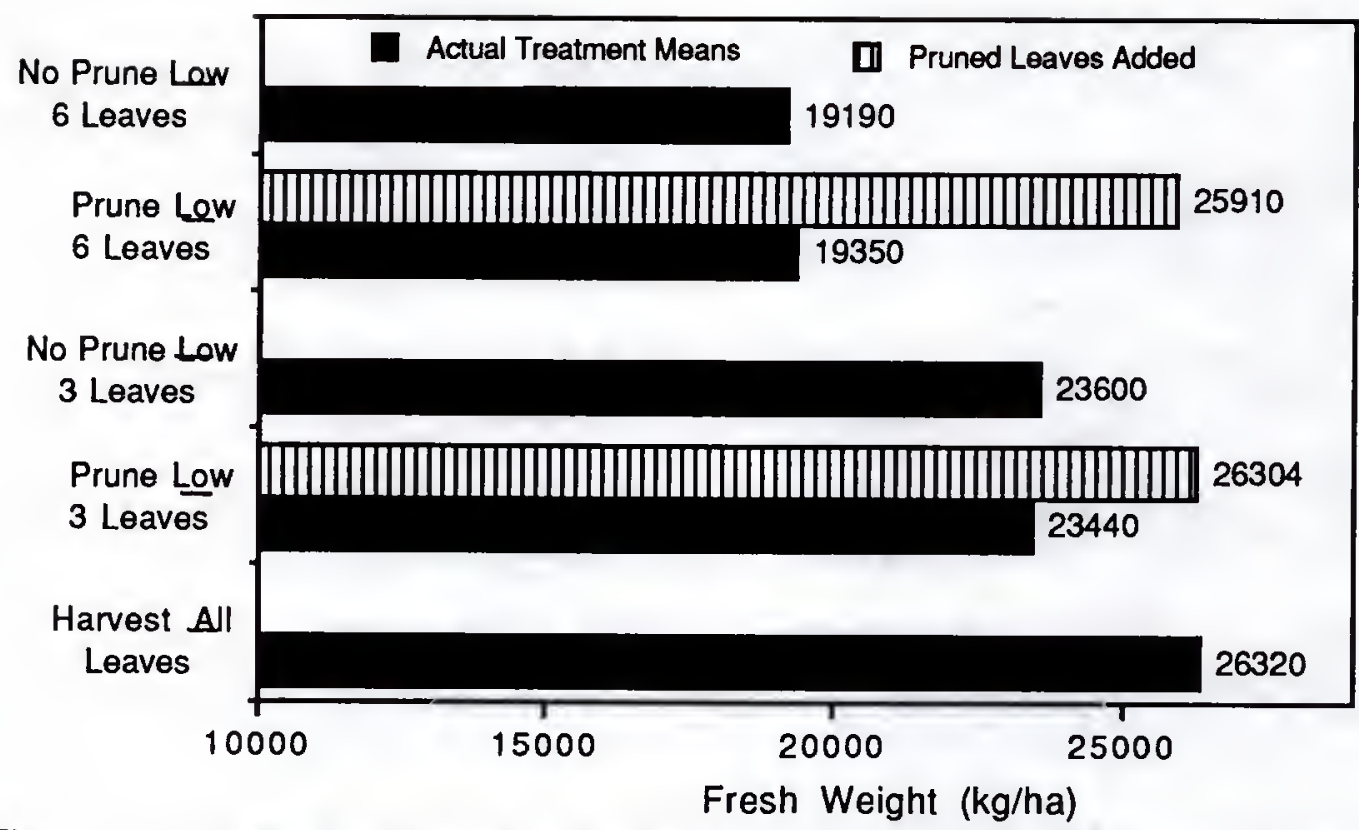

Fig. 3-1. The effects of lower leaf havesting on fresh weight of flue-cured tobacco and the effects of the pruned leaves on the total yield of the pruning treatments. $\operatorname{LSD}(0.05)=1197$ for all comparisons. Values outside bars are the treatment means.

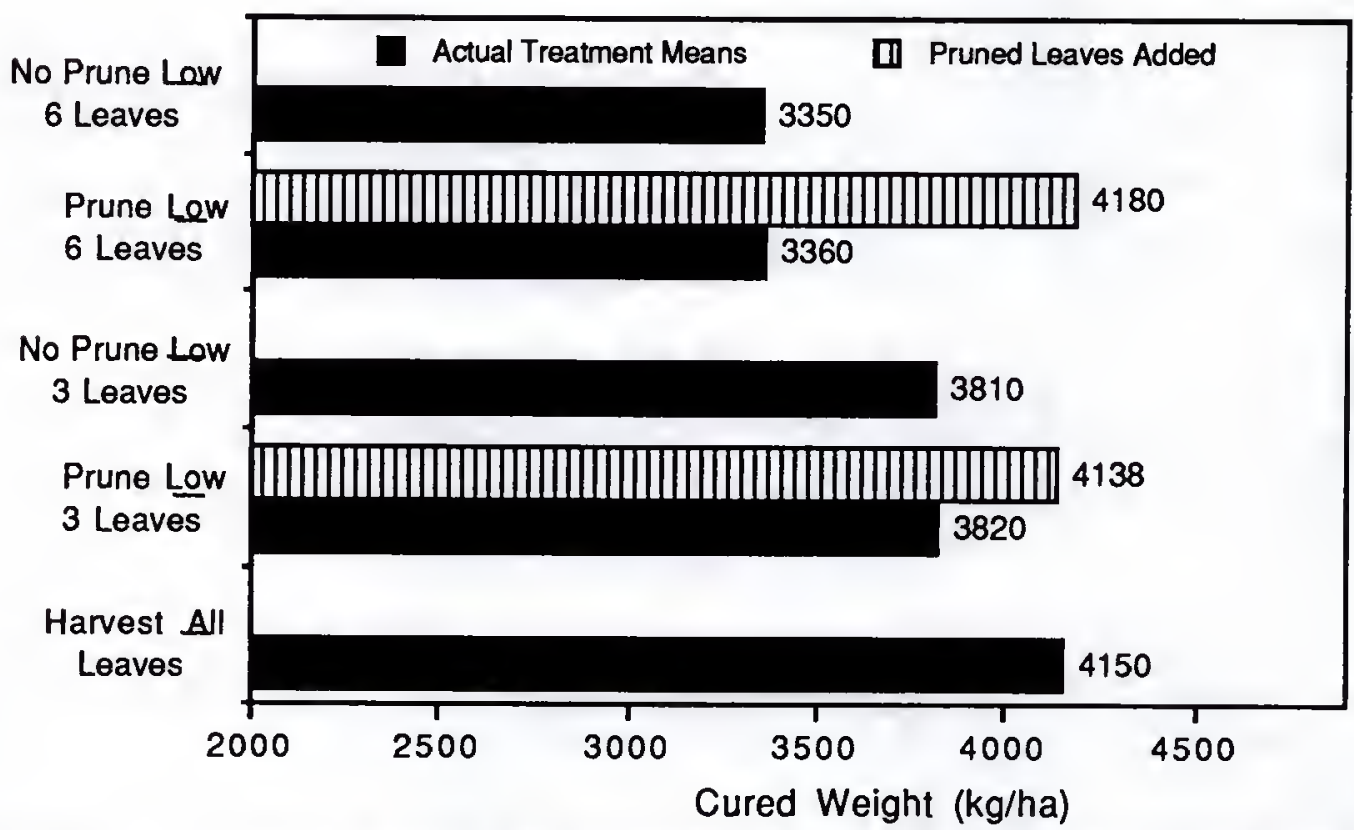

Fig. 3-2. The effects of lower leaf harvesting on cured weight of flue-cured tobacco and the effects of the pruned leaves on the total yield of the pruning treatments. $\operatorname{LSD}(0.05)=148$ for all comparisons. Values outside bars are the treatment means. 


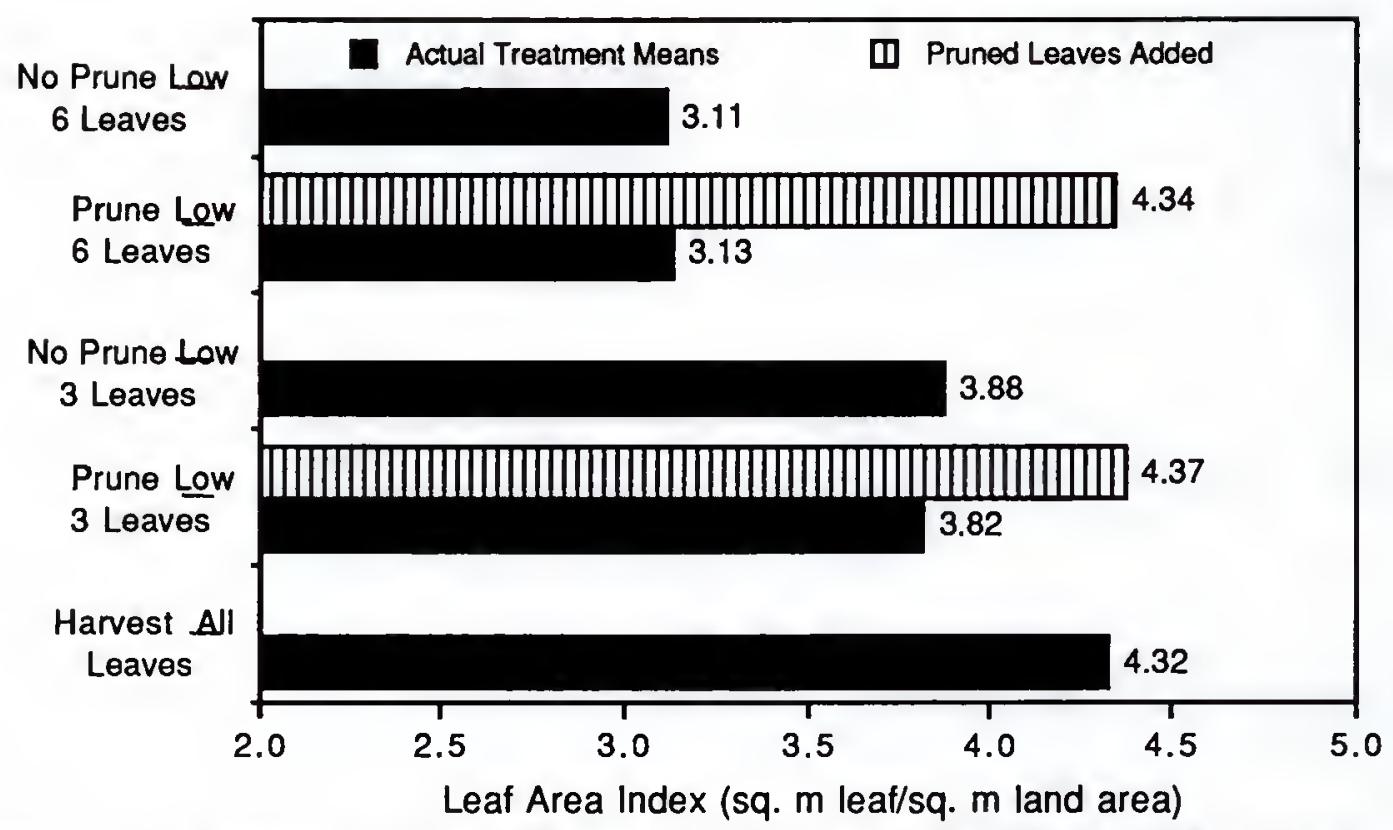

Fig. 3-3. The effects of lower leaf harvesting on the leaf area index of flue-cured tobacco and the effects of the pruned leaves on the leaf area index of the pruning treatments. $\operatorname{LSD}(0.05)=0.17$ for all comparisons. Values outside bars are the treatment means. 
No previous studies dealing with the effects of lower leaf removal evaluated the leaves that were pruned.

Harvest index $(\mathrm{HI})$ is a ratio of the weight of the economic portion of a crop to the total shoot biomass of the above-ground portion of the crop. The $\mathrm{HI}$ is typically used with grain crops to evaluate the grain yield efficiency of a cultivar. A reduction in the number of leaves harvested resulted in a decline in HI (Fig. 3-4). However, a higher HI was found when the lower six leaves were pruned compared to not pruning or harvesting the same six leaves. This result was due to the lower stalk cured weight when six leaves were pruned (Fig. 3-5) since CWs were equal for the two treatments (Fig 3-2). The difference in stalk weight was unexpected. Literature relating tobacco stalk weight to such treatments does not exist. Kollman et al. (1974) found reduced sink size of soybeans (Glycine max L. Merr.) increased stem and petiole weight. A maximum $\mathrm{HI}$ of 71 was found when no leaves were pruned and all leaves were harvested. As with other agronomic parameters previously discussed, the addition of the $\mathrm{CW}$ of pruned leaves resulted in Hls which were almost identical to the treatment where all leaves were harvested (Fig. 3-4). A HI for tobacco by the definition given above has not been reported, but Suggs (1984) found leaf weight to total leaf plus stalk weight ranged from $47 \%$ to $64 \%$.

Cured weight yield (CWY) (Fig. 3-6) and specific cured leaf weight (SCLW) (Fig. 3-7) increased as more lower leaves were pruned and discarded or were not harvested. The average CWY and SCLW of the pruning treatments were not different from the control when the corresponding CWY and SCLW of the pruned leaves were included in the totals. In Chapter 2, the CWY and SCLW were found to be lowest in the lowest LPs. Consequently, the average CWY and SCLW of the total crop would be expected to increase as the number of lower leaves harvested decreased. Suggs et al.(1987) found the CWY of the first harvest of a tobacco crop was the lowest of all harvests. This first harvest also required one of the longest curing times. More importantly, the ratio of 


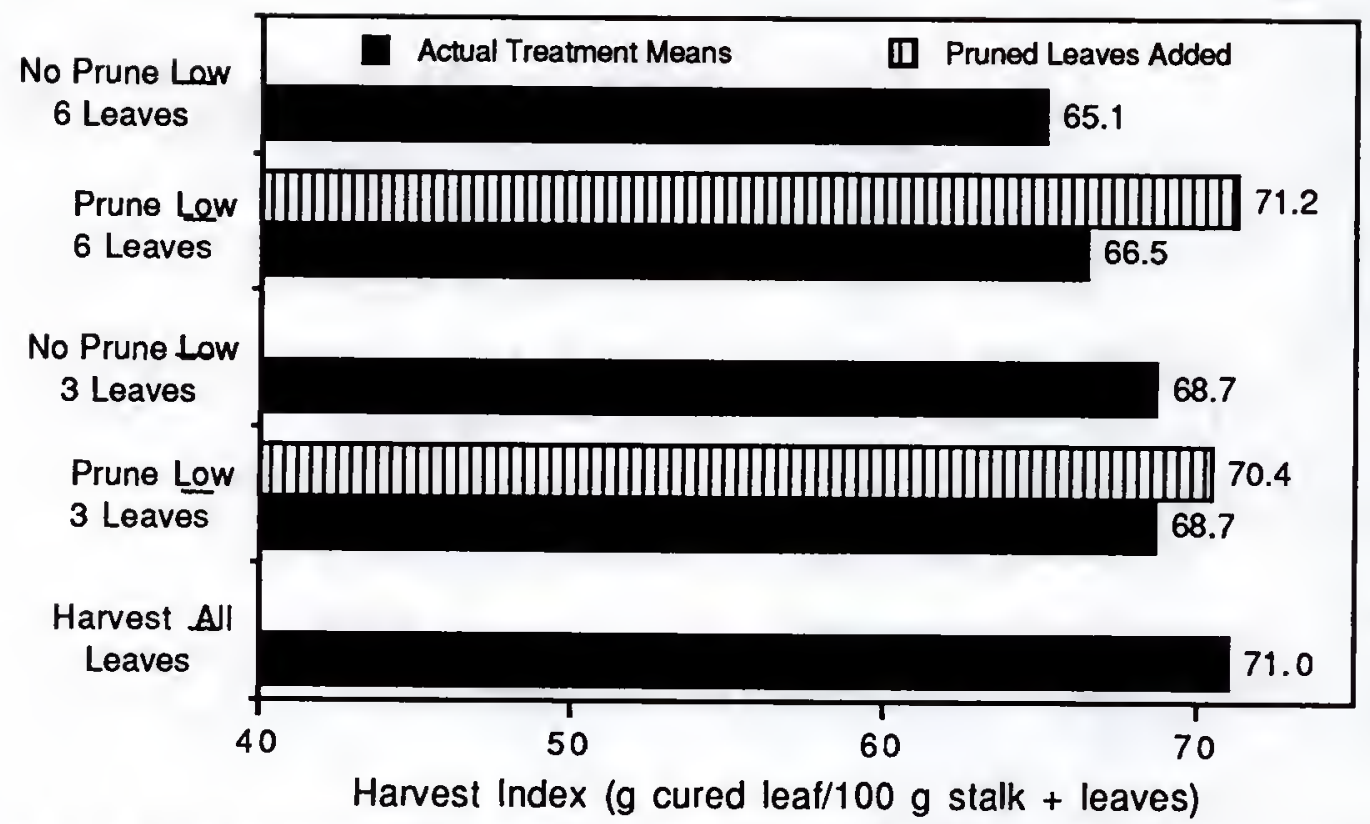

Fig. 3-4. The effects of lower leaf harvesting on the harvest index of flue-cured tobacco and the effects of the pruned leaves on the harvest index of the pruning treatments. LSD $(0.05)=1.0$ for all comparisons. Values outside bars are the treatment means.

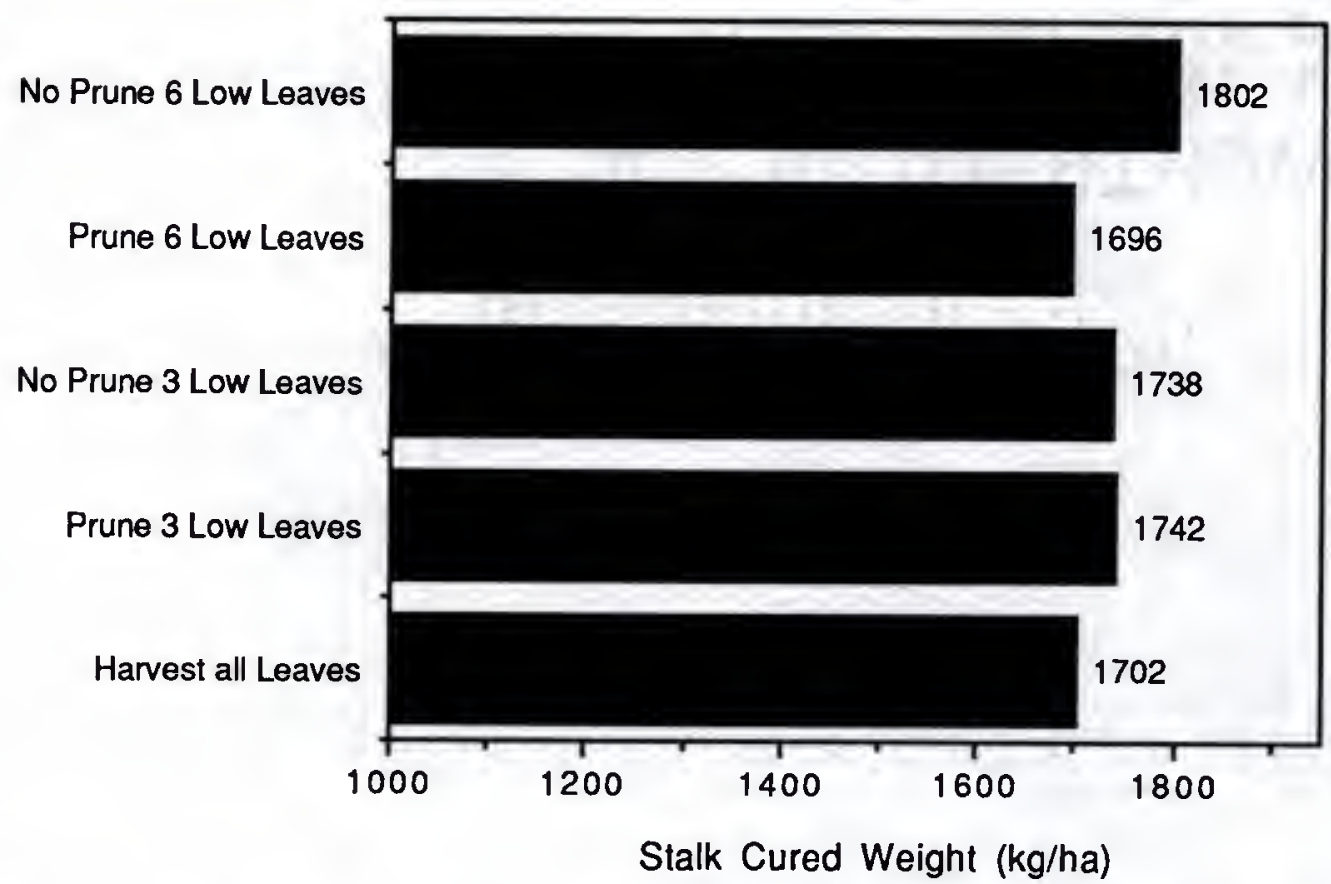

Fig. 3-5. The effects of lower leaf harvesting on the stalk weight of flue-cured tobacco. LSD $(0.05)=88$ for all comparisons. Values outside bars are the treatment means. 


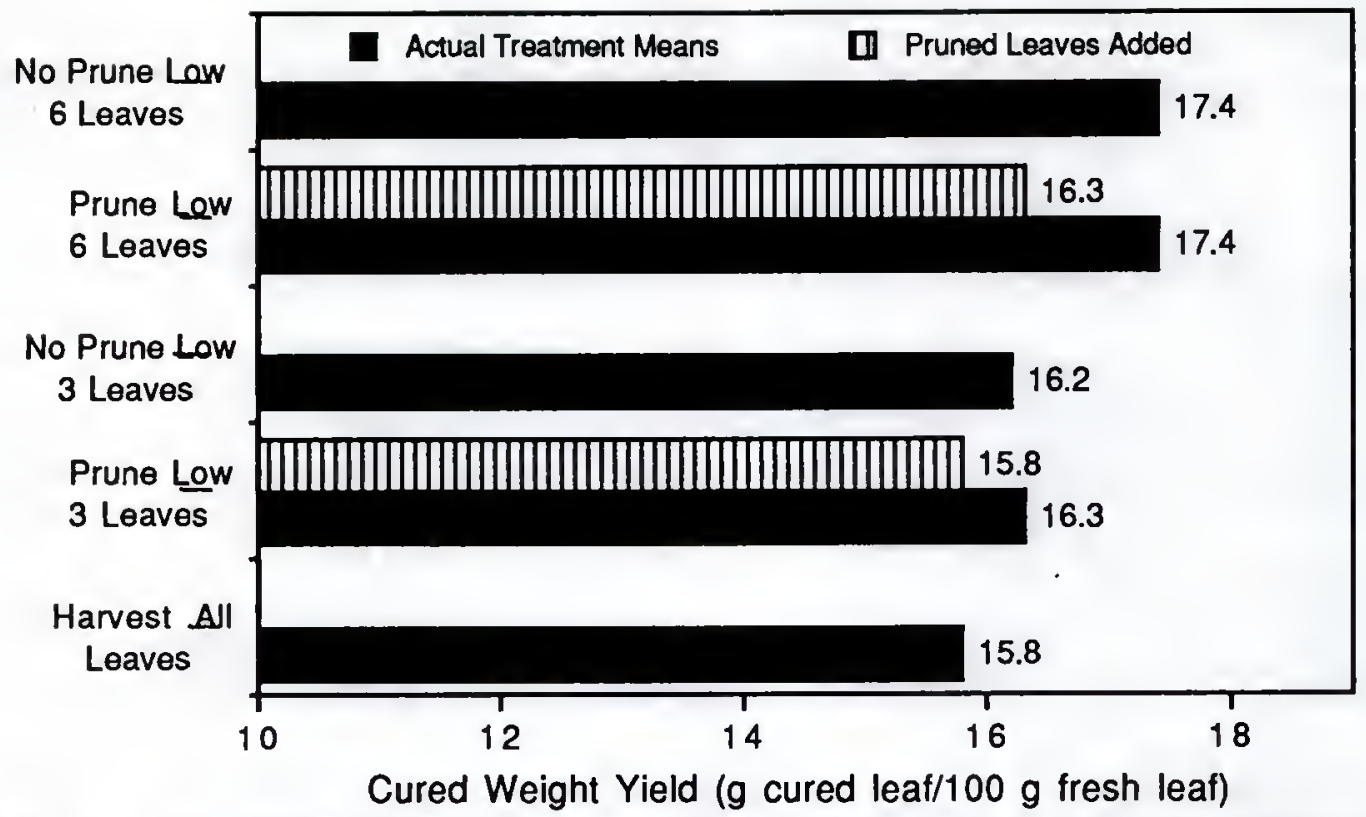

Fig. 3-6. The effects of lower leaf harvesting on the cured weight yield of flue-cured tobacco and the effects of the pruned leaves on the cured weight yield of the pruning treatments. LSD $(0.05)=0.5$ for all comparisons. Values outside bars are the treatment means.

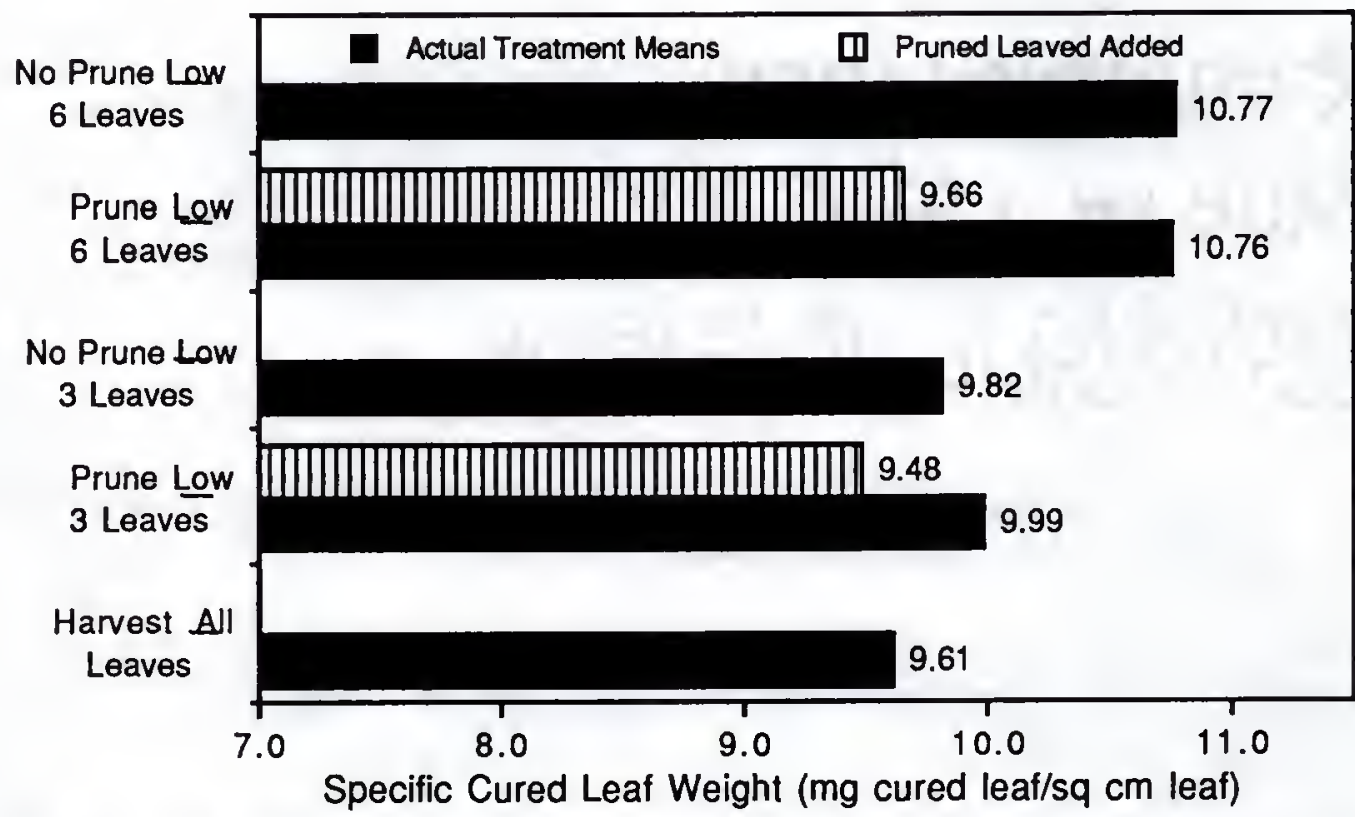

Fig. 3-7. The effects of lower leaf harvesting on the specific cured leaf weight of fluecured tobacco and the effects of the pruned leaves on the specific cured leat weight of the pruning treatments. LSD $(0.05)=0.31$ for all comparisons. Values outside bars are the treatment means. 
curing cost to $\mathrm{CW}$ was highest for the first harvest. Not harvesting the lower leaves may result in more efficient handling and curing of the tobacco crop due to the higher $\mathrm{CW}$ per unit of FW harvested and reduced curing cost per unit of $\mathrm{CW}$.

Value per hectare of the tobacco crop declined as the total number of leaves harvested decreased (Fig. 3-8). As with FW and CW, the values of the pruned LPS were equal to the values of the those same LPs when normally harvested. Value per kilogram improved when the lowest three or more leaves were not harvested (Fig. 3-9). An increase in the average value per kilogram as a result of lower leaf pruning has been observed in other studies (Suggs, 1972; Currin and Pitner, 1980; Stocks, 1988; Court and Hendel, 1989; Currin and Stanton, 1989). The increase in average price resulted because the lowest LPs were of the lowest value per kilogram (Table 3-1).

The potential benefits associated with not harvesting lower leaves include: 1) a higher average price per unit of the crop, 2) higher returns of $\mathrm{CW}$ per unit of $\mathrm{FW}$ handled, 3) a lower curing cost per unit of $\mathrm{CW}$, and 4) a higher value returned to quota. Although there was a statistically significant increase in value per kilogram in the present study, there also was a significant reduction in yield and value per hectare when the lower leaves were not harvested.

The critical value used to determine if a given lower leaf harvesting treatment significantly influenced value per hectare was $\$ 627$ ha-1 $^{-1}$ Fig. 3-10). The difference between the control and harvest 18 leaves treatments was $\$ 1060 \mathrm{ha}^{-1}$. The difference between the critical value and the actual difference was $\$ 433 \mathrm{ha}^{-1}$. For there to be no statistical difference in the values of the treatments, the harvest 18 leaves treatments must increase in value by at least $\$ 433 \mathrm{ha}^{-1}$. This difference can be made up by increased yield of the remaining leaves as found by Currin and Pitner (1980), Stocks (1988), and Currin and Stanton (1989). However, in the present study and that by Court and Hendel (1989) yield and value were lowered by reducing the total number of 


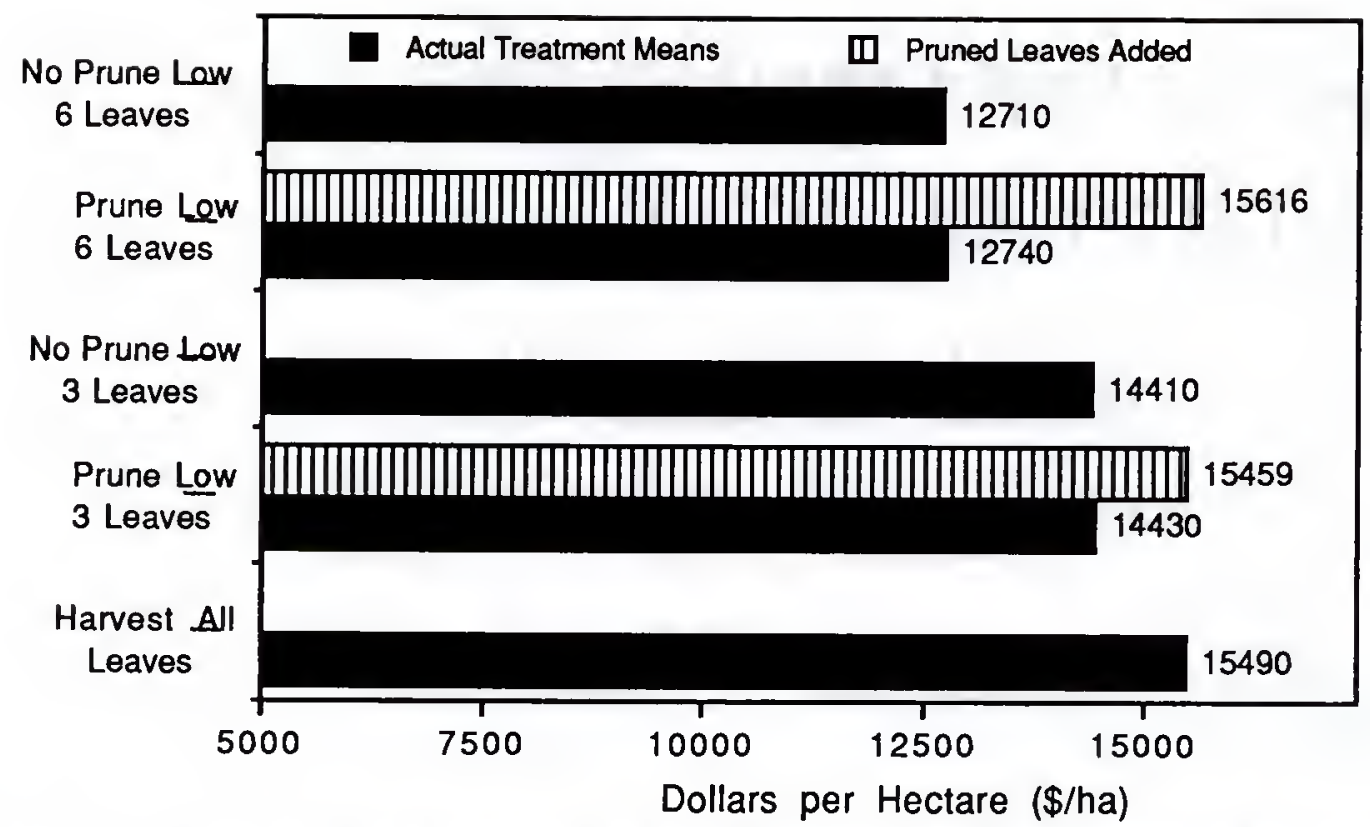

Fig. 3-8. The effects of lower leaf harvesting on the value per hectare of flue-cured tobacco and the effects of the pruned leaves on the value per hectare of the pruning treatments. LSD $(0.05)=573$ for all comparisons. Values outside bars are the treatment means.

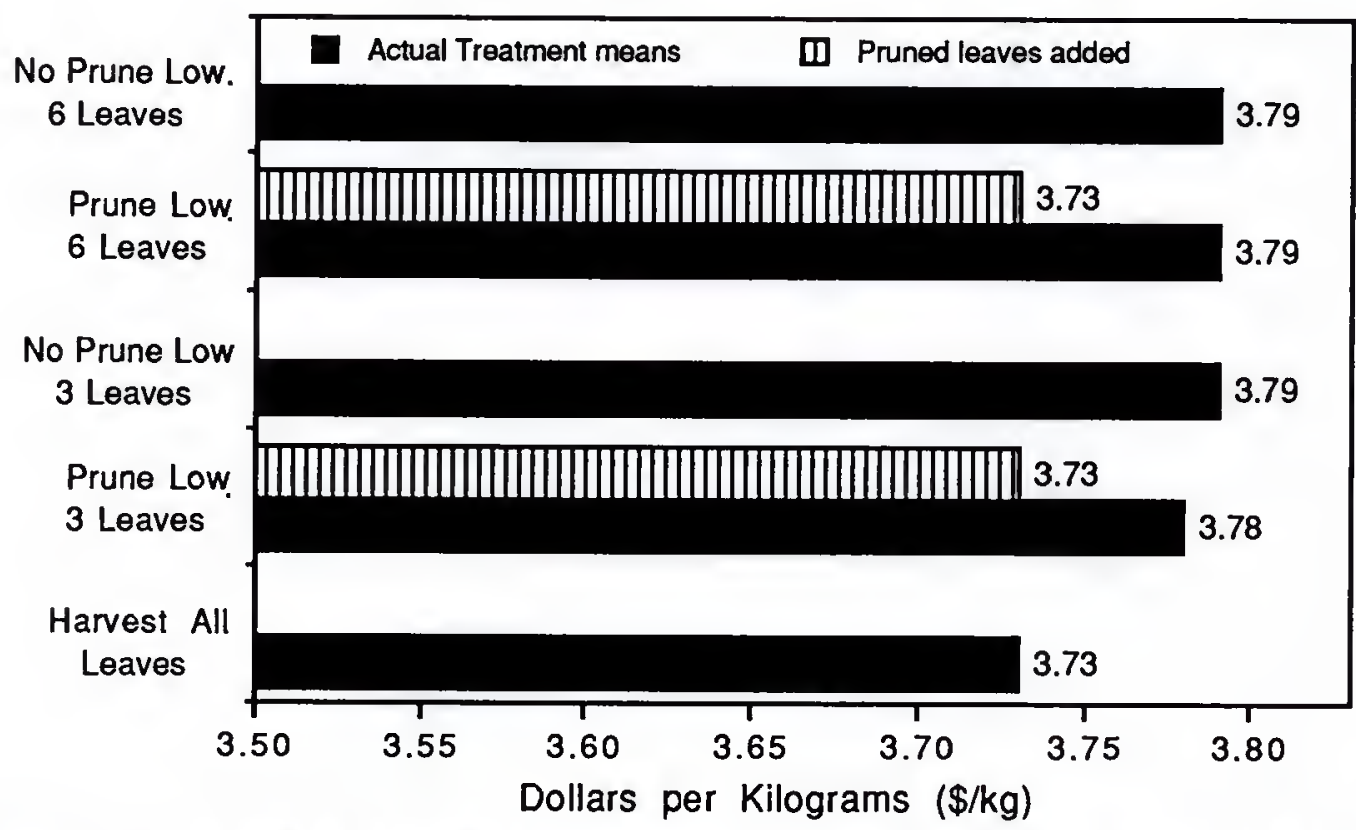

Fig. 3-9. The effects of lower leaf harvesting on the value per kilogram of flue-cured tobacco and the effects of the pruned leaves on the value per kilogram of the pruning treatments. LSD $(0.05)=0.04$ for all comparisons. Values outside bars are the treatment means. 
Table 3-1. Value per kilogram by leaf position of the lower leaf harvesting treatments.

\begin{tabular}{cccccc}
\hline $\begin{array}{c}\text { Leaf } \\
\text { Position }\end{array}$ & $\begin{array}{c}\text { harvest all } \\
\text { leaves }\end{array}$ & $\begin{array}{c}\text { Lower } \\
\text { prune low } \\
3 \text { leaves }\end{array}$ & $\begin{array}{c}\text { Harvesting } \\
\text { no prune } \\
\text { low 3 leaves }\end{array}$ & $\begin{array}{c}\text { Treatments } \\
\text { prune low } \\
6 \text { leaves }\end{array}$ & $\begin{array}{c}\text { no prune } \\
\text { low 6 leaves }\end{array}$ \\
\hline $19-21$ & 3.77 & 3.76 & 3.73 & 3.75 & 3.73 \\
$16-18$ & 3.79 & 3.79 & 3.81 & 3.74 & 3.74 \\
$13-15$ & 3.82 & 3.82 & 3.84 & 3.84 & 3.86 \\
$10-12$ & 3.71 & 3.72 & 3.77 & 3.74 & 3.75 \\
$7-9$ & 3.67 & 3.69 & 3.69 & 3.70 & 3.70 \\
$4-6$ & 3.57 & 3.63 & 3.61 & $3.49 \times$ & NHY \\
$1-3$ & 3.29 & $3.41 \times$ & NHY & $3.40 \times$ & NHy \\
\hline
\end{tabular}

$\mathrm{x} /$ indicates these leaves were pruned at topping.

$y /$ /indicates these leaves from these treatments were not harvested.

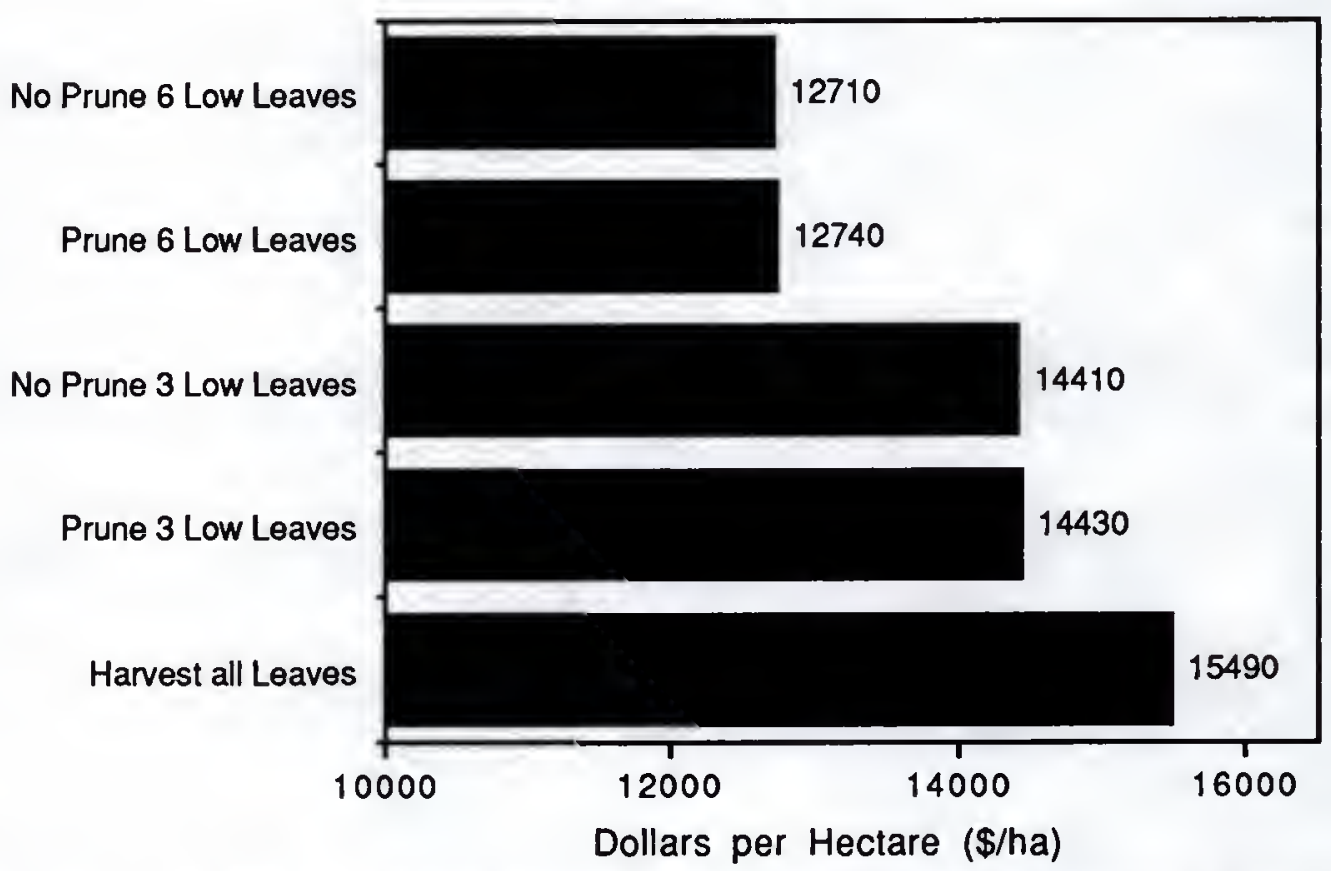

Fig. 3-10. The effects of lower leaf harvesting on the value per hectare of flue-cured tobacco. LSD $(0.05)=627$ for all comparisons. Values outside bars are the treatment means. 
leaves harvested. Consequently, in these cases the value differences must be compensated for by either increasing the value per kilogram or planting more area.

The harvest 18 leaves treatments yielded $3815 \mathrm{~kg} \mathrm{ha}^{-1}$. Based on this yield and the needed minimum value increase ( $\left.\$ 433 \mathrm{ha}^{-1}\right)$ not to be different from the control, value per kilogram would need to increase by $\$ 0.11 \mathrm{~kg}^{-1}\left(\$ 433 \mathrm{ha}^{-1} / 3815 \mathrm{~kg} \mathrm{ha}^{-1}\right)$. An increased value of $\$ 0.11 \mathrm{~kg}^{-1}$ is not unrealistic, but the same value per kilogram to make up the value loss for the harvest 15 leaves option was $\$ 0.64 \mathrm{~kg}^{-1}\left(\$ 2138 \mathrm{ha}^{-1}\right.$ /3355 kg ha-1). Pruning or otherwise not harvesting the lowest six leaves was not feasible based on the results from the present study.

The other method of compensating for value lost by not harvesting lower leaves is planting more area. The value per hectare when all 21 leaves were harvested was $\$ 15,490 \mathrm{ha}^{-1}$. The average value per hectare when only 18 or 15 leaves were harvested was $\$ 14,420 \mathrm{ha}^{-1}$ or $\$ 12,730 \mathrm{ha}^{-1}$, respectively. The additional hectareage required to compensate for the reduced value when harvesting 18 leaves was 1.07 , whereas 1.22 additional ha would be required for the 15-leaf harvest. Pruning or otherwise not harvesting the lowest three leaves appeared to be the more viable option since value per kilogram was equal and yield and value per hectare were higher when compared to the pruning or otherwise not harvesting the lower six leaves.

In the middle 1980's, lower leaf harvesting decisions were based on economics. The average value per kilogram for the lower leaf ( $P$ group) grades of flue-cured tobacco were well below all others. A comparison of leaf position grade groups for 1986 and 1990 revealed the dramatic changes that have occurred on the U.S. flue-cured tobacco market floor (Table 3-2). Beginning in 1989, increased demand for lower leaf U.S. flue-cured tobacco drove prices for that leaf to levels approaching that of middle leaves. The lower leaf grades ( $P$ group) increased 22 to $31 \%$ in value depending on maturity classification, while the middle and upper stalk grades ( $X, C$, and $B$ groups) increased very little in value over the same period (Table 3-2). The concept of not 
Table 3-2. Changes in the Georgia-Florida (Type 14) flue-cured tobacco market average value per kilogram from 1986 to 1990 of all ripe and mature or unripe and immature grades common to both years.

--- Ripe \& Mature Grades --- $\quad$-- Unripe \& Immature Grades .-

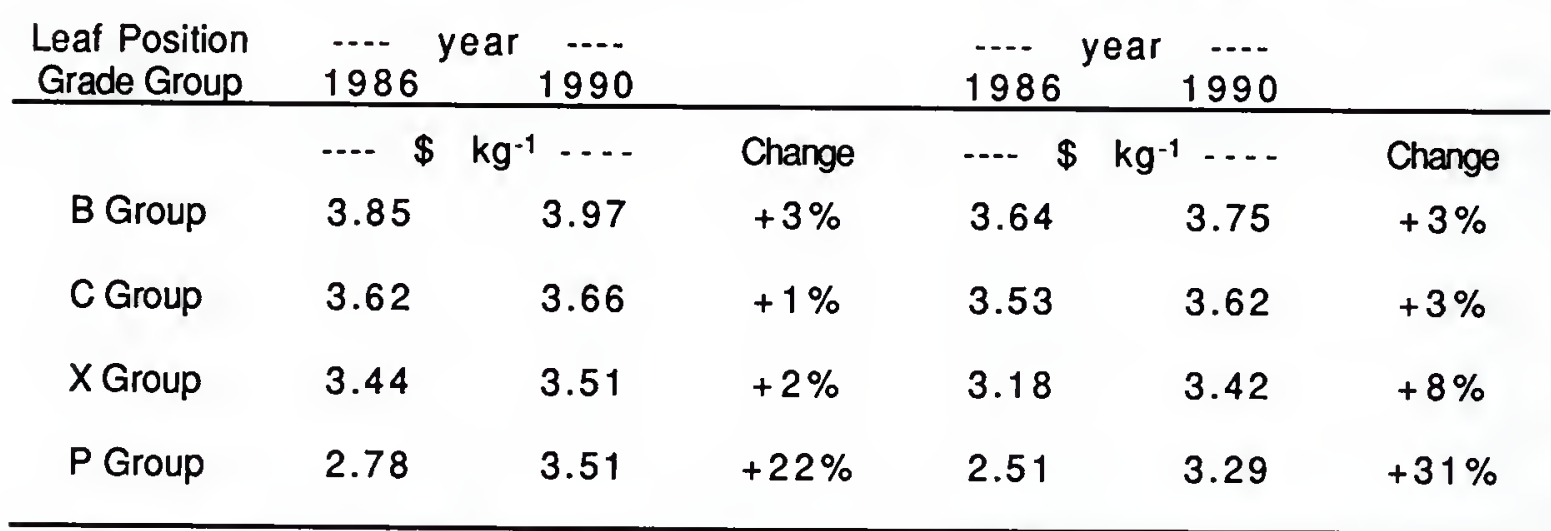

Source: 1986 and 1990 Georgia-Florida (Type 14) tobacco market grade reports from the Market News Reporter, Doug Hendrix. 
harvesting the lowest leaves at the present price structure is not economically sound, unless potential yield exceeds quota. Still, if the present price structure were similar to that of 1986 , not harvesting the lower leaves would be a realistic option.

\section{Conclusions}

Harvesting methods for lower leaves of tobacco did not affect yield parameters of individual leaves. Pruning and discarding lower leaves was no more or less beneficial to total yield and value than leaving the lower leaves on the stalk and not harvesting or discarding them. Total yield and value was reduced as the total number of leaves harvested was reduced by lower leaf harvesting treatments. Average value per kilogram was increased by not harvesting three or more lower leaves because these leaves were the lowest in value per kilogram and $\mathrm{CW}$. At the time of pruning, the lower leaves had reached their maximum yield and value because returning their yields and values to the respective pruning treatments resulted in no differences between the total yield or value of the control treatment, which involved normal harvesting of the same leaves that were pruned.

If the potential yield of the tobacco crop is such that the yield lost by not harvesting lower leaves can be tolerated, this practice is advantageous because the average price per kilogram is enhanced. Total curing cost likely will be lower by not having to handle the lowest yielding leaves. Yield and value loss must be tolerated, but not harvesting lower leaves of flue-cured tobacco will likely result in a higher per kilogram profit margin. 


\section{CHAPTER 4}

\section{LOWER LEAF HARVESTING: THE INFLUENCE OF TIME ON THE CHEMICAL AND MINERAL CHARACTERISTICS OF FLUE-CURED TOBACCO LEAF POSITIONS.}

\section{Introduction}

Lower leaf harvesting options of flue-cured tobacco (Nicotiana tabacum L.) have been recommended based on the total crop response to removal of lower leaves. Studies by Suggs (1972), Currin and Pitner (1980), and Stocks (1988) found pruning and discarding the lowest three or four leaves had no impact on the total yield or chemical balance of tobacco leaves. Court and Hendel (1989) reported yield reductions associated with reduced leaf number harvested by either lower leaf pruning or topping to a lower leaf number, but no effects on the leaf chemical components.

In tobacco production, the leaves to be harvested are in a constant state of flux as they progress from young, very immature leaves to mature leaves which are ready for harvest. Turgeon (1989) stated that "leaves of dicotylendous plants stop importing and begin to export photoassimilate when they are 30-60\% fully expanded. Developing leaves continue to import photoassimilate from source leaves for a period after they have begun to export their own products of photosynthesis." Prior to the topping process, a definitive source-sink relationship exists on the tobacco plant. There is an apical meristem (sink) that may have terminated to an inflorescence, newly-unfolded leaves (sink), leaves in a source-sink transition, and leaves that are mature or maturing and are exclusively exporters of photosynthate. Hurng et al. (1989) concluded that removal of the reproductive sink (topping) caused the leaves of tobacco plants to act as alternate sinks. Crafts-Brandner et al. (1984) found that depodding (or sink removal) of soybean (Glycine max L. Merr.) plants caused leaves and stems to act 
as alternate sinks. After topping, based on changes in the area of the leaves at given LPS over time (Chapter 2), only the leaves at the upper-most LP (19-21) probably would be in the transition phase of source-sink development as described by Turgeon (1989). All other leaves should be exclusive exporters of photoassimilate. After topping, the leaves of a tobacco plant serve two purposes: 1) generation of substrates for dry matter production via photosynthesis, and 2) storage organs for the products of photosynthesis (starch) and other processes, i.e. nicotine synthesis of the roots.

Lower leaf harvesting options are essentially manipulations of the source and sink leaves. If one chooses to not prune or harvest lower leaves, it is possible they may act as sinks. If one chooses to prune the lower leaves, potential sinks are removed and the remaining leaf area (sinks) remaining will be smaller. Normal havesting of fluecured tobacco is essentially a leaf pruning procedure in that leaves are removed methodically throughout the harvest season as they mature on the stalk.

Numerous studies have quantitified the effects of source-sink manipulations of other plants. Removal of the grain sink of corn (Zea mays L.) caused increases in the carbohydrate concentration of both upper and lower leaves (Allison and Weinmann, 1970). Soybean pod pruning increased leaf carbohydrate concentration (McAlister and Krober, 1958; Kollmann et al., 1974; Ciha and Brun, 1978; Mondal et al., 1978; Streeter and Jeffers, 1979; Crafts-Brandner et al., 1984), and also increased leaf $N$ and $P$ concentrations (Kollman et al. 1974; Crafts-Brandner et al., 1984). Kollmann et al. (1974) further reported that leaf $\mathrm{Ca}$ and $\mathrm{K}$ concentrations were decreased due to depodding of soybean. Lawn and Brun (1974) found soybean depodding decreased net photosynthesis, and that the photosynthetic decline was linked to an accumulation of assimilates in the leaves that would have been translocated to the developing pods. Depodding of soybean also delayed leaf senescence (Hicks and Pendleton, 1969; Mondal et al., 1978; Crafts-Brandner et al., 1984). The effects of reproductive sink removal can be summarized to include increased leaf carbohydrate levels with a subsequent decline in 
net photosynthesis, increase in leaf $\mathrm{N}$ and $\mathrm{P}$ concentrations, decreases in leaf $\mathrm{Ca}$ and $\mathrm{K}$ concentrations, and a delay in the onset of senescence.

Removal of more than $10 \%$ of the leaf area of wheat (Iriticum aestivum L.) and oat (Avena sativa L.) plants reduced grain yield (Womack and Thurman, 1962). Pauli and Stickler (1961) found that increasing the percentage of leaves pruned from grain sorghum (Sorahum bicolor L. Moench) plants decreased the total carbohydrate concentration in the vegetative tissue and grain. Grain $\mathrm{N}$ concentration increased, but vegetative tissue $\mathrm{N}$ concentration and the grain yield of sorghum were reduced as defoliation increased (Stickler and Pauli, 1961). Weber (1955) and McAlister and Krober (1958) found soybean seed yield and size decreased in response to increasing defoliation. Grain yield reductions by defoliation were induced by a decline in the total photosynthetic capacity of the plant caused by a reduction in leaf area.

Flue-cured tobacco is managed differently than most other agronomic crops in that the leaves, and not the seed, are harvested. Also, leaves are removed as they mature on the plant. Most source-sink manipulation studies have dealt with either the effects of removal of the reproductive sink on leaf and seed characters or the influence of defoliation on seed characters.

The objective of the present study was to evaluate the effects of pruning, not pruning or harvesting, or harvesting normally, the lower three or six leaves on fluecured tobacco plants. The effects were evaluated on leaves harvested as they matured on the stalk, or monitored over time to maturity. Because previous studies have not been designed to examine effects relative to leaves at specific stalk positions, the present study focused on changes by leaf position.

\section{Materials and Methods}

The location, cultivars, and management practices for the present study were identical to those previously discussed in Chapter 2. The lower leaf harvesting treatments used in the present study were the same as those previously described in 
Chapter 3. Methods that differ from those discussed in Chapters 2 or 3 are described below.

Two separate studies were included to evaluate the effects of lower leaf harvesting options. A normal harvest study was conducted to evaluate the effects of lower leaf harvesting options under typical management. A time after pruning and topping study was designed to monitor temporal changes in leaves at a given LP to determine when differences appeared.

Nermal Harvest Study

Plots consisted of ten plants spaced $41 \mathrm{~cm}$ apart, planted in rows spaced $121 \mathrm{~cm}$ apart. Four replications of lower leaf harvesting treatments and cultivars were evaluated each year in a split-split-plot design. Cultivars were main plots, harvesting options were sub-plots, and leaf positions were sub-sub-plots. A split-split-splitplot design was used for statistical analysis with years being main plots, cultivars being sub-plots, harvesting options being sub-sub-plots, and leaf positions being sub-subsub-plots. Analysis of variance and single degree of freedom contrast procedures were carried out by methods described by Gomez and Gomez (1984).

Eight cured leaves were subsampled for chemical or mineral analyses from leaves at LPs 7-9, 13-15, and 19-21. These LPs were selected because they were common to all treatments and inherently different in many characteristics. The midribs were removed from the lamina. The lamina was ground using a Wiley mill with a $1 \mathrm{~mm}$ screen. Total N, nicotine, and reducing sugar analyses were performed by R.J. Reynolds Tobacco Company in Winston-Salem, NC, and Philip Morris Tobacco Company in Richmond, VA. For $\mathrm{Ca}, \mathrm{Mg}, \mathrm{K}$, and $\mathrm{P}$ analyses, samples were prepared by the ashing and acid digestion method described by Walsh (1971). The resulting solutions were analyzed by Inductively Coupled Argon Plasma (ICAP) in the University of Florida's Institute of Food and Agricultural Science Extension Soil Testing Laboratory by methods described by Hanlon and Devore (1989). 
The leaf chemical and mineral data are reported for leaf lamina only. Midribs were not evaluated, and previous work indicated that their chemical and mineral constituents are different from those of the lamina (Darkis et al., 1952).

\section{Time After Pruning Study}

Plots consisted of two plants spaced $41 \mathrm{~cm}$ apart, planted in rows spaced $121 \mathrm{~cm}$ apart ( $1 \mathrm{~m}^{2}$ of total area). Three replicates of cultivars and lower leaf harvesting treatments were evaluated each year and were arranged in the field in a split-splitsplit-plot design with cultivars being main plots, harvesting options being sub-plots, leaf position being sub-sub-plots, and harvest dates being sub-sub-sub-plots. The 21 leaves were partitioned into seven, 3-leaf stalk positions for harvesting purposes. Weekly harvests were taken of all 3-leaf stalk positions that remained on the stalk, beginning one week after topping. A set of samples was taken at topping, when the pruning treatments were imposed, to establish a baseline of the initial levels for the components at all LPs. Because this study was designed to monitor LP changes over time, LPs that were harvested in the normal harvest study were removed from all plants that were to be used for future harvest date analysis. The progression of the LPS as they were harvested is indicated in Table 4-1.

Because the lower leaf harvesting options resulted in reductions in the number of leaves harvested either by pruning, or not pruning or harvesting of the lower leaves, all LPs were not harvested for all treatments. When the lower three leaves were pruned and discarded at topping or were otherwise not pruned or harvested, only LPs 4-6 through 19-21 were harvested. When the lower six leaves were pruned and discarded at topping or were otherwise not pruned or harvested, only LPS 7-9 through 19-21 were harvested. The control treatment (harvest all 21 leaves) resulted in harvesting of all LPs. For the harvest dates from 21 to 49 days after pruning or topping, all treatments had an equal number of LPs since LPs 7-9 through 19-21 were common to all treatments. 
Table 4-1. The leaf positions removed per plant by harvest date in the days after pruning and topping study.

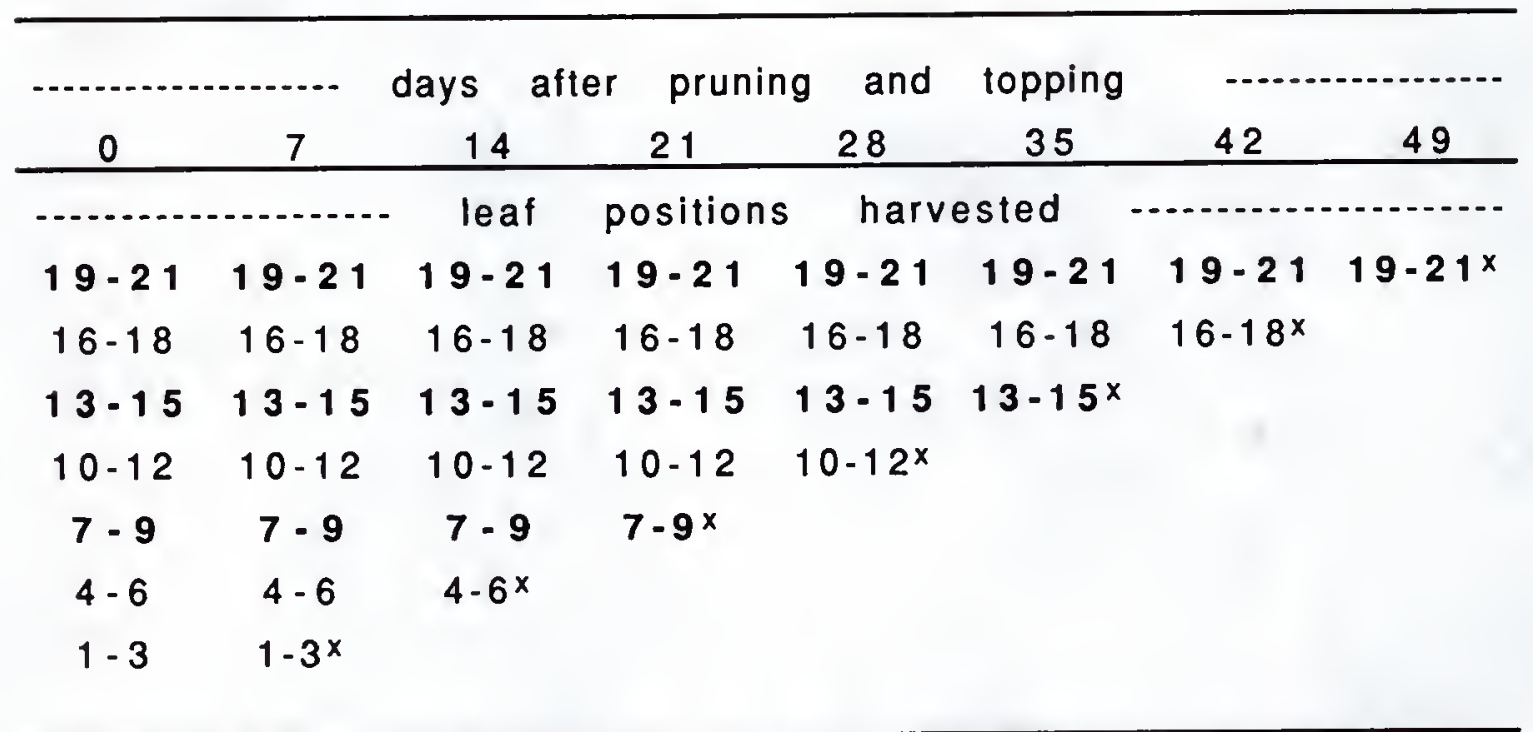

***Bold type indicates that leaf area, leaf mineral and chemical components, and total non-structural carbohydrates (TNC) were measured on those leaf positions.

$x$ Indicates leaf positions which were harvested normally on this date. 
Each LP sample consisted of six leaves (2 plants $X$ a 3-leaf position). All leaf samples were cured in the normal flue-curing manner. After curing, the leaves were rehydrated for handling purposes. The six leaves at each LP were used for leaf chemical or mineral analyses. The midribs were removed and the lamina was ground to $1 \mathrm{~mm}$ using a Wiley mill. Total $\mathrm{N}$, nicotine, reducing sugar, $\mathrm{Ca}, \mathrm{Mg}, \mathrm{K}$, and $\mathrm{P}$ analyses were performed by the same methods described above.

Analysis of the entire data set was not possible due to lack of balance. With each successive harvest date there was a loss of one LP that was harvested in the normal harvest study (Table 4-1). As a result, each harvest date was analyzed individually. Leaf position was an overwhelming factor across harvest dates. For analysis of the influence of harvesting effects at LP over time, each LP was analyzed for each harvest date. The statistical design used then was a split-split-plot design with years being main plots, cultivars being sub-plots, and harvesting options being sub-sub-plots. Analysis of variance and single degree of freedom contrasts procedures were carried out by methods described by Gomez and Gomez (1984).

\section{Lower Leaf Harvesting Options Statistical Comparisons}

Single-degree of freedom contrasts were chosen to determine differences between harvesting schemes. With contrasts the possible comparisons are limited to the number of degrees of freedom for the effect analyzed. There were a total of five harvesting treatments, so there were four possible contrasts. The comparisons chosen were derived from a desire to determine combined and individual effects of the harvesting schemes. To determine the effects of pruning lower leaves versus not pruning and not harvesting lower leaves, a comparison was made between the combined effects of pruning the lower three and six leaves and the combined effects of not pruning and not harvesting the lower three and six leaves. This contrast was designated "prune vs no prune". There were few effects associated with the lower three leaf harvesting options, but strong effects associated with the lower six leaf harvesting options. Consequently, a comparison was 
made between pruning of the lower six leaves and not pruning or harvesting the lower six leaves. This contrast was designated "prune 6 vs no prune 6 ". The harvest all leaves treatment was considered the control. To evaluate deviations from the norm of the lower leaf harvesting regimes, comparisons were made between the control versus the combined pruning treatments, designated "harv all vs prune", and the control versus the combined not pruning and not harvesting lower leaves treatments, designated "harv all vs no prune".

\section{Besults and Discussion}

\section{Leaf Chemical Characters}

Nicotine concentration was lower in the leaves that comprised 13-15 due to not pruning or harvesting the lower six leaves in the normal harvest study (Table 4-2). Suggs (1972) found higher nicotine concentrations when nine lower leaves were pruned, but no differences when six or less leaves were pruned. Currin and Pitner (1980), Stocks (1988), and Court and Hendel (1989) reported no differences in nicotine concentration due to lower leaf pruning. Over time, nicotine concentrations in leaves at LPs $7-9,13-15$, and 19-21 were lower as a result of not pruning or harvesting the lower leaves (Fig. 4-1 \& Table 4-3, Fig. 4-2 \& Table 4-4, Fig. 4-3 \& Table 4-5). Nicotine concentration for the control was not different from that of the pruning treatments in the normal harvest study. This result was also observed over time, however, over the first 14 days after pruning the nicotine concentrations at all LPs were similar to those at the LPs in the no pruning treatments. Leaves were discarded from the pruning treatments at topping. Normal harvesting is technically a pruning process, but since only three leaves were removed per harvest, all lower six leaves of the control treatment had not been harvested until 14 days after the pruning treatments were imposed. Nicotine concentrations under normal harvesting were similar to the no pruning treatments initially, but as more leaves were harvested from the control treatment the nicotine concentration approached that observed in the pruning 
Table 4-2. The effects of lower leaf harvesting options on nicotine concentration of flue-cured tobacco by leaf position (normal harvest study).

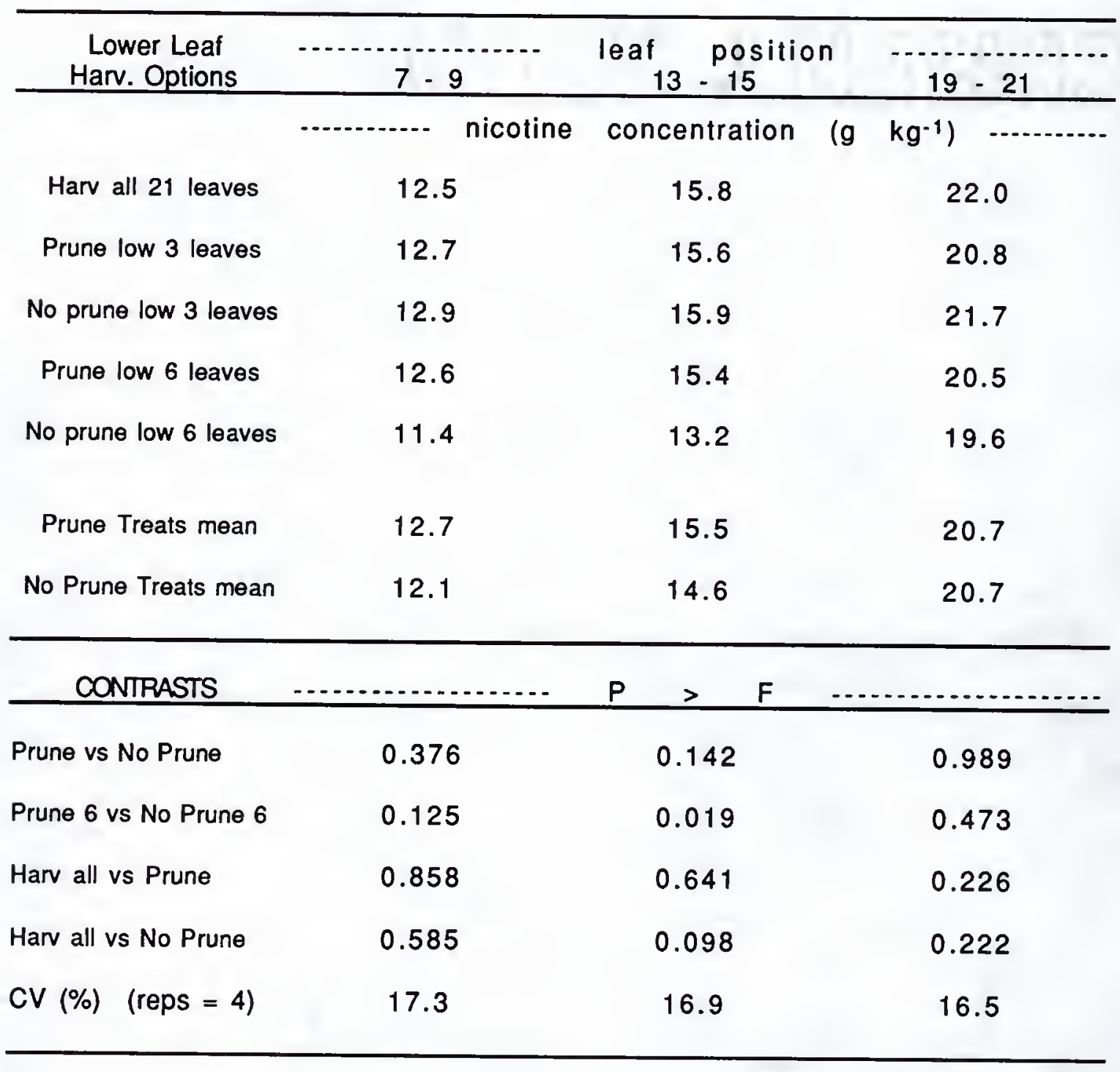




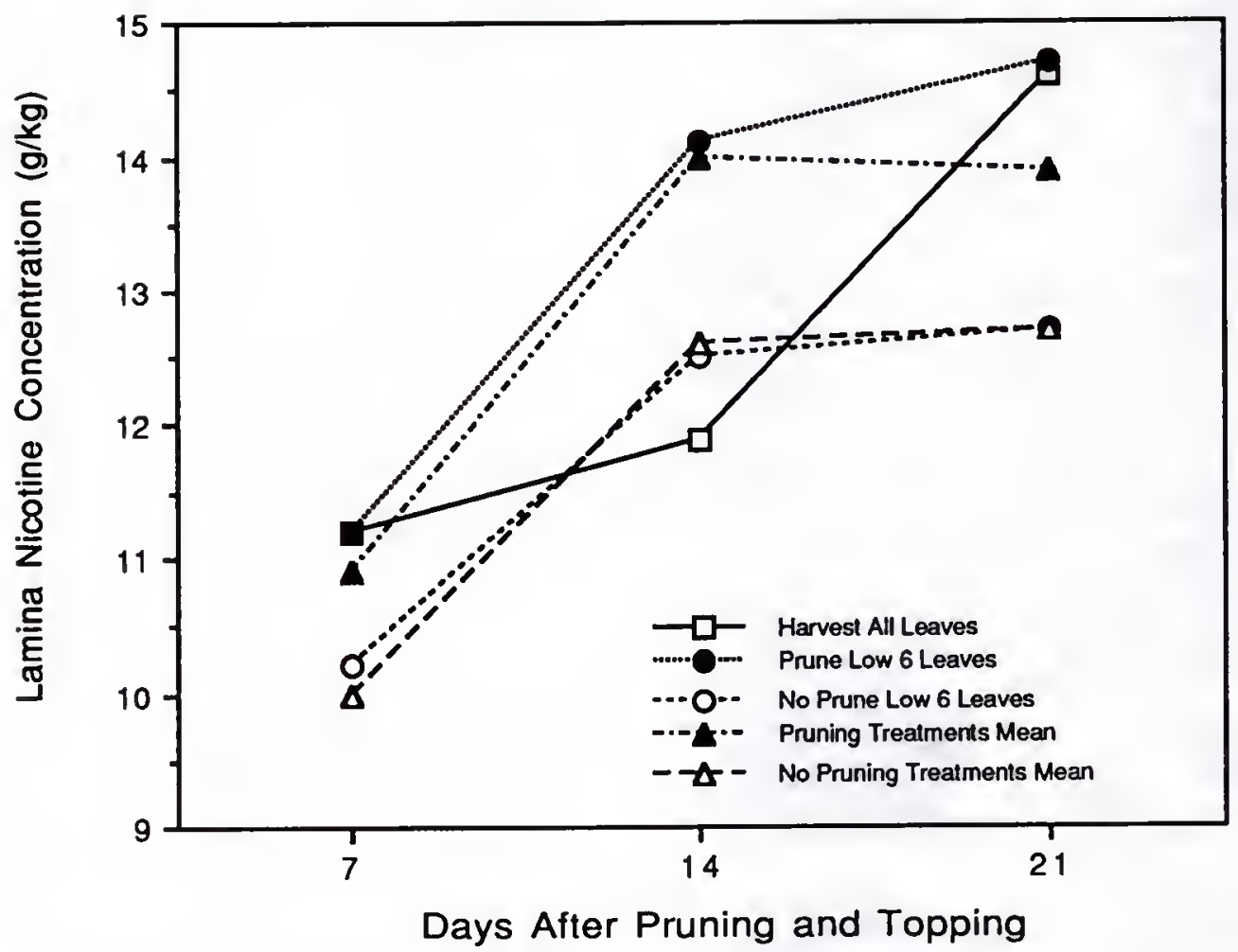

Fig. 4-1. Influence of lower leaf harvesting options on the lamina nicotine concentration of flue-cured tobacco leaf position 7-9. Appropriate contrasts are given below.

Table 4-3. Single degree of freedom contrasts for the data presented in Fig. 4-1.

\begin{tabular}{|c|c|c|c|c|c|c|c|}
\hline & 7 & $d a$ & & $\begin{array}{l}\text { fter } \\
14\end{array}$ & & ing & 21 \\
\hline CONIRASTS & $\ldots \ldots \ldots$ & $\ldots$ & $\mathbf{P}$ & $>$ & $\mathrm{F}$ & $\ldots$ & - n \\
\hline Prune vs No Prune & 0.084 & & & 0.009 & & & 0.042 \\
\hline Prune 6 vs No Prune 6 & 0.187 & & & 0.034 & & & 0.012 \\
\hline Harv all vs Prune & 0.711 & & & 0.002 & & & 0.244 \\
\hline Harv all vs No Prune & 0.077 & & & 0.284 & & & 0.006 \\
\hline CV $(\%) \quad($ reps $=3)$ & 17.3 & & & 13.6 & & & 13.2 \\
\hline
\end{tabular}




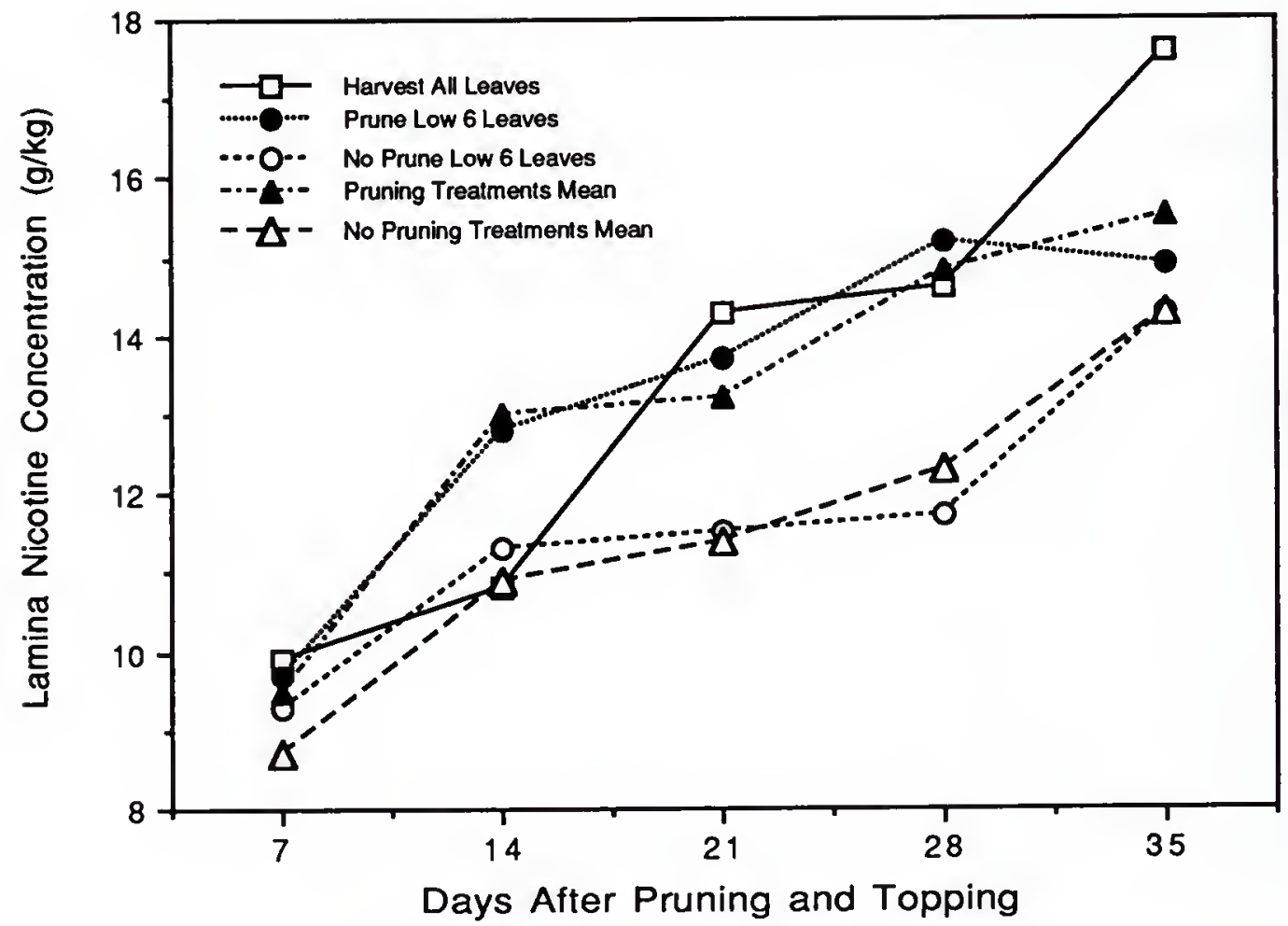

Fig. 4-2. Influence of lower leaf harvesting options on the lamina nicotine concentration of flue-cured tobacco leaf position 13-15. Appropriate contrasts are given below.

Table 4-4. Single degree of freedom contrasts for the data presented in Fig. 4-2.

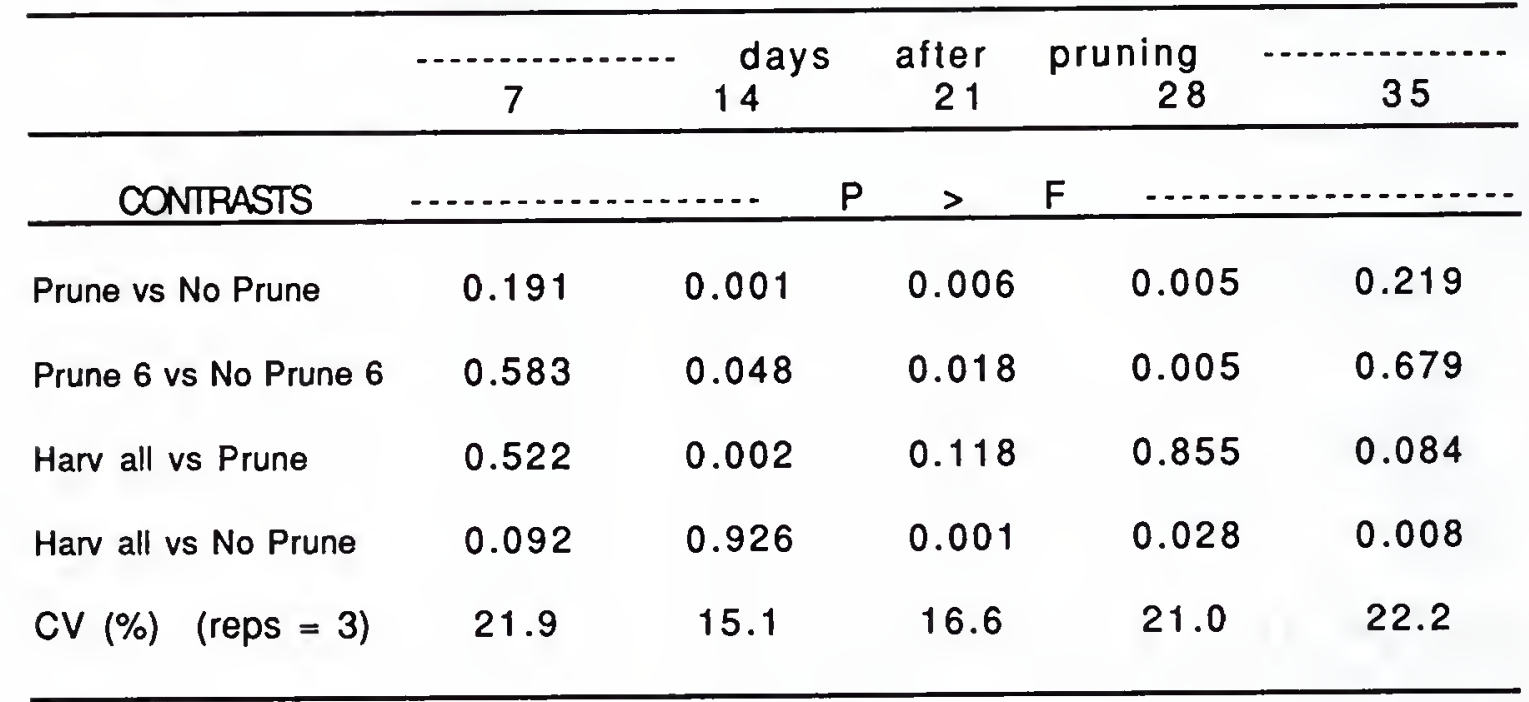




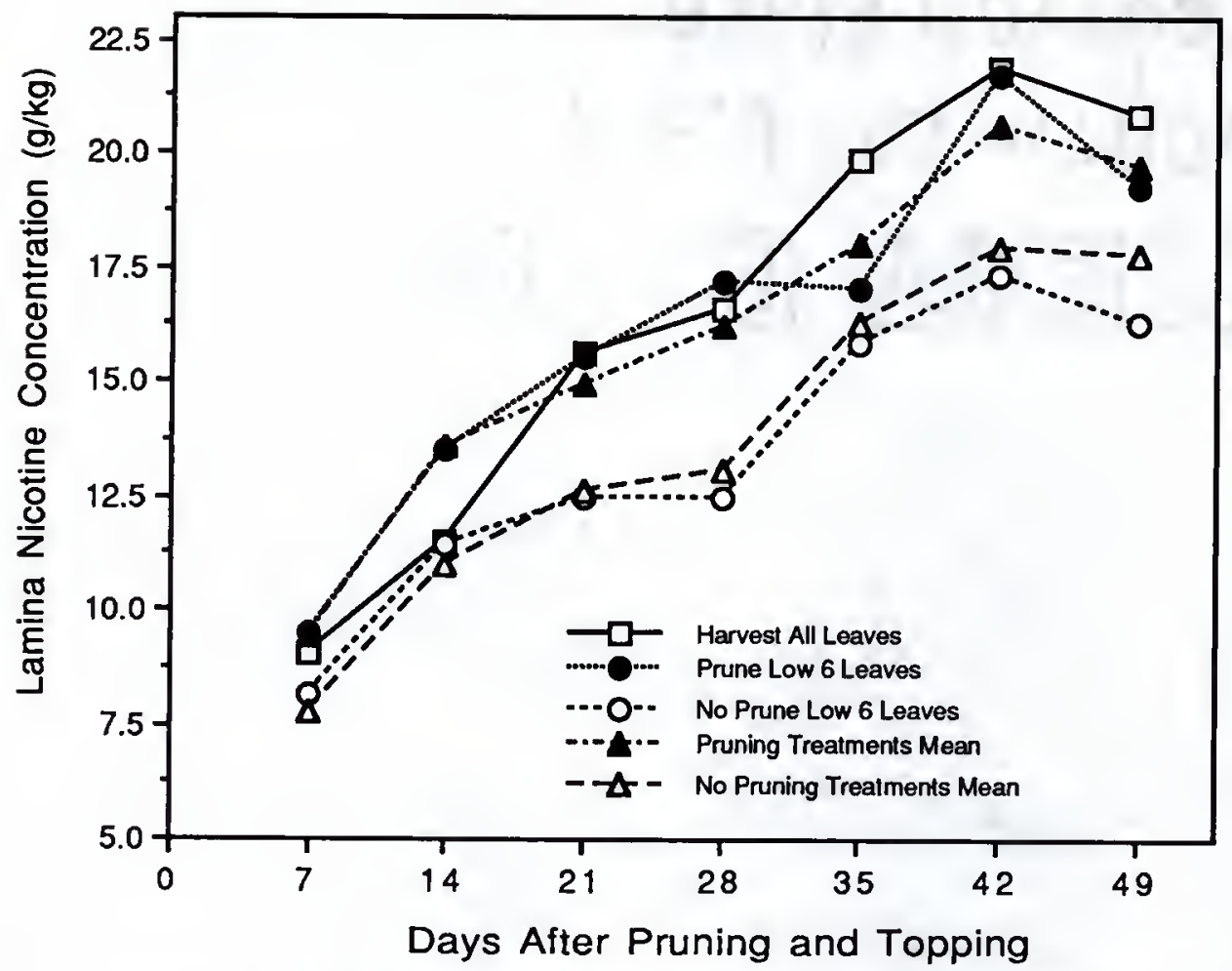

Fig. 4-3. Influence of lower leaf harvesting options on the lamina nicotine concentration of flue-cured tobacco leaf position 19-21. Appropriate contrasts are given below.

Table 4-5. Single degree of freedom contrasts for the data presented in Fig. 4-3.

\begin{tabular}{|c|c|c|c|c|c|c|c|}
\hline & 7 & 14 & $\begin{array}{c}\text { days } \\
21\end{array}$ & $\begin{array}{r}\text { after } \\
28\end{array}$ & $\begin{array}{l}\text { pruning } \\
35\end{array}$ & 42 & 49 \\
\hline CONTRASTS & $\ldots \ldots \ldots$ & $\ldots \ldots \ldots$ & $\mathbf{P}$ & $>$ & $\ldots$ & 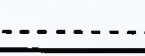 & $\ldots \ldots$ \\
\hline Prune vs No Prune & 0.035 & 0.001 & 0.007 & 0.004 & 0.171 & 0.019 & 0.009 \\
\hline Prune 6 vs No Prune 6 & 0.199 & 0.031 & 0.013 & 0.002 & 0.496 & 0.009 & 0.004 \\
\hline Harv all vs Prune & 0.710 & 0.020 & 0.461 & 0.856 & 0.241 & 0.345 & 0.197 \\
\hline Harv all vs No Prune & 0.203 & 0.525 & 0.004 & 0.100 & 0.026 & 0.006 & 0.001 \\
\hline CV (\%) Reps = 3 & 28.8 & 18.6 & 19.8 & 22.8 & 24.8 & 19.4 & 12.5 \\
\hline
\end{tabular}


treatments. Nicotine is synthesized in the roots and translocated to the shoot where it accumulates predominantly in the leaf (Wolf and Bates, 1964). Based on the nicotine concentration data over time, it seems likely that the lower leaves that remained on the plants acted as sinks for nicotine.

Nitrogen concentration was not affected by lower leaf harvesting. This response was surprising since the concentration of nicotine, a $\mathrm{N}$-containing compound, was decreased by not removing lower leaves. Leaf $\mathrm{N}$ concentration was found to increase in response to reproductive sink removal in soybean (Glycine max L. Merr.) (Kollman et al., 1974; Crafts-Brandner et al., 1984). The $\mathrm{N}$ concentration of composited leaf and stem tissue decreased as a result of leaf removal of grain sorghum (Serghum bicolor L. Moench) (Pauli and Stickler, 1961). However, delayed topping of flue-cured tobacco decreased the nicotine concentration in leaves with no affect on the $\mathrm{N}$ concentration (Woltz, 1955; Marshall and Seltmann, 1964; Elliot, 1966).

In the normal harvest study, the $\mathrm{N}$ to nicotine concentration ratio ( $\mathrm{N}: \mathrm{Nic})$ at LP 13-15 was higher as a result of not pruning the lowest six leaves (Table 4-6). The N:Nic at LPs 13-15 and 19-21 were also higher for the no pruning treatments over time (Fig. 4-4 \& Table 4-7, Fig. 4-5 \& Table 4-8). The responses for N:Nic largely paralleled those observed for nicotine concentration. Since $N$ concentration was not affected by pruning or not pruning lower leaves, the changes in the N:Nic were due primarily to changes in the nicotine concentration. Tso (1972) reported that an N:Nic approximating 1:1 was desirable for the best smoking quality of flue-cured tobacco leaves. While small differences in N:Nic were found among treatments and the N:Nic was always higher than $1: 1$, it is questionable whether the smoking quality would differ significantly among any of the imposed treatments. Weybrew et al. (1984) found that smoker preference, being a qualitative variable, and quantitative chemical measures were not always closely correlated. 
Table 4-6. Effects of lower leaf harvesting options on the $N$ to nicotine concentration ratio of flue-cured tobacco by leaf position (normal harvest study).

\begin{tabular}{|c|c|c|c|}
\hline $\begin{array}{l}\text { Lower Leaf } \\
\text { Han. Options } \\
\end{array}$ & $7 \cdot 9$ & $\begin{array}{c}\text { leaf } \\
13-15 \\
\end{array}$ & $19-21$ \\
\hline & $N$ to & nicotine concentration & ratio \\
\hline Harv all 21 leaves & 1.29 & 1.14 & 1.10 \\
\hline Prune low 3 leaves & 1.27 & 1.17 & 1.10 \\
\hline No prune low 3 leaves & 1.27 & 1.16 & 1.09 \\
\hline Prune low 6 leaves & 1.25 & 1.16 & 1.10 \\
\hline No prune low 6 leaves & 1.34 & 1.29 & 1.15 \\
\hline Prune Treats mean & 1.26 & 1.17 & 1.10 \\
\hline No Prune Treats mean & 1.31 & 1.23 & 1.12 \\
\hline
\end{tabular}

\begin{tabular}{lcccc}
\hline \multicolumn{1}{c}{ CONTRASTS } & & & & \\
Prune vs No Prune & 0.246 & 0.120 & 0.555 \\
Prune 6 vs No Prune 6 & 0.094 & 0.016 & 0.332 \\
Harv all vs Prune & 0.563 & 0.515 & 0.967 \\
Harv all vs No Prune & 0.708 & 0.057 & 0.659 \\
CV (\%) (reps $=4)$ & 11.5 & 11.7 & 13.1 \\
\hline
\end{tabular}




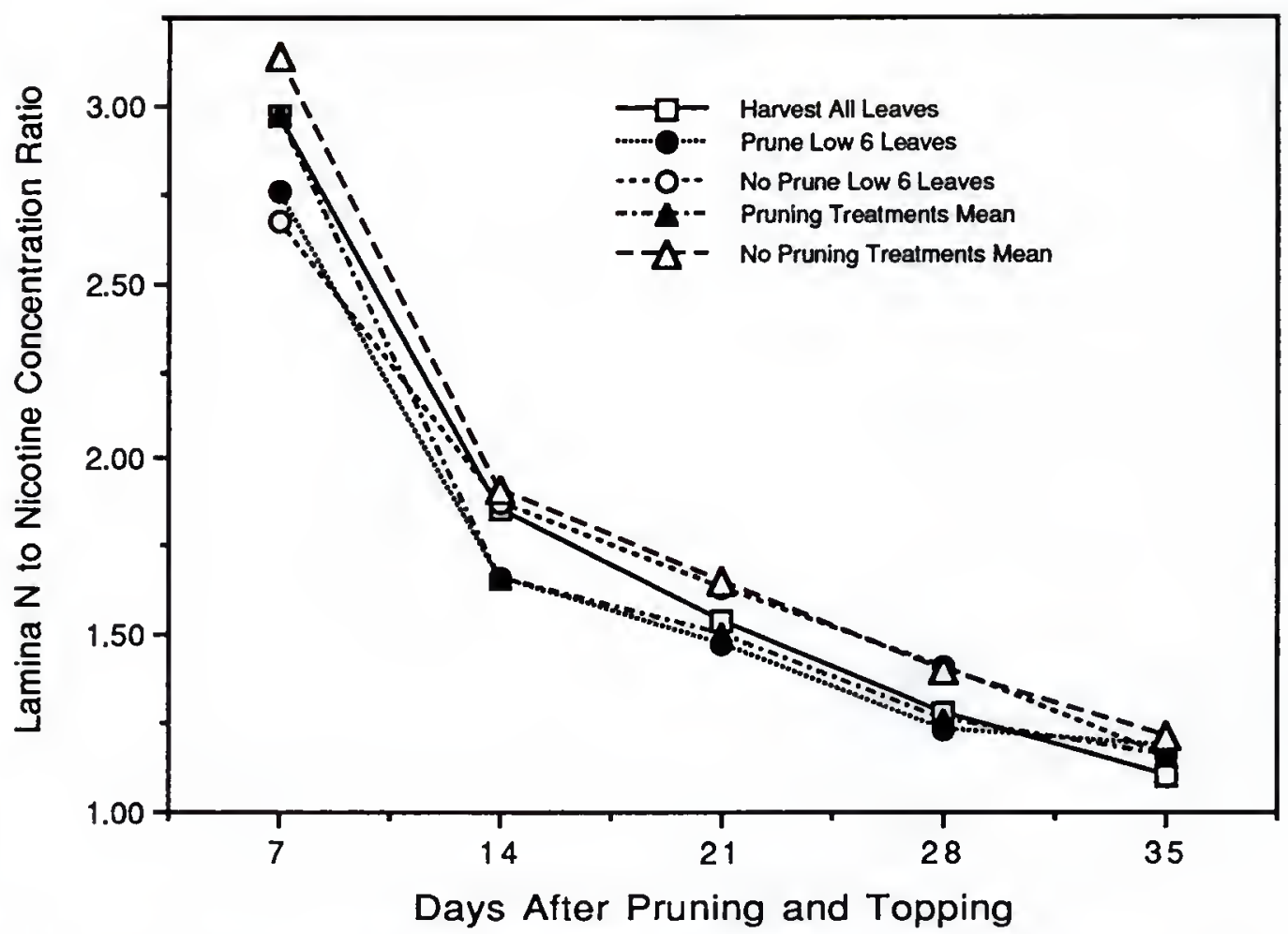

Fig. 4-4. Influence of lower leaf harvesting options on lamina $N$ to nicotine concentration ratio of flue-cured tobacco leaf position 13-15. Appropriate contrasts are given below.

Table 4-7. Single degree of freedom contrasts for the data presented in Fig. 4-4.

\begin{tabular}{|c|c|c|c|c|c|}
\hline & 7 & $\begin{array}{l}\text { days } \\
14\end{array}$ & $\begin{array}{r}\text { after } \\
21\end{array}$ & $\begin{array}{r}\text { pruning } \\
28\end{array}$ & 35 \\
\hline CONIRASTS & - n & $\ldots$. & $>$ & $\ldots \ldots$ & $\ldots$ \\
\hline Prune vs No Prune & 0.464 & 0.007 & 0.045 & 0.001 & 0.148 \\
\hline Prune 6 vs No Prune 6 & 0.802 & 0.097 & 0.132 & 0.006 & 0.524 \\
\hline Harv all vs Prune & 0.983 & 0.065 & 0.589 & 0.547 & 0.138 \\
\hline Harv all vs No Prune & 0.563 & 0.652 & 0.256 & 0.029 & 0.015 \\
\hline CV $(\%) \quad($ reps $=3)$ & 27.7 & 16.9 & 15.4 & 10.8 & 9.7 \\
\hline
\end{tabular}




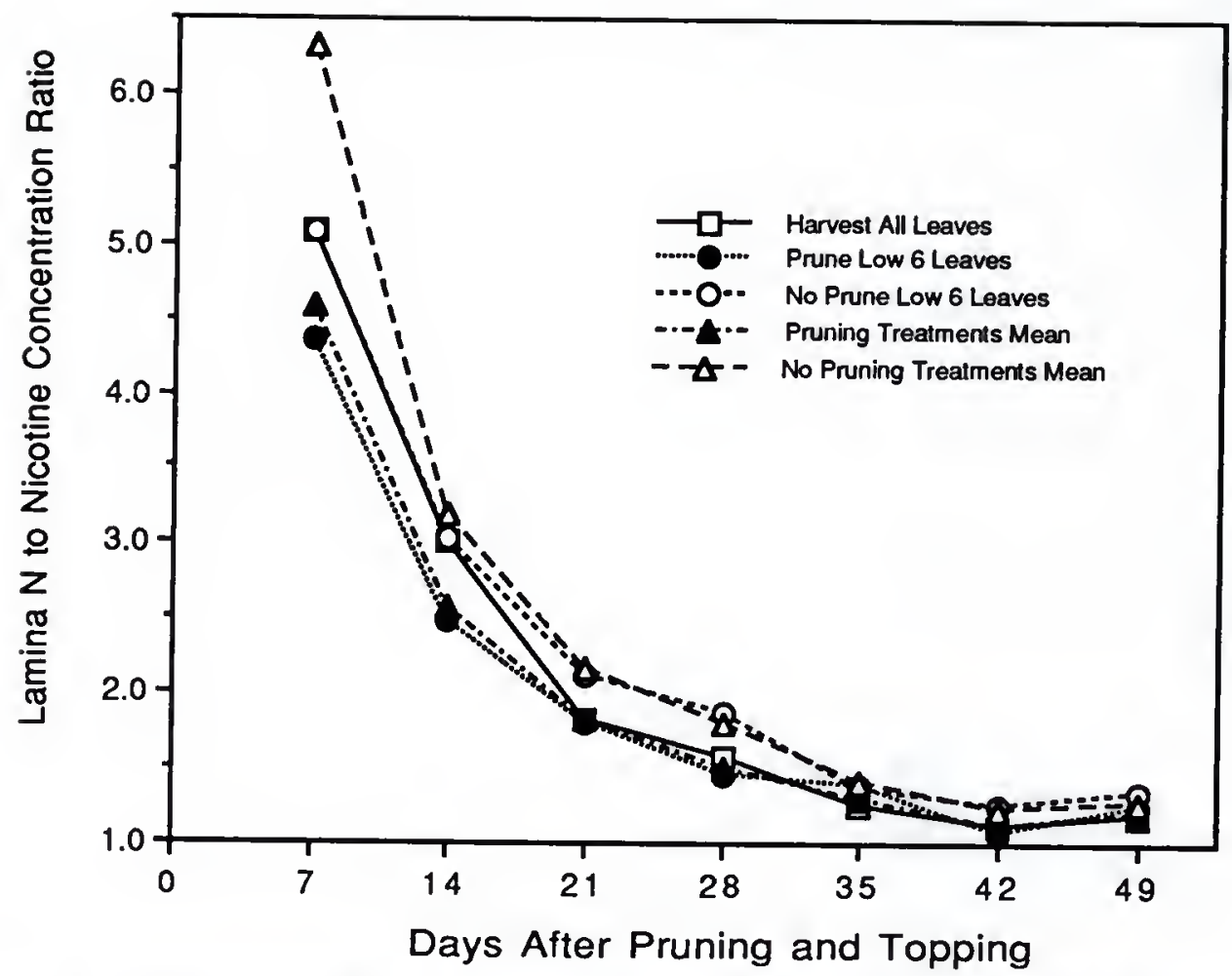

Fig. 4-5. Influence of lower leaf harvesting options on lamina $\mathbf{N}$ to nicotine concentration ratio of flue-cured tobacco leaf position 19-21. Appropriate contrasts are given below.

Table 4-8. Single degree of freedom contrasts for the data presented in Fig. 4-5.

\begin{tabular}{|c|c|c|c|c|c|c|c|}
\hline & 7 & 14 & $\begin{array}{c}\text { days } \\
21\end{array}$ & $\begin{array}{r}\text { after } \\
28 \\
\end{array}$ & $\begin{array}{c}\text { pruning } \\
35\end{array}$ & 42 & 49 \\
\hline CONTRASTS & $\ldots \ldots$ & $\ldots \ldots$ & $P$ & $>$ & $\ldots$ & 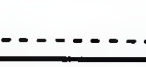 & \\
\hline Prune vs No Prune & 0.049 & 0.002 & 0.002 & 0.003 & 0.038 & 0.002 & 0.017 \\
\hline Prune 6 vs No Prune 6 & 0.543 & 0.039 & 0.030 & 0.003 & 0.891 & 0.001 & 0.023 \\
\hline Harv all vs Prune & 0.045 & 0.061 & 0.962 & 0.463 & 0.507 & 0.816 & 0.913 \\
\hline Harv all vs No Prune & 0.013 & 0.390 & 0.009 & 0.065 & 0.021 & 0.016 & 0.038 \\
\hline CV (\%) Reps = 3 & 54.5 & 21.2 & 17.1 & 18.8 & 13.2 & 9.8 & 9.6 \\
\hline
\end{tabular}


The reducing sugar concentration of leaves from LP 7-9 were higher when lower leaves were not pruned or harvested, both over time and in the normal harvest study (Table 4-9, Fig. 4-6 \& Table 4-10). Higher leaf carbohydrate levels resulted when reproductive sinks were removed from soybean and corn (McAlister and Krober, 1958; Allison and Weinmann, 1970; Kollmann et al., 1974; Ciha and Brun, 1978; Mondal et al., 1978; Streeter and Jeffers, 1979; Crafts-Brandner et al.,1984). Pauli and Stickler (1961) reported lower plant tissue carbohydrate concentration in grain sorghum resulted from defoliation. Total non-structural carbohydrate (TNC) concentration at LP 7-9 was not affected by harvesting treatments. Intuitively, a higher reducing sugar concentration should be the result of a higher TNC concentration. As discussed in Chapter 2, the reducing sugar concentration changed proportionally with the TNC concentration at LPS 13-15 and 19-21, however, reducing sugar concentration did not change proportionally with TNC concentration at LP 7-9.

The reducing sugar to nicotine concentration ratio (Sug:Nic) was higher at LP 79 and LP 13-15 from the normal harvest study in response to not pruning or discarding lower leaves (Table 4-11). The Sug:Nic of the leaves from LP 7-9 was higher because of a combination of higher sugar concentration and lower nicotine concentration when the lower leaves were not pruned or harvested. However, a higher Sug:Nic at LP 13-15 solely resulted from a higher nicotine concentration. Over time, the Sug:Nic of leaves within LPs 7-9, 13-15, and 19-21 varied due to the effects of either pruning, not pruning or harvesting, or harvesting the lower leaves in the normal manner (Fig. 4-7 \& Table 4-12, Fig. 4-8 \& Table 4-13, Fig. 4-9 \& Table 4-14). Mineral Characteristics

Phosphorus was the only mineral whose concentration was responsive to the harvesting treatments. In the normal harvest study, the $\mathrm{P}$ concentrations in leaves from LPS 7-9 and 13-15 were lower as a result of not pruning or harvesting the lower 
Table 4-9. Effects of lower leaf harvesting options on the reducing sugar concentration of flue-cured tobacco by leaf position (normal harvest study).

\begin{tabular}{|c|c|c|c|c|}
\hline $\begin{array}{l}\text { Lower Leaf } \\
\text { Harv. Options } \\
\end{array}$ & $7-9$ & $\begin{array}{r}\text { leaf } \\
1\end{array}$ & $\begin{array}{l}\text { position } \\
13-15 \\
\end{array}$ & $19-21$ \\
\hline & .......... reducing & sugar & concentration & $\left(g \mathrm{~kg}^{-1}\right)$ \\
\hline Harv all 21 leaves & 234.5 & & 210.6 & 148.3 \\
\hline Prune low 3 leaves & 232.3 & & 217.8 & 143.9 \\
\hline No prune low 3 leaves & 241.8 & & 214.0 & 147.7 \\
\hline Prune low 6 leaves & 231.9 & & 217.6 & 141.9 \\
\hline No prune low 6 leaves & 255.0 & & 224.0 & 151.3 \\
\hline Prune Treats mean & 232.1 & & 217.7 & 142.9 \\
\hline No Prune Treats mean & 248.4 & & 219.0 & 149.5 \\
\hline CONIRASTS & - n & $\mathbf{P}$ & - & (n) \\
\hline Prune vs No Prune & 0.006 & & 0.791 & 0.206 \\
\hline Prune 6 vs No Prune 6 & 0.006 & & 0.361 & 0.205 \\
\hline Harv all vs Prune & 0.728 & & 0.248 & 0.399 \\
\hline Harv all vs No Prune & 0.052 & & 0.172 & 0.847 \\
\hline CV (\%) (reps $=4)$ & 9.5 & & 9.1 & 14.0 \\
\hline
\end{tabular}




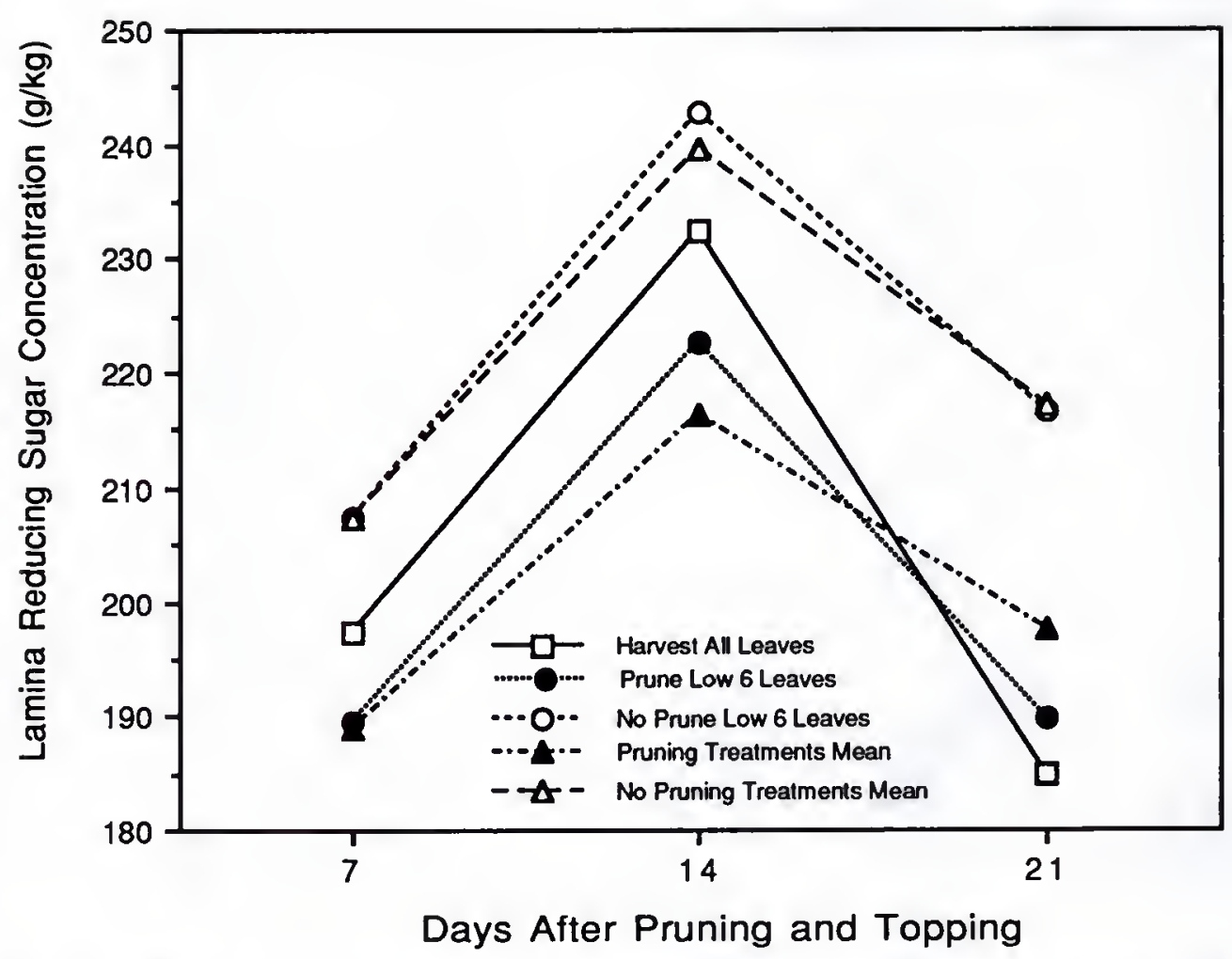

Fig. 4-6. Influence of lower leaf harvesting options on reducing sugar concentration of flue-cured tobacco leaf position 7-9. Appropriate contrasts are given below.

Table 4-10. Single degree of freedom contrasts for the data presented in Fig. 4-6.

\begin{tabular}{|c|c|c|c|c|c|}
\hline & 7 & days & $\begin{array}{r}\text { after } \\
14\end{array}$ & pruning & 21 \\
\hline CONTRASTS & 等 & $\ldots$ & $\mathrm{P}$ & $\ldots$ & $\ldots$ \\
\hline Prune vs No Prune & 0.104 & & 0.057 & & 0.025 \\
\hline Prune 6 vs No Prune 6 & 0.259 & & 0.234 & & 0.032 \\
\hline Harv all vs Prune & 0.543 & & 0.274 & & 0.225 \\
\hline Harv all vs No Prune & 0.457 & & 0.623 & & 0.004 \\
\hline CV $(\%) \quad($ reps $=3)$ & 19.4 & & 17.9 & & 14.4 \\
\hline
\end{tabular}


Table 4-11. Effects of lower leaf harvesting options on the reducing sugar to nicotine concentration ratio of flue-cured tobacco by leaf position (normal harvest study).

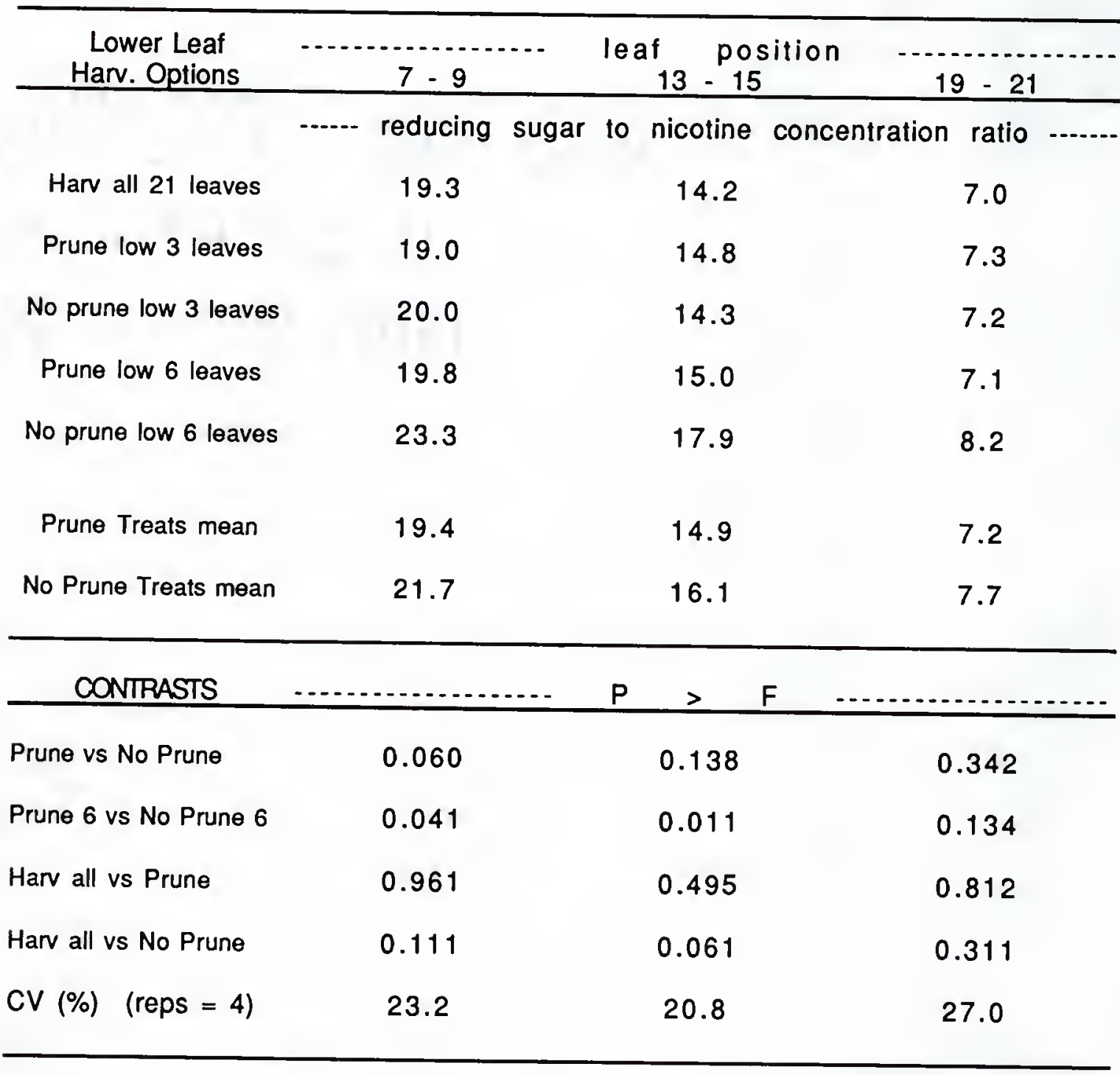




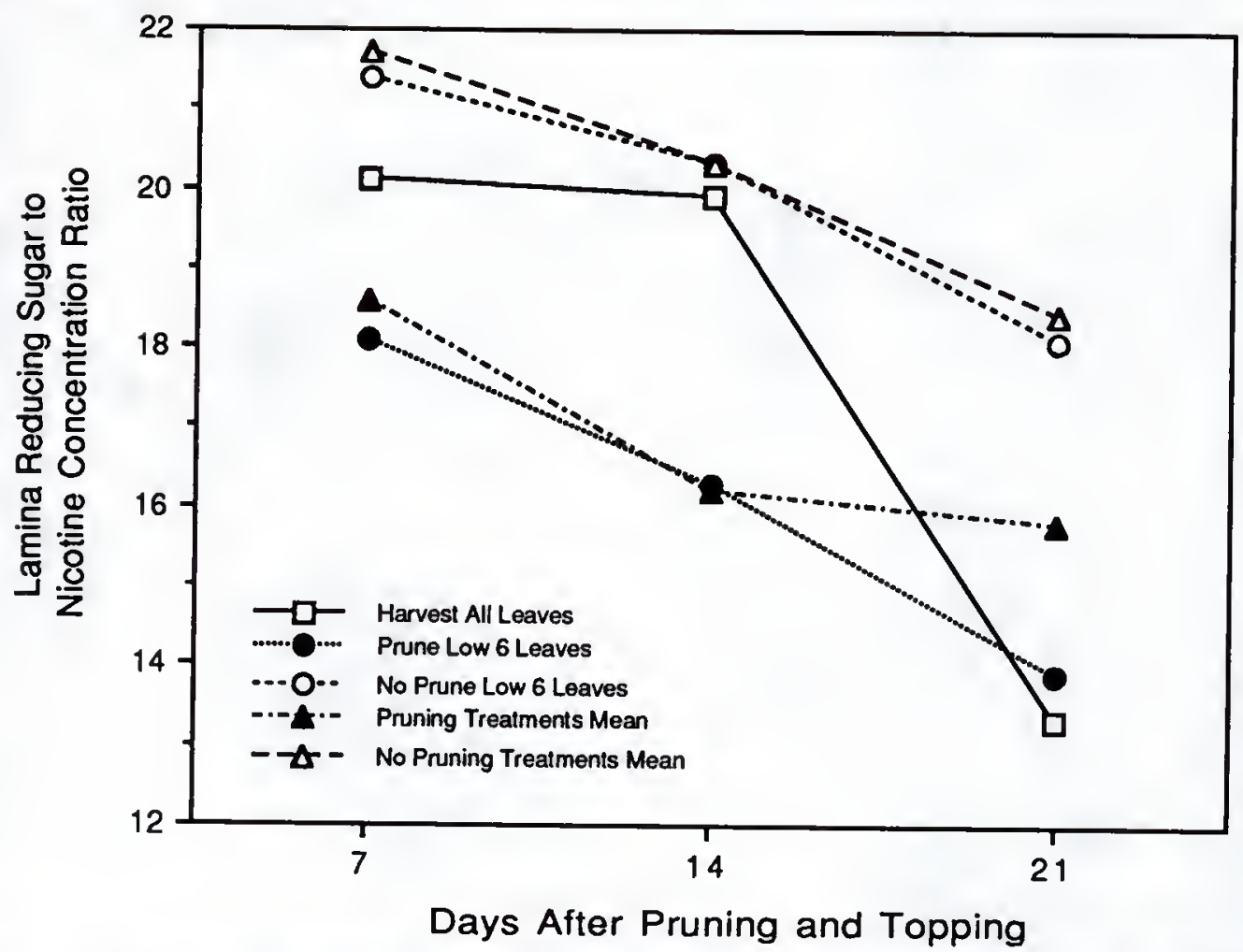

Fig. 4-7. Influence of lower leaf harvesting options on reducing sugar to nicotine concentration ratio of flue-cured tobacco leaf position 7-9. Appropriate contrasts are given below.

Table 4-12. Single degree of freedom contrasts for the data presented in Fig. 4-7.

\begin{tabular}{|c|c|c|c|c|c|}
\hline & 7 & days & $\begin{array}{r}\text { after } \\
14\end{array}$ & pruning & 21 \\
\hline CONTRASTS & $\ldots$ & $\ldots$ & $\mathrm{P}$ & $F$ & , \\
\hline Prune vs No Prune & 0.101 & & 0.007 & & 0.033 \\
\hline Prune 6 vs No Prune 6 & 0.208 & & 0.055 & & 0.016 \\
\hline Harv all vs Prune & 0.517 & & 0.040 & & 0.081 \\
\hline Harv all vs No Prune & 0.474 & & 0.837 & & 0.001 \\
\hline CV $(\%) \quad($ reps $=3)$ & 31.4 & & 26.4 & & 24.5 \\
\hline
\end{tabular}




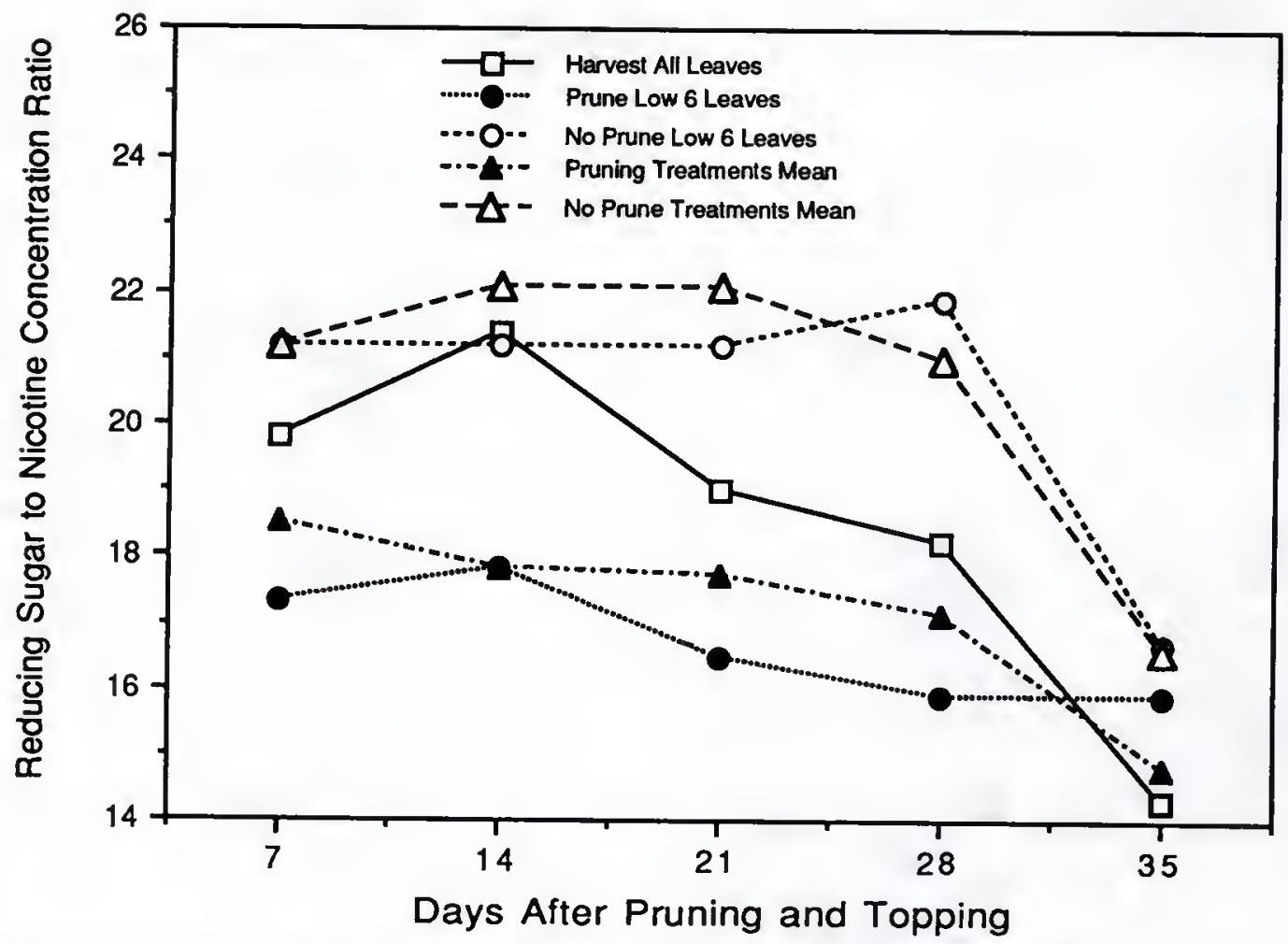

Fig. 4-8. Influence of lower leaf harvesting options on reducing sugar to nicotine concentration ratio of flue-cured tobacco leaf position 13-15. Appropriate contrasts are given below.

Table 4-13. Single degree of freedom contrasts for the data presented in Fig. 4-8.

\begin{tabular}{|c|c|c|c|c|c|}
\hline & 7 & $\begin{array}{l}\text { days } \\
14\end{array}$ & $\begin{array}{r}\text { after } \\
21\end{array}$ & $\begin{array}{r}\text { pruning } \\
28\end{array}$ & 35 \\
\hline CONIRASTS & - $\ldots \ldots \ldots \ldots$ & $\ldots$ & $P$ & $\ldots \ldots$ & (n) \\
\hline Prune vs No Prune & 0.187 & 0.009 & 0.001 & 0.007 & 0.067 \\
\hline Prune 6 vs No Prune 6 & 0.186 & 0.131 & 0.011 & 0.004 & 0.572 \\
\hline Harv all vs Prune & 0.596 & 0.070 & 0.081 & 0.516 & 0.711 \\
\hline Harv all vs No Prune & 0.575 & 0.692 & 0.001 & 0.103 & 0.064 \\
\hline CV (\%) (reps = 3) & 35.7 & 27.2 & 22.8 & 24.8 & 22.1 \\
\hline
\end{tabular}




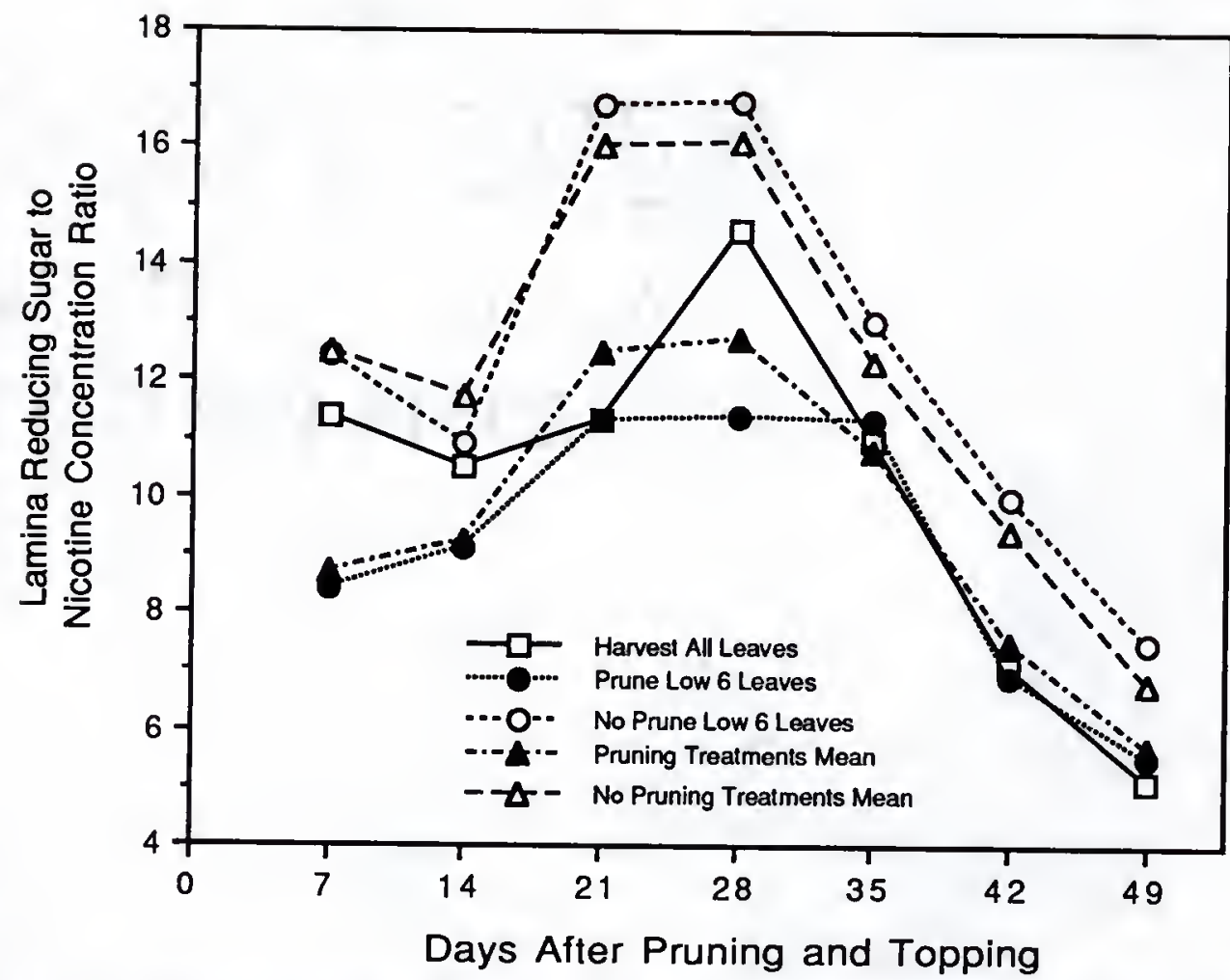

Fig. 4-9. Influence of lower leaf harvesting options on reducing sugar to nicotine concentration ratio of flue-cured tobacco leaf position 19-21. Appropriate contrasts are given below.

Table 4-14. Single degree of freedom contrasts for the data presented in Fig. 4-9.

\begin{tabular}{|c|c|c|c|c|c|c|c|}
\hline & 7 & 14 & $\begin{array}{c}\text { days } \\
21\end{array}$ & $\begin{array}{r}\text { after } \\
28\end{array}$ & $\begin{array}{c}\text { pruning } \\
35\end{array}$ & 42 & 49 \\
\hline CONTRASTS & $\ldots \ldots$ & $\ldots \ldots \ldots$ & $P$ & $>$ & $\ldots$ & - - & \\
\hline Prune vs No Prune & 0.032 & 0.038 & 0.010 & 0.021 & 0.124 & 0.004 & 0.001 \\
\hline Prune 6 vs No Prune 6 & 0.105 & 0.277 & 0.005 & 0.010 & 0.212 & 0.001 & 0.001 \\
\hline Harv all vs Prune & 0.254 & 0.349 & 0.444 & 0.290 & 0.890 & 0.628 & 0.182 \\
\hline Harv all vs No Prune & 0.655 & 0.420 & 0.005 & 0.374 & 0.259 & 0.005 & 0.001 \\
\hline CV (\%) Reps = 3 & 54.0 & 38.3 & 32.2 & 33.7 & 28.7 & 26.4 & 18.8 \\
\hline
\end{tabular}


leaves (Table 4-15). Differences in the P concentrations at LPS 7-9 and 13-15 due to not removing lower leaves were also found over time (Fig. 4-10 \& Table 4-16, Fig. 411 \& Table 4-17). Soybean pod pruning increased $P$ concentration in the leaves (Kollman et al., 1974; Crafts-Brandner et al., 1984). Whereas soybean depodding involves removal of a strong sink for $P$, the $P$ concentrations of leaves likely differed in the present study because the lower leaves that were not pruned or harvested acted as a sink for $P$.

\section{Conclusions}

The quality of the cured leaf is affected by the ratios of the chemical components of the leaf. If the chemical characteristics of the control (harvest all leaves) treatment were used as standards, some generalizations can be made about the effects of the lower leaf harvesting. The leaf chemical balance of the lower leaf pruning treatments more closely approximated that of the control. When lower leaves were left on the plant, nicotine dilution in the remaining leaves was the most obvious response. The lower nicotine concentration resulted in higher than normal $N$ to nicotine and reducing sugar to nicotine concentration ratios. Phosphorous concentration of leaves from LPs 7-9 and 13-15 were lowered in response to not pruning or harvesting the lower leaves. The concentration of other minerals were not affected by lower leaf harvesting.

Interesting responses occurred as a result of pruning, not pruning, or normal harvesting, of lower leaves over time. Over the first 14 days after pruning, the chemical and mineral characteristics were similar for the leaves above those which were either not pruned or were harvested normally. However, as normal harvesting of lower leaves progressed, the chemical and mineral characteristics of leaves above those normally harvested approached those observed for the same leaves when lower leaves were pruned and discarded. 
Table 4-15. Effects of lower leaf harvesting options on the P concentration of fluecured tobacco by leaf position (normal harvest study).

\begin{tabular}{|c|c|c|c|c|}
\hline $\begin{array}{l}\text { Lower Leaf } \\
\text { Harv. Options } \\
\end{array}$ & $7-9$ & $-\cdot$ & $\begin{array}{c}\text { leaf } \\
13-15 \\
\end{array}$ & $19-21$ \\
\hline & - & $P$ & concentration $\quad$ (g & $\left.k g^{-1}\right)$ \\
\hline Harv all 21 leaves & 3.23 & & 3.05 & 3.32 \\
\hline Prune low 3 leaves & 3.31 & & 3.12 & 3.17 \\
\hline No prune low 3 leaves & 3.28 & & 2.96 & 3.18 \\
\hline Prune low 6 leaves & 3.43 & & 3.03 & 3.10 \\
\hline No prune low 6 leaves & 3.05 & & 2.81 & 3.42 \\
\hline Prune Treats mean & 3.37 & & 3.08 & 3.14 \\
\hline No Prune Treats mean & 3.14 & & 2.87 & 3.33 \\
\hline
\end{tabular}

\begin{tabular}{lccc}
\multicolumn{1}{c}{ CONTRASTS } & P & $>$ & $F$ \\
Prune vs No Prune & 0.009 & 0.011 & 0.203 \\
Prune 6 vs No Prune 6 & 0.001 & 0.032 & 0.078 \\
Harv all vs Prune & 0.133 & 0.752 & 0.220 \\
Harv all vs No Prune & 0.482 & 0.070 & 0.852 \\
CV (\%) (reps $=4)$ & 9.1 & 9.7 & 15.5 \\
\hline
\end{tabular}




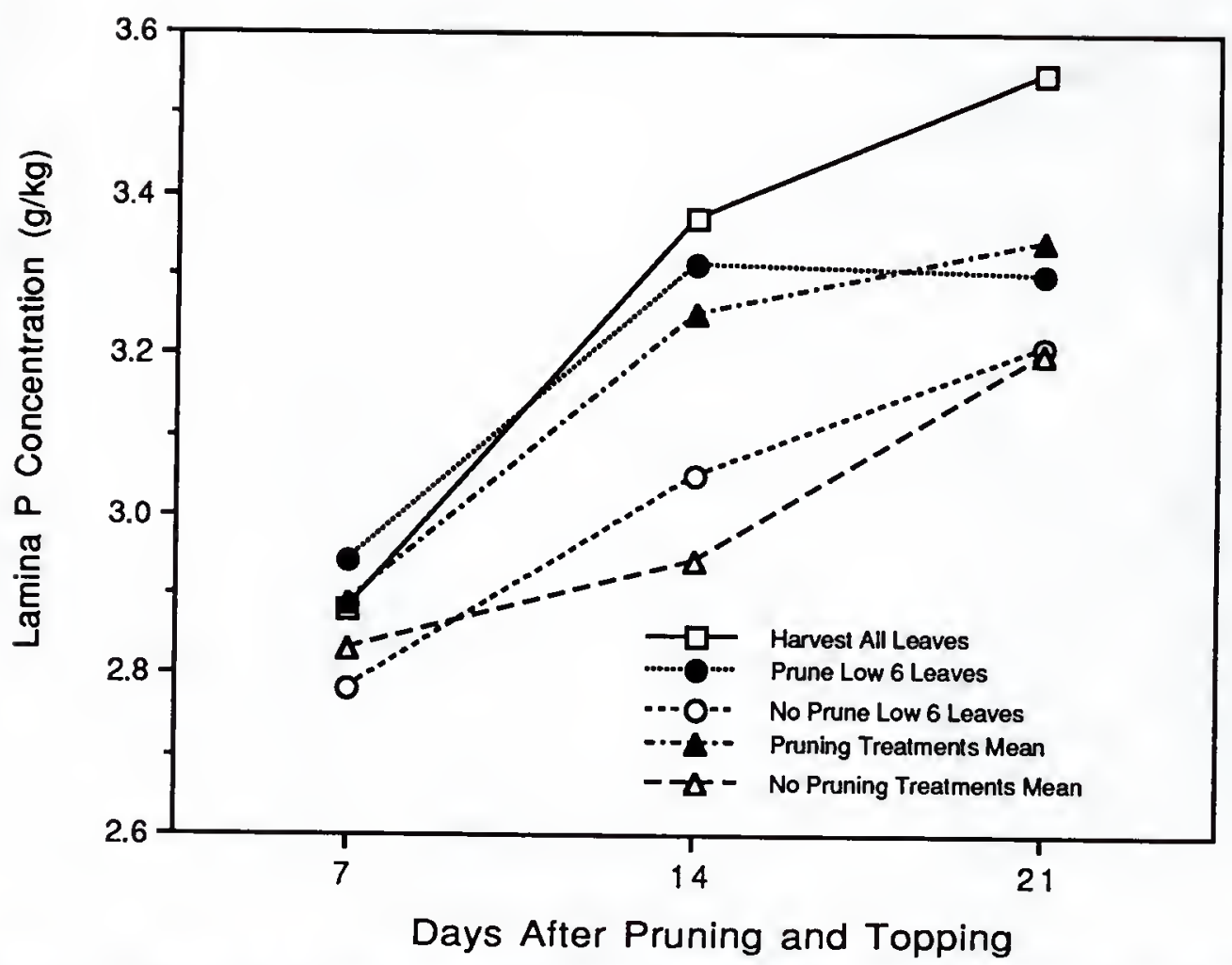

Fig. 4-10. Influence of lower leaf harvesting options on the $P$ concentration of fluecured tobacco leaf position 7-9. Appropriate contrasts are given below.

Table 4-16. Single degree of freedom contrasts for the data presented in Fig. 4-10.

\begin{tabular}{|c|c|c|c|c|c|c|}
\hline & 7 & da & & $\begin{array}{r}\text { after } \\
14\end{array}$ & pruning & 21 \\
\hline CONIRASTS & 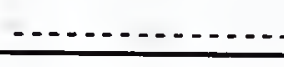 & $\ldots$ & & $>$ & $F$ & n \\
\hline Prune vs No Prune & 0.601 & & & 0.079 & & 0.242 \\
\hline Prune 6 vs No Prune 6 & 0.293 & & & 0.289 & & 0.589 \\
\hline Harv all vs Prune & 0.999 & & & 0.552 & & 0.162 \\
\hline Han all vs No Prune & 0.669 & & & 0.045 & & 0.022 \\
\hline CV (\%) (reps = 3) & 13.4 & & & 18.7 & & 12.4 \\
\hline
\end{tabular}




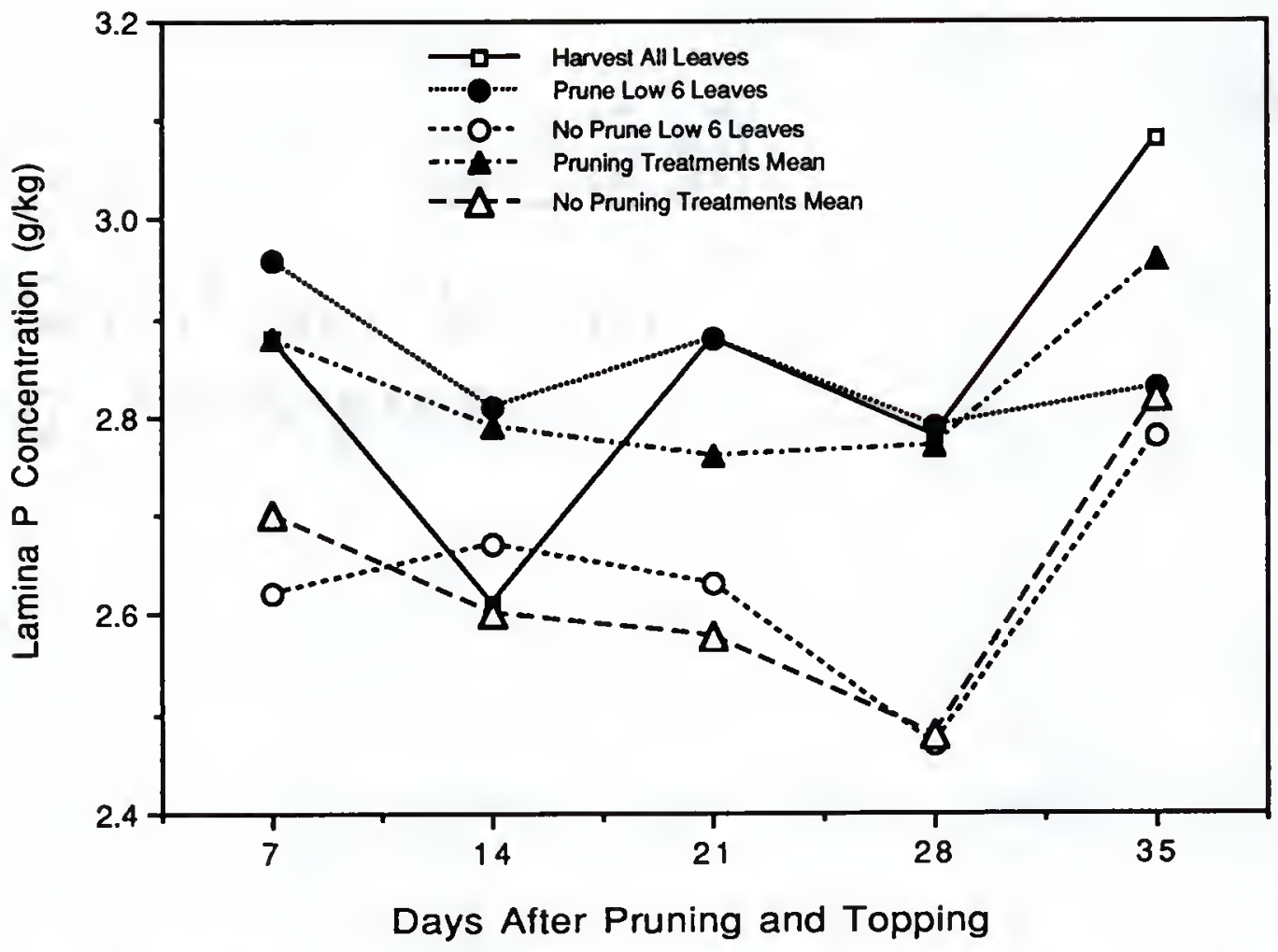

Fig. 4-11. Influence of lower leaf harvesting options on the $P$ concentration of fluecured tobacco leaf position 13-15. Appropriate contrasts are given below.

Table 4-17. Single degree of contrasts for the data presented in Fig. 4-11.

\begin{tabular}{|c|c|c|c|c|c|c|}
\hline & 7 & $\begin{array}{l}\text { days } \\
14\end{array}$ & & $\begin{array}{r}\text { after } \\
21\end{array}$ & $\begin{array}{r}\text { pruning } \\
28\end{array}$ & 35 \\
\hline CONTRASTS & $\ldots \ldots$ & $\ldots .$. & $P$ & $>$ & $\ldots$ & $\ldots \ldots \ldots \ldots$ \\
\hline Prune vs No Prune & 0.047 & 0.045 & & 0.092 & 0.005 & 0.278 \\
\hline Prune 6 vs No Prune 6 & 0.009 & 0.284 & & 0.104 & 0.024 & 0.743 \\
\hline Harv all vs Prune & 0.999 & 0.130 & & 0.357 & 0.890 & 0.403 \\
\hline Harv all vs No Prune & 0.101 & 0.883 & & 0.025 & 0.014 & 0.090 \\
\hline CV (\%) (reps = 3) & 10.7 & 11.9 & & 13.5 & 12.7 & 14.7 \\
\hline
\end{tabular}




\section{CHAPTER 5 \\ SUMMARY AND CONCLUSIONS}

The effects of five lower leaf harvesting treatments involving the lowest three or six leaves on flue-cured tobacco (Nicotiana tabacum L.) plants were evaluated in 1989 and 1990. Previous work had suggested there were positive effects on yield and value associated with pruning and discarding lower leaves and negative effects on yield when the same lower leaves were not pruned or harvested. The lower leaf harvesting treatments were evaluated in situ on plants having exactly 21 leaves. Inherent differences in the yield, chemical, and mineral properties of tobacco leaves in relation to the position or node on the stalk at which leaves are formed have been reported. The 21 leaves were partitioned into seven, 3-leaf positions (LP) for harvesting purposes. Controlling leaf number per plant and acquiring a given number of leaves per harvest enabled a strict evaluation of the effects that lower leaf harvesting methods had on the leaves above those involved in the treatments.

The characteristics of the leaves comprising a given LP were monitored under two harvesting regimes. One harvesting regime involved harvesting leaves at a single LP as they matured on the plant. This regime was termed normal harvest because it was similar to the farmer's production practices. The other harvesting regime involved weekly harvests of all LPs remaining on plants coinciding with the treatments in the normal harvest study. This regime was termed whole plant harvesting because the leaves within a given LP were monitored over the duration that each LP remained on the plant, i.e. up to full maturity and normal harvesting. The whole plant harvesting regime allowed any treatment effects observed at a given LP under normal harvesting to be monitored over time, i.e. as leaves at an LP developed. 
Data are lacking that describe the agronomic, chemical, and mineral properties of currently-grown flue-cured tobacco cultivars by LP. The control treatment and the two treatments involving pruning or not harvesting the lowest three leaves did not result in significant effects for any parameters examined. Consequently, data from those three treatments were used to provide information on the agronomic, chemical, and mineral characteristics of flue-cured tobacco leaves harvested when the leaves were mature (normal harvesting) or over time after topping to monitor changes with leaf development.

\section{Characterization of Flue-Cured Tobacco Leaves}

There were inherent differences in the agronomic, chemical, and mineral characteristics of the tobacco leaves based on the position or nodes on the stalk at which leaves were formed. Yield, value, and nicotine and $\mathrm{N}$ concentrations increased with higher leaves. The reducing sugar concentration and the concentration ratios of $N$ to nicotine and reducing sugar to nicotine were highest in the middle leaves. The $\mathrm{Ca}, \mathrm{Mg}$, and $\mathrm{K}$ concentrations were highest in the lowest leaves and generally decreased to the highest leaves. Phosphorous concentration was similar for all leaves.

Tobacco companies depend on the differences in the characteristics of tobacco leaves to manufacture their products. The fact that leaf chemical components were different depending upon the position on the stalk at which leaves were formed would discourage large harvests which mix different leaf groups.

At topping, there were distinct differences in the agronomic, chemical, and mineral characteristics of leaves dependent upon the position on the stalk. These differences were the result of leaf age. Over time after topping, the agronomic, chemical, and mineral properties of the youngest leaves changed the most. The lowest nine leaves were near maturity at topping and few changes in their agronomic, chemical, or mineral characteristics occurred from topping to final harvest. The characteristics 
of the upper 12 leaves changed signifcantly over time. The changes depended upon the age of the leaves with more extreme changes with younger leaves.

\section{Lower Leaf Harvesting}

Pruning and discarding the lower three or six leaves was no more advantageous than not pruning or harvesting the same leaves because yields and values for the respective treatments were equal. In short, the remaining leaves in the present study did not compensate for the loss of the dry matter by pruning. Yields and values were lower for treatments that involved not harvesting lower leaves than those observed for the control treatment. This yield and value loss was associated with a reduction in the total number of leaves harvested from 21 to 18 to 15 . However, not harvesting three or more lower leaves increased the average value per kilogram, cured weight yield, and specific cured leaf weight. More cured leaf resulted from less fresh weight coupled with a higher average price. The implications of this result are that the tobacco crop may be cheaper to handle and cure per unit, and would likely result in a higher profit per unit.

In the present study, the pruned lower leaves were handled as normal harvests to evaluate what their potential contribution would have been to the respective treatments. The addition of the yields and values of these pruned leaves to their respective treatments resulted in there being no differences for any agronomic parameters between the pruning treatments with 21 total leaves and the control treatment which also had 21 total leaves.

Nicotine and $\mathrm{P}$ concentrations were lower in the leaves above those that were not pruned or harvested, however, $\mathrm{N}$ concentration was not affected by lower leaf harvesting. Reducing sugar concentration was lower in the leaves comprising LP 7-9 only. The lower nicotine concentration associated with not removing lower leaves caused differences in the $\mathrm{N}$ to nicotine and nicotine to reducing sugar concentration ratios.

For the first 14 days after pruning, the leaf chemical concentrations were similar for treatments involving normal harvesting of lower leaves and not harvesting 
lower leaves. However, as normal harvesting progressively removed lower leaves, the chemical characteristics of leaves under normal harvesting were similar to leaves from treatments that involved pruning of lower leaves. Leaves were pruned at topping, and normal harvest of the lowest three leaves was not initiated until seven days after topping. Consequently, the lowest six leaves were not completely removed from the control plants until 14 days after topping. Pruning lower leaves allowed chemical compounds to accumulate in less leaf area resulting in the higher chemical concentrations initially. But, over time as leaves were harvested from control plants, equal leaf numbers per plant were attained for both the pruning treatments and the control resulting in the control treatment accumulating chemical compounds in less leaf area as well. However, the no pruning treatments always had the lower leaves on the plants and those leaves likely acted as sinks for nicotine and $P$.

In summary, lower leaf pruning did not result in equal yields to a control. Some previous work on this subject indicated that pruning lower leaves was advantageous because yields were not reduced. In those studies, leaf number per plant was not explicitly controlled, i.e. leaf numbers were not actually counted. The assumption that topping to an equivalent height will result in an equivalent leaf number can be erroneous. (There are no published data on this claim, but from the author's experience with this and other studies that involve topping to a given leaf number, plant heights at a given leaf number vary greatly.) If topping height is used as a point of reference for leaf number, and more leaves than planned remain, equivalent yields due to the treatment could be inferred when actually leaf number was the compensating factor.

At topping, the lowest leaves that were pruned had reached maturity. Given that the lowest leaves are mature at topping, pruning those leaves should not cause an increase in the yield of the leaves above those pruned. In the present study, yield lost due to pruning was not compensated for by increased weights of the remaining leaves. Neither did not pruning or harvesting lower leaves affect yield of remaining leaves. 
However, the average value per kilogram was enhanced by not harvesting three or more lower leaves because these leaves were the lowest in value. The average cured weight yield and specific cured leaf weight were improved by not harvesting lower leaves as well because the lower leaves were the thinnest and likely had the highest water percentage of any leaves.

The bottom line on not harvesting lower leaves is that yield will be lost unless additional leaves are added by topping to a higher leaf number. Based on the yield data from each LP, one extra leaf at the top of the plant would likely compensate for the yield lost by pruning or otherwise not harvesting the lowest three leaves. If the potential yield of the tobacco crop is such that the yield loss by not harvesting lower leaves can be tolerated, this practice is advantageous because the average price per kilogram is enhanced. Total curing cost likely would be lower by not having to handle the lowest yielding leaves. Yield and value loss must be tolerated, but not harvesting lower leaves of flue-cured tobacco will likely result in a higher per kilogram profit margin.

\section{Suggestions for Further Study}

The LP data re-enforced the suggestion that future studies with flue-cured tobacco should report data by $L P$ because of the inherent differences that existed between leaf characteristics due to the position on the stalk of a given group of leaves.

Some leaf chemical and mineral parameters were influenced by lower leaf harvesting options. Those differences were inferred to be a result of the lower leaves being left on the plant and not harvested causing dilution of nicotine and $P$. However, the lower leaves from the treatments that involved not pruning and not harvesting were not actually sampled, consequently the dilution theory is only a suggestion. If those leaves had been sampled over time, the suggestion that they were accumulating nicotine and $P$ to the detriment of higher leaves could have been confirmed. Not removing the lower leaves revealed an interesting observation. When the lower leaves that were not pruned or harvested were again exposed to full solar radiation by removing all the leaves above 
them, they became greener and survived on the plant much longer than the same leaves which were shaded by higher leaves.

Although treatment differences were not found for total non-structural carbohydrate (TNC) concentration, this parameter proved to be a most interesting part of this study. The extremely high levels of TNC found in tobacco leaves were unprecedented in the literature for leaves of other crop species. The actual TNC for tobacco leaves has been reported sparingly in other studies. The measurement of TNC may prove to be a useful variable for describing many basic and applied phenomena in tobacco research. 


\section{REFERENCES}

Allison, J.C.S., and H. Weinmann. 1970. Effect of absence of developing grain on carbohydrate content and senescence of maize leaves. Plant Phys. 46:435-436.

Askew, H.O., and R.T.J. Blick. 1947. Flue-cured tobacco. Il. Development of sugars in leaf during curing. New Zealand J. Sci. Tech. 28:338-344.

Askew, H.O., R.T.J. Blick, and J. Watson. 1947. Flue-cured tobacco. IV. Effect of position on the plant on chemical composition of tobacco leaf. New Zealand J. Sci. and Tech. 29:158-163.

Atkinson, W.O., L.P. Bush, and J.L. Sims. 1977. Dry matter and nutrient accumulation in burley tobacco. Tob. Sci. 21:81-82.

Bowman, D.R., and B.C. Nichols. 1968. Composition of burley tobacco leaves in relation to stalk position and leaf portion. Tob. Sci. 12:91-94.

Bowman, D.R., T.C. Tso, and J.F. Chaplin. 1973. Leaf characteristics of four fluecured tobacco varieties according to stalk position. III. Starch, cellulose, lignin, wax, crude ash, and alkalinity of water soluble ash. Tob. Sci. 17:8-9.

Bowman, D.T., A.G. Tart, E.A. Wernsman, and T.C. Corbin. 1988. Revised North Carolina grade index for flue-cured tobacco. Tob. Sci. 32:39-40.

Brown, G.W. and T.R. Terrill. 1972. Effects of method of harvest on flue-cured tobacco Part I. Agronomic factors. Agron. J. 64:619-622.

Brown, G.W. and T.R. Terrill. 1973. Effects of method of harvest on flue-cured tobacco Part II. Chemical components. Agron. J. 65:268-273.

Bruns, H.A., and M.S. Mclntosh. 1988. Growth rates and nutrient concentrations in Maryland tobacco. Tob. Sci. 32:82-87.

Campbell, C.R., J.F. Chaplin, W.H. Johnson, and G.S. Miner. 1980. Close-grown tobacco: Yield, alkaloids, and sugar content by stalk position. Agron. J. 72:929932.

Carlisle, V.W., M.E. Collins, F. Sodek, III, and L.C. Hammond. 1989. Characterization data for selected Florida soils. Soil Sci. Res. Report. 89-1.

Ciha, A.J., and W.A. Brun. 1978. Effect of pod removal on nonstructural carbohydrate concentration in soybean tissue. Crop Sci. 18:773-776.

Collins, W.K., S.N. Hawks, Jr., and B.U. Kittrell. 1969. Effects of plant spacing and height of topping at two nitrogen rates on some agronomic-economic characteristics on bright tobacco. Tob. Sci. 13:150-152. 
Court, W.A., and J.G. Hendel. 1989. Influence of removing lower leaves and topping height on agronomic and chemical characteristics of flue-cured tobacco. Tob. Sci. 33:15-17.

Crafts-Brandner, S.J., F.E. Below, J.E. Harper, and R.H. Hageman. 1984. Effects of pod removal on metabolism and senescence of nodulating and nonnodulating soybean isolines. Plant Physiol. 75:311-317.

Currin, R.E., and J.B. Pitner. 1980. Agronomic and chemical effects of removing the four bottom leaves from flue-cured tobacco at various stages of growth. South Carolina Agric. Exp. Stat. Bull. 628 pp. 1-4.

Currin, R.E., and LA. Stanton. 1989. Agronomic and economic effects of time of topping and bottom leaf removal of flue-cured tobacco prior to harvest. Current Issues in Tob. Econ. 3:343-347.

Darkis, F.R., L.A. Baisden, P.M. Gross, F.A. Wolf. 1952. Flue-cured tobacco: Chemical composition of rib and blade tissue. Ind. Eng. Chem. 44(2):297-301.

Darkis, F.R., L.F. Dixon, F.A. Wolf, and P.M. Gross. 1936. Flue-cured tobacco: Correlation between chemical composition and stalk position of tobaccos produced under varying weather conditions. Ind. Eng. Chem. 28(10):12141223.

Dawson, R.F., and M.L. Solt. 1959. Estimated contributions of root and shoot to the nicotine content of the tobacco plant. Plant Phys. 34:656-661.

Elliot, J.M. 1966. Some effects of topping five flue-cured tobacco varieties at three stages of floral develpment. Tob. Sci. 10:100-104.

Elliot, J.M. 1975. The effects of stage of topping flue-cured tobacco on certain properties of the cured leaves and smoke characteristics of cigarettes. Tob. Sci. 19:7-9.

Elliot, J.M. 1976. Effects of height of topping and plant spacing of flue-cured tobacco on certain properties of the cured leaves and smoke characteristics of cigarettes. Can. J. Plant Sci. 56:161-167.

Gomez, K.A., and A.A. Gomez. 1984. Statistical procedures for agricultural research. 2nd Ed. John Wiley \& Sons. New York.

Grizzard, A.L., H.R. Davies, and L.R. Kangas. 1942. The time and rate of nutrient absorption by flue-cured tobacco. Agron. J. 34:327-339.

Hanlon, E.A., and J.M. Devore. 1989. Institute of Food and Agricultural Science extension soil testing laboratory, chemical procedure and training manual. Inst. Food and Agr. Sci., Univ. of Florida, Gainesville, FL.

Heberer, J.A., F.E. Below, and R.H. Hageman. 1985. Drying method effect on leaf chemical constituents of four crop species. Crop Sci. 25:1117-1119.

Hicks, D.R., and J.W. Pendleton. 1969. Effect of floral bud removal on performance of soybeans. Crop Sci. 9:435-437. 
Hurng, W.P., C.S. Chang, and C.H. Kao. 1989. Sink removal and leaf senescence in tobacco. Bot. Bull. Acad. Sin. 30(1):25-30 (abstract). In Tobacco Abstracts $34: 104$, no. 504.

Kakie, T. 1972. Physical properties of starch granules of tobacco leaves during maturity stage. Soil Sci. and Plant Nut. 18:7-14.

Kakie, T., and Y. Sugizaki. 1970. Starch and sugars of tobacco leaves during maturity stage. Soil Sci. and Plant Nut. 17:27-36.

Kittrell, B.U., S.N. Hawks, Jr., and W.K. Collins. 1972. Effects of leaf numbers and sucker control and topping methods on flue-cured tobacco production. Tob. Sci. 16:154-156.

Kollman, G.E., J.G. Streeter, D.L. Jeffers, and R.B. Curry. 1974. Accumulation and distrubution of mineral nutrients, carbohydrate, and dry matter in soybean plants as influenced by reproductive sink size. Agon. J. 66:549-554.

Lawn, R.J., and W.A. Brun. 1974. Symbiotic nitrogen fixation in soybeans. I. Effect of photosynthetic source-sink manipulations. Crop Sci. 14:11-16.

Leopold, A.C. 1961. Senescence in plant development. Science 134:1727-1732.

Marshall, H.V., Jr., and H. Seltmann. 1964. Time of topping and application studies with maleic hydrazide on flue-cured tobacco. Tob. Sci. 8:74-78.

McAlister, D.F., and O. Krober. 1958. Response of soybeans to leaf and pod removal. Agron. J. 50:674-677.

Mondal, M.H., W.A. Brun, and M.L. Brenner. 1978. Effects of sink removal on photosynthesis and senescence in leaves of soybean plants. Plant Physiol. 61:394-397.

Moseley, J.M., W.G. Woltz, J.M. Carr, and J.A. Weybrew. 1963. The relationship of maturity of the leaf at harvest and certain properties of the cured leaf of fluecured tobacco. Tob. Sci. 7:67-75.

Neas, I., G.W. Brown, J.P. Dickerson, R.M. Henderson, W.B. James, W.B. Line, and H.C. Threatt, Jr. 1978. Evaluation of once-over low-profile harvested tobacco: Part I. Processing and leaf analysis. Tob. Sci. 22:59-63.

Nel, J.G., G.L. Passanah, J.H. Swanepoel, and C.W. Glennie. 1974. Bulk and conventional flue-curing of tobacco with respect to the stalk position of the leaf. Agroplantae $7(1): 17-22$.

Pauli, A.W., and F.C. Stickler. 1961. Leaf removal in grain sorghum. II. Trends in dry matter, carbohydrates, and nitrogen following defoliation. Agron. J. 53:102105.

Raper, C.D., and C.B. McCants. 1966. Nutrient accumulation in flue-cured tobacco. Tob. Sci. 10:190.

Raper, C.D., D.T. Patterson, L.R. Parsons, and P.J. Kramer. 1977. Relative growth and nutrient accumulation rates for tobacco. Plant and Soil 46:473-486. 
Sims, J.L., and W.O. Atkinson. 1971. Influence of nitrogen nutrition and suckering practice on content and distribution of certain mineral elements in burley tobacco. Agron. J. 63:775-778.

Sims, J.L., and W.O. Atkinson. 1973. Accumulation of dry matter and nitrogen content of burley tobacco growing in fertilizer-induced acid soil. Agron. J. 65:762765.

Sims, J.L., and W.O. Atkinson. 1974. Soil and plant factors influencing accumulation of dry matter in burley tobacco growing in soil made acid by fertilizer. Agron. J. 66:775-778.

Sinclair, T.R., and C.T. de Wit. 1975. Photosynthate and nitrogen requirements for seed production by various crops. Science 189:565-567.

Smith, D. 1981. Removing and analyzing total non-structural carbohydrates from plant tissue. Univ. of Wisc. Agric. Res. Exp. Stn. Rep. R2107.

Srivastava, R.P., D.S. Rao, and N.C. Gopalachari. 1984. Nutrient and dry matter accumulation of Dixie Shade wrapper tobacco at different stages of growth. Tob. Sci. 28:99-101.

Steinberg, R.A., and R.N. Jeffery. 1957. Comparison of pruning (topping, suckering) effects in normal and boron-deficient tobacco on relative growth and alkaloid content of leaf, stalk, and root. Plant and Soil 9(1):64-74.

Stickler, F.C., and A.W. Pauli. 1961. Leaf removal in grain sorghum. I. Effects of certain defoliation treatments on yield and components of yield. Agron. J. 53:99102.

Stocks, G.R. 1988. Topping time and bottom leaf removal of flue-cured tobacco. M.S. Thesis, Univ. of Florida.

Stocks, G.R., and E.B. Whitty. 1992. Delayed topping effects on mammoth flue-cured tobacco. Tob. Sci. (in press).

Streeter, J.G., and D.L. Jeffers. 1979. Distribution of total non-structural carbohydrates in soybeans having increased reproductive load. Crop Sci. 19:729-734.

Suggs, C.W. 1972. Effects of leaf pruning on some characteristics of tobacco plants. Tob. Sci. 16:68-70.

Suggs, C.W. 1984. Mechanical harvesting of flue-cured tobacco. Part 14. Properties of green and dry stalks. Tob. Sci. 28:85-90.

Suggs, C.W. 1986. Effects of tobacco ripeness at harvest on yield, value, leaf chemistry and curing barn utilization potential. Tob. Sci. 30:152-158.

Suggs, C.W., S.M. Leary, and H.S. Bland. 1987. Effects of leaf curing configuration and bulk density on curing characteristics. Tob. Sci. 31:16-19.

Thomas, H., and J.L. Stoddart. 1980. Leaf senescence. Ann. Rev. Plant Physiol. 31:83111. 
Tisdale, S.L., and W.L. Nelson. 1975. Soil fertility and fertilizers. 3rd Ed. Macmillan Publishing Co., Inc. New York.

Tso, T.C. 1972. Physiology and biochemistry of tobacco plants. 1st Ed. Dowden, Hutchinson, \& Ross, Inc. Stroudberg, PA.

Turgeon, R. 1989. The sink-source transition in leaves. Ann. Rev. Plant Phy. Plant Mol. Biol. 40:119-138.

Turner, N.C. and L.D. Incoll. 1971. The vertical distribution of photosynthesis in crops of tobacco and sorghum. J. Appl. Ecol. 8:581-591.

Walker, E.K. 1968. Some chemical characteristics of cured leaves of flue-cured tobacco relative to time of harvest, stalk position and chlorophyll content of the green leaves. Tob. Sci. 12:58-65.

Walsh, L.M. 1971. Instrumental methods for analysis of soils and plant tissue. Soil Sci. Soc. Am. Madison, WI.

Weber, C.R. 1955. Effects of defoliation and topping simulating hail injury on soybeans. Agron. J. 47:262-266.

Wernsman, E.A., and D.F. Matzinger. 1980. Mammoth genotypes and tobacco management regimes for reduced production of downstalk tobaccos. Agron. J. 72:1047-1050.

Weybrew, J.A., W.G. Woltz, and R.J. Monroe. 1984. Harvesting and curing of fluecured tobacco. North Carolina Ag. Res. Serv. Tech. Bull. 275.

Williamson, R.E., and J.F. Chaplin. 1981. Levels of chemical constituents in cured leaves of four burley tobacco cultivars according to stalk position. Tob. Sci. 25:75-78.

Wolf, F.A., and W.W. Bates. 1964. Extent of tobacco root development as related to nicotine content of plant parts. Tob. Sci. 8:67-69.

Wolf, F.A., and P.M. Gross. 1937. Flue-cured tobacco: A comparative study of structural responses induced by topping and suckering. Bull. Torrey Bot. Club 64(3): 117-131.

Woltz, W.G. 1955. Some effects of topping and suckering flue-cured tobacco. N.C. Agr. Exp. Stn. Tech. Bull. 106.

Woltz, W.G., and D.D. Mason. 1966. Effect of plant spacing and height of topping of bright tobacco on some agronomic characteristics. Proc. Fourth International Tobacco Scientific Cong. Athens, Greece, September 19-23, pp. 197-208.

Womack, D., and R.L. Thurman. 1962. Effect of leaf removal on the grain yield of wheat and oats. Crop Sci. 2:423-426. 


\section{BIOGRAPHICAL SKETCH}

Glenn Ralph Stocks, born December 23, 1963, was the first of three children for Guyland and Carolyn Stocks of Battleboro, North Carolina. His father was a farmer of tobacco, peanuts, cotton, corn, soybeans, and a small herd of beef cattle. His mother was an elementary school teacher.

Being the eldest of the three siblings, Glenn was exposed to the real world of farming at an early age. As a fourth grader, at the age of 9 , Glenn was excused from school to assist in the harvesting of the 200 acre peanut crop. As the years went by, the responsibilities on the farm increased.

In 1975, after a successful cotton crop, the Stocks's purchased a farm in Halifax County, about 7 miles northwest of Enfield, North Carolina. Having been renters of farm land previously, the family moved to their own farm in 1977 and began a new life of independent farming. Of course, land still had to be leased, but now they had a homestead.

At the previous farming location, peanuts and cotton were king. The leased farm had been a 600 acre (cleared land) plantation owned by the great grandson of General Matt W. Ransom of the Civil War era. However, at the new homestead, leaseable acreage was hard to come by.

Because of the difficulty in renting acreage, a high value crop, tobacco, was planted. The newly purchased farm had about five acres of tobacco quota so more tobacco poundage had to be leased. In 1978, 20 acres of tobacco were grown. Now 14 years old, Glenn served as his father's right hand man in the farming operation. Having ridden a tractor with his dad since the age of 2, farming was in the boy's blood.

During the years from 1978 to 1982 , Glenn learned much about farming. Over this period, his dad grew about 30 acres of tobacco, 40 acres of peanut, and 30 to 40 
acres each of com and soybeans each year. Also, during this period, Glenn attended Enfield Academy for his high school education. At Enfield Academy, he was a varsity athlete in baseball, football, and basketball.

After graduation from Enfield Academy in 1982, Glenn enrolled in the agronomy undergraduate program at North Carolina State University in Raleigh. The initial intention was to get an education in agriculture and return to the farm; however, over the four years of undergraduate study, it became all too clear that farming was not going to be a viable option.

In 1984, Glenn worked as an R.J. Reynolds research apprentice, under the direction of Dr. D.T. Bowman, the director of the North Carolina Variety Testing program for tobacco, corn, soybeans, and small grains. It was during this program that Glenn developed a great appreciation for agricultural research and extension.

Prior to receipt of his bachelor's degree, Glenn accepted an offer to pursue a Master of Science degree under the direction of Dr. E.B. Whitty at the University of Florida in Gainesville. On May 10, 1986, Glenn graduated from N.C. State. On May 12, 1986, he moved to Florida, and on May 15 he was in the tobacco research field preparing for his thesis work.

During his master's program, Glenn was undecided on what route he would take upon completion of that degree. During the M.S. program, Glenn learned a great deal about research and extension under Dr. Whitty's direction. Nearing the end of his master's program, Glenn realized that if he could not farm, the best way he could help farmers was to get a doctorate degree and hopefully be involved in a research and/or extension program helping to assist farmers with their problems.

In January, 1988, Glenn initiated a Ph.D. program again under the direction of Dr. E.B. Whitty. Glenn wanted to study whole plant physiology as his major focus. Ideally, he would like to be a general agronomist, rather than focus on one aspect of plant physiology. The supervisory committee chosen was broad based, further emphasizing 
the desire for diversification. The research project chosen was ambitious, but it had to be this way for the successful transition from master's student to capable Ph.D.

Now, as Glenn nears completion of the Doctor of Philosophy degree, he feels ready and able to go out into the world of agriculture research and extension. He realized a few years ago that he could not be directly involved in production agriculture; however, if upon receipt of the Ph.D. degree he can be employed in a position where he is conducting research or supporting farmers on methods in which they can maintain their livelihood, he will realize the purpose he has been educated to pursue.

The University of Florida has been more than just an educational facility for Glenn. Having spent five and a half years and acquiring two graduate degrees at UF, Glenn has developed into an agricultural professional. The interaction with the fine faculty, staff, and students at UF have greatly enhanced Glenn's professional, as well as educational, development.

Not only does Glenn leave UF with two graduate degrees, but on November 9, 1991, Glenn was married to Kathleen Nadine Best, a graduate of UF from the College of Journalism.

The University of Florida has been very, very good to and for Glenn, and he will forever hold fond memories and high esteem for the "home of the Gators." 
I certify that I have read this study and that in my opinion it conforms to acceptable standards of scholarly presentation and is fully adequate, in scope and quality, as a dissertation for the degree of Doctor of Philosophy.

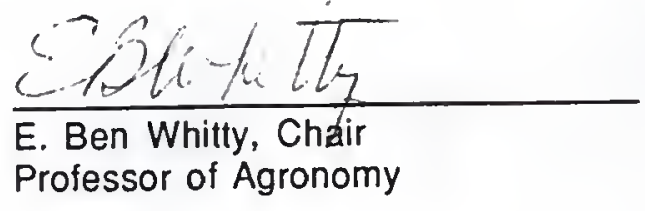

I certify that I have read this study and that in my opinion it conforms to acceptable standards of scholarly presentation and is fully adequate, in scope and quality, as a dissertation for the degree of Doctor of Philosophy.

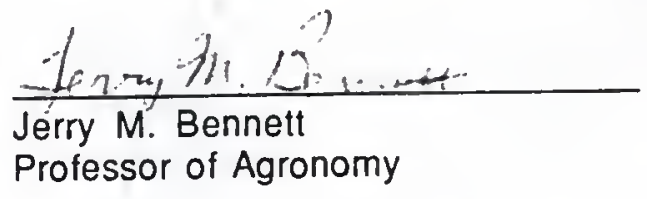

I certify that I have read this study and that in my opinion it conforms to acceptable standards of scholarly presentation and is fully adequate, in scope and quality, as a dissertation for the degree of Doctor of Philosophy.

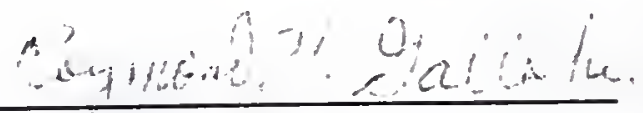

Raymond N. Gallaher

Professor of Agronomy

I certify that I have read this study and that in my opinion it conforms to acceptable standards of scholarly presentation and is fully adequate, in scope and quality, as a dissertation for the degree of Doctor of Philosophy.

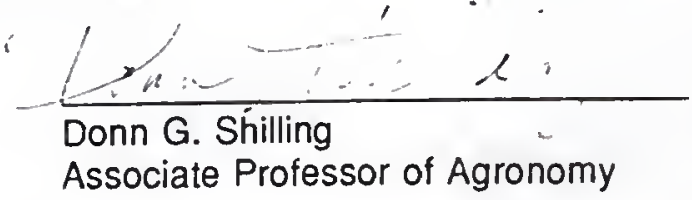

I certify that I have read this study and that in my opinion it conforms to acceptable standards of scholarly presentation and is fully adequate, in scope and quality, as a dissertation for the degree of Doctor of Philosophy.

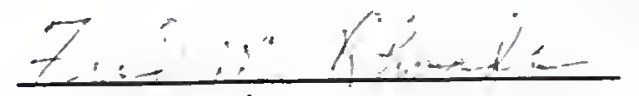

Fred M. Rhoads

Professor of Soil Science 
This dissertation was submitted to the Graduate Faculty of the College of Agriculture and to the Graduate School and was accepted as partial fulfillment of the requirements for the degree of Doctor of Philosophy.

December, 1991

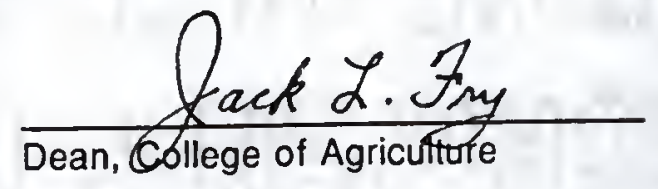

Dean, Graduate School 
UNIVERSITY OF FLORIDA

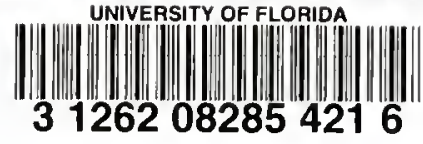

